OAK RIDGE

NATIONAL LABORATORY

MANAGED BY UT-BATTELLE

FOR THE DEPARTMENT OF ENERGY

\title{
Assumptions and Criteria for Performing a Feasibility Study of the Conversion of the High Flux Isotope Reactor Core to Use Low-Enriched Uranium Fuel
}

\author{
R. T. Primm III \\ R. J. Ellis \\ J. C. Gehin \\ D. L. Moses \\ J. L. Binder
}

Oak Ridge National Laboratory

N. Xoubi

University of Cincinnati

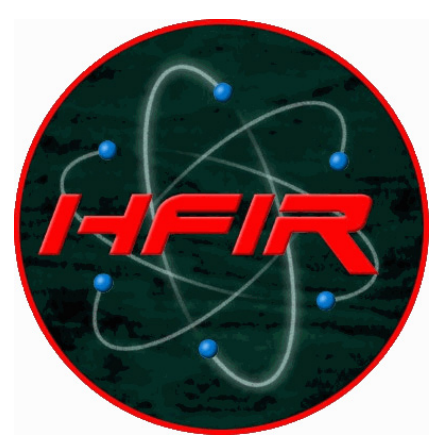

UT-BATTELLE 


\section{DOCUMENT AVAILABILITY}

Reports produced after January 1,1996, are generally available free via the U.S. Department of Energy (DOE) Information Bridge:

Web site: http://www.osti.gov/bridge

Reports produced before January 1, 1996, may be purchased by members of the public from the following source:

National Technical Information Service

5285 Port Royal Road

Springfield, VA 22161

Telephone: 703-605-6000 (1-800-553-6847)

TDD: $703-487-4639$

Fax: 703-605-6900

E-mail: info@ntis.fedworld.gov

Web site: http://www.ntis.gov/support/ordernowabout.htm

Reports are available to DOE employees, DOE contractors, Energy Technology Data Exchange (ETDE) representatives, and International Nuclear Information System (INIS) representatives from the following source:

Office of Scientific and Technical Information

P.O. Box 62

Oak Ridge, TN 37831

Telephone: 865-576-8401

Fax: 865-576-5728

E-mail: reports@adonis.osti.gov

Web site: http://www.osti.gov/contact.html

This report was prepared as an account of work sponsored by an agency of the United States Government. Neither the United States Government nor any agency thereof, nor any of their employees, makes any warranty, express or implied, or assumes any legal liability or responsibility for the accuracy, completeness, or usefulness of any information, apparatus, product, or process disclosed, or represents that its use would not infringe privately owned rights. Reference herein to any specific commercial product, process, or service by trade name, trademark, manufacturer, or otherwise, does not necessarily constitute or imply its endorsement, recommendation, or favoring by the United States Government or any agency thereof. The views and opinions of authors expressed herein do not necessarily state or reflect those of the United States Government or any agency thereof. 


\title{
ASSUMPTIONS AND CRITERIA FOR PERFORMING A FEASIBILITY STUDY OF THE CONVERSION OF THE HIGH FLUX ISOTOPE REACTOR CORE TO USE LOW-ENRICHED URANIUM FUEL
}

\author{
R. T. Primm III* \\ R. J. Ellis \\ J. C. Gehin* \\ D. L. Moses \\ J. L. Binder \\ Oak Ridge National Laboratory \\ N. Xoubi \\ University of Cincinnati
}

February 2006

*Principal Investigators

Prepared by

OAK RIDGE NATIONAL LABORATORY

P.O. Box 2008

Oak Ridge, Tennessee 37831-6283

managed by

UT-BATTELLE, LLC

for the

U.S. DEPARTMENT OF ENERGY

under contract DE-AC05-00OR22725 


\section{CONTENTS}

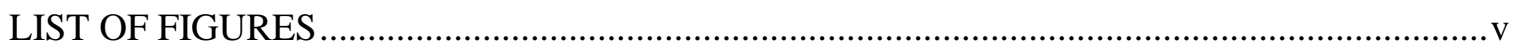

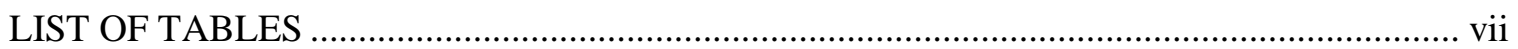

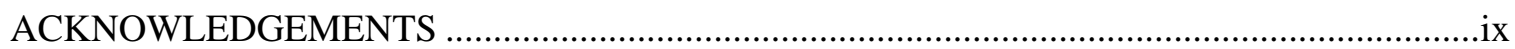

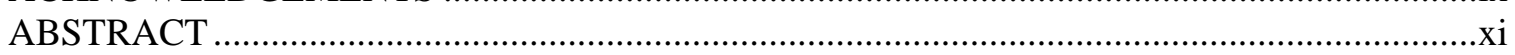

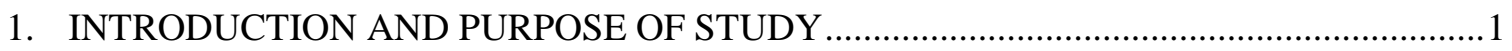

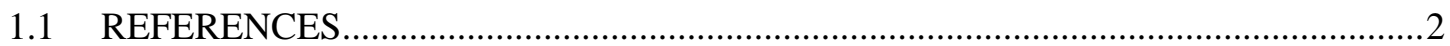

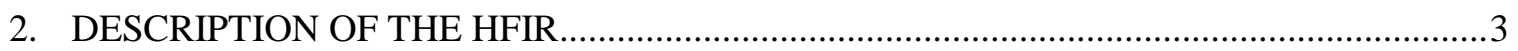

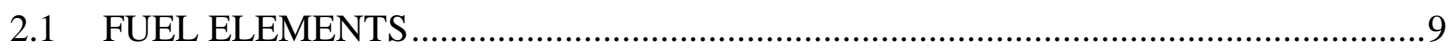

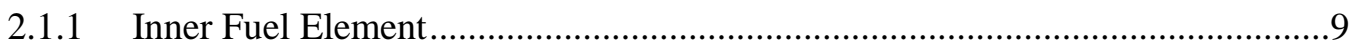

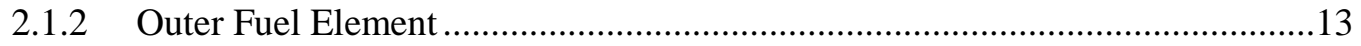

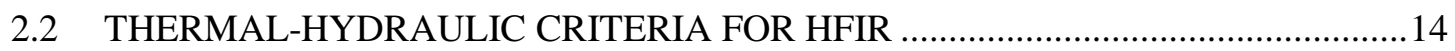

2.2.1 Linear Heat Generation Rate.......................................................................... 14

2.2.2 Thermal-hydraulic Analyses at Full Power.....................................................15

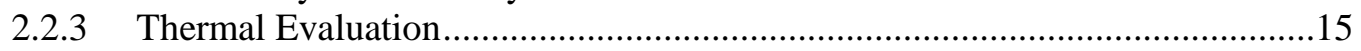

2.3 COMPONENTS OF HFIR FUEL ELEMENTS IMPACTED BY CHANGE

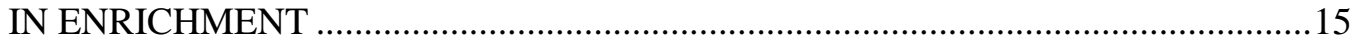

2.4 PERFORMANCE OF EXISTING FUEL FABRICATION TECHNOLOGY ..............16

2.5 POTENTIAL INDICATORS FOR JUDGING PERFORMANCE WITH LEU ............ 16

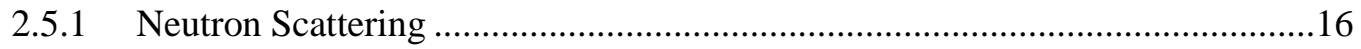

2.5.2 Isotope Production and Materials Irradiation.............................................. 18

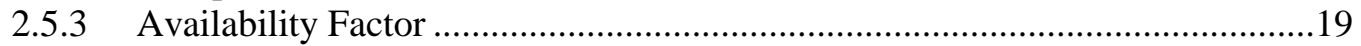

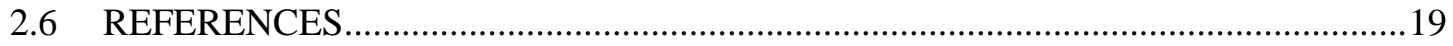

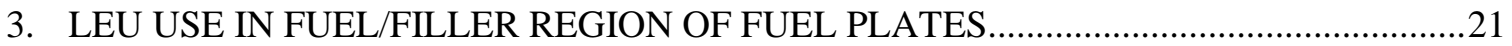

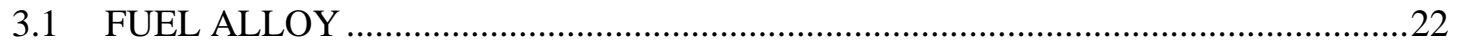

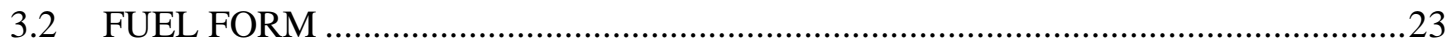

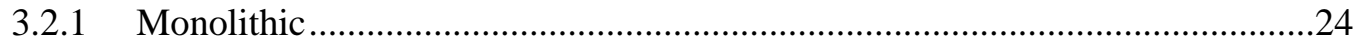

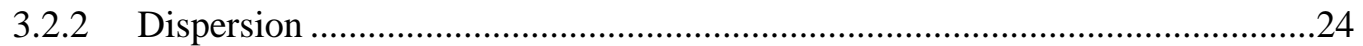

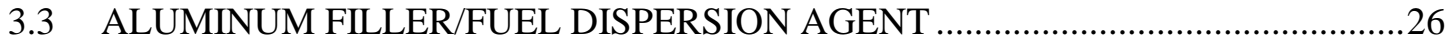

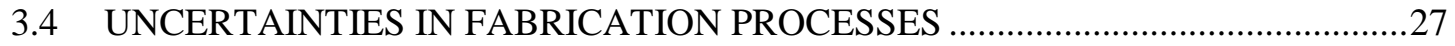

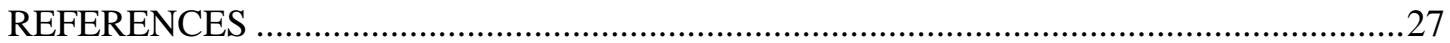

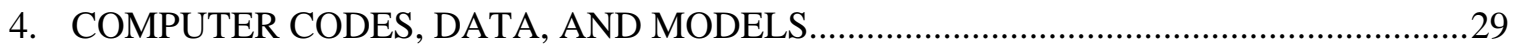

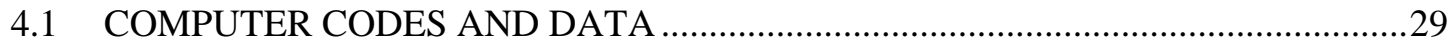

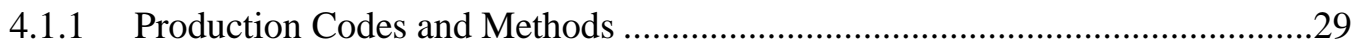

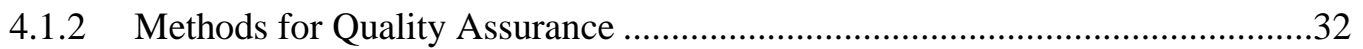

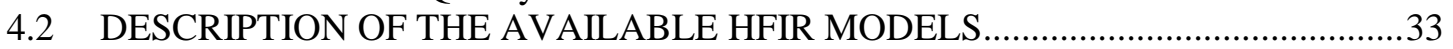

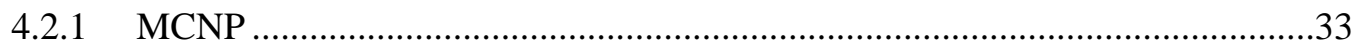

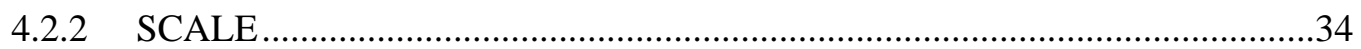

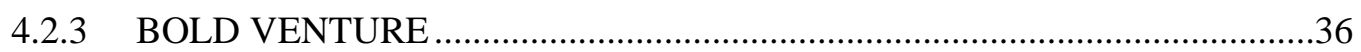

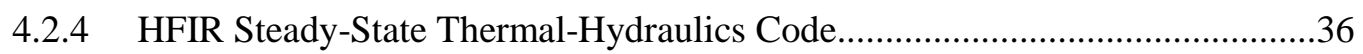

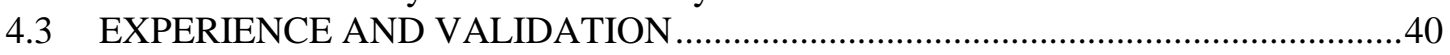

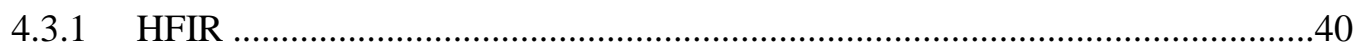

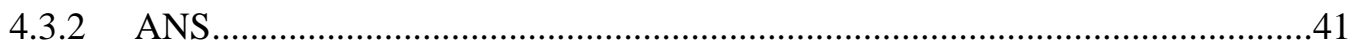

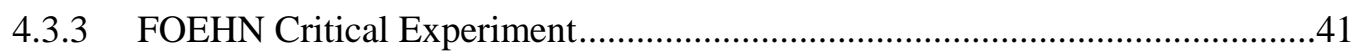

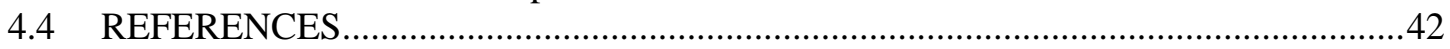

5. ENGINEERING/ECONOMIC ASSESSMENT ASSUMPTIONS _.....................................45

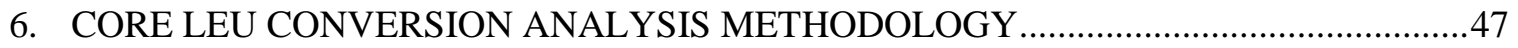

6.1 REFERENCE HEU CALCULATIONS .................................................................. 


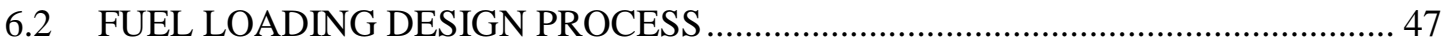

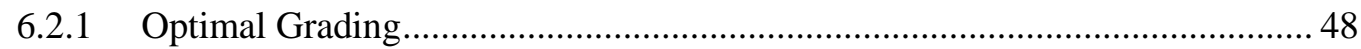

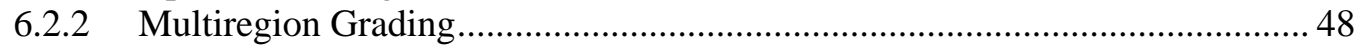

6.3 ADDITIONAL CALCULATIONS TO ASSESS LEU CORE DESIGNS .................. 48

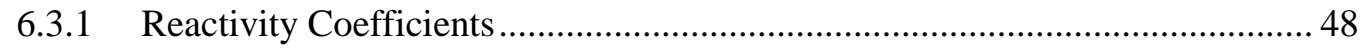

6.3.2 Control Element Reactivity Worth................................................................ 49

6.3.4 Central Element Void Reactivity Worth ............................................................ 49

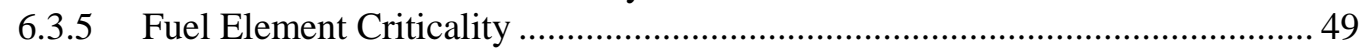

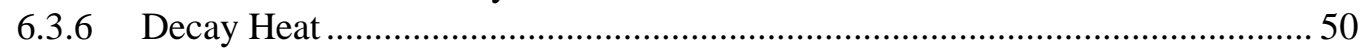

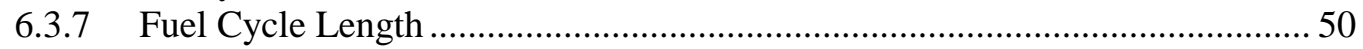

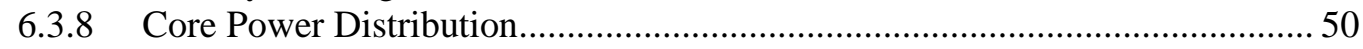

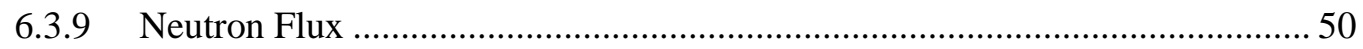

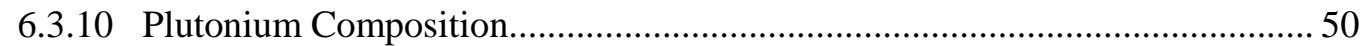

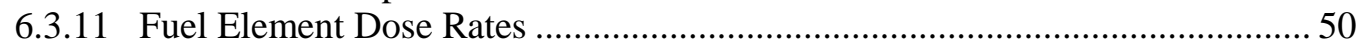

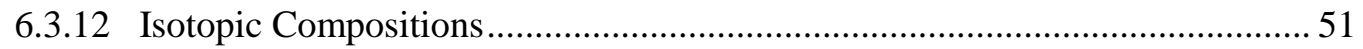

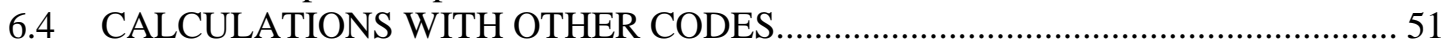

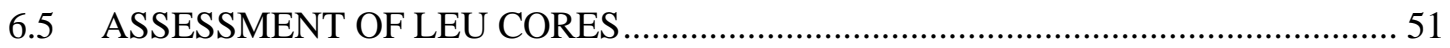

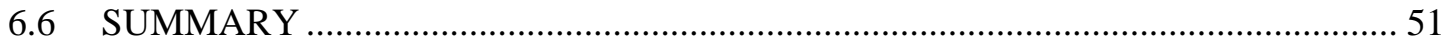

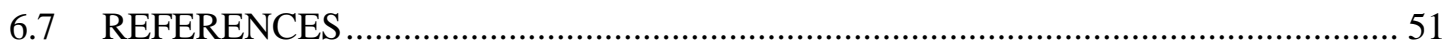

Appendix A. CRITERIA TO BE CONSIDERED QUALITATIVELY IN THIS STUDY ......... 53

Appendix B. FUEL CHARACTERISTICS FOR SELECTED FUEL FORMS …...................... 55

Appendix C. URANIUM-MOLYBDENUM THERMAL CONDUCTIVITY DURING

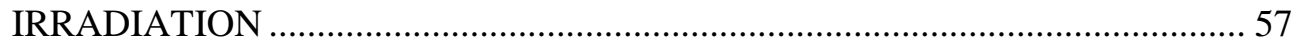




\section{LIST OF FIGURES}

Figure

Page

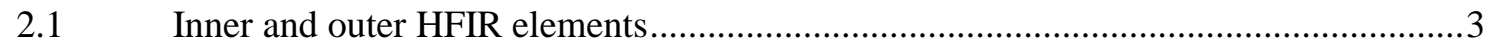

2.2 The HFIR core with the beryllium reflector ...........................................................4

2.3 Cross section of the HFIR reactor core at horizontal midplane ...................................5

$2.4 \quad$ Visualization of mesh referenced in Table 2.2 ........................................................ 7

2.5 Fuel and burnable poison distribution in the as-built element ..................................... 10

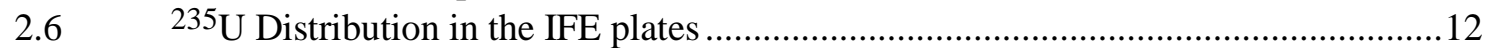

2.7 Axially averaged radial relative power density for beginning-of-cycle ....................12

$2.8 \quad$ Axially averaged radial relative power density for end-of-cycle............................... 13

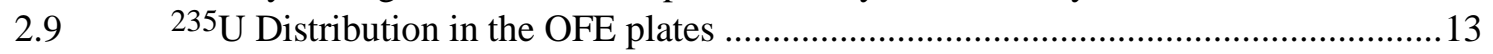

2.10 Neutron scattering instrumentation existing or under construction at HFIR ..............17

3.1 Fuel and aluminum filler distribution inside inner element and outer element fuel plates for current HFIR elements.....................................................................2 21

4.1 MCNP model of HFIR: cross section of reactor core at horizontal midplane .............34

4.2 Flow diagram of an example representative SCALE/AMPX cross-section

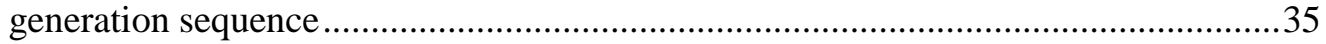

C.1 Measured data and model predictions for unirradiated U-Mo alloys .......................58

C.2 Burnup dependence of U-10Mo gaseous swelling …...........................................60

C.3 Dependence of molybdenum content on swelling at the temperature range

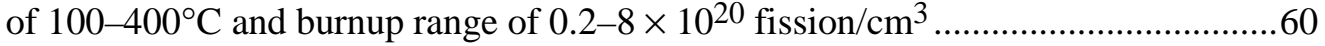

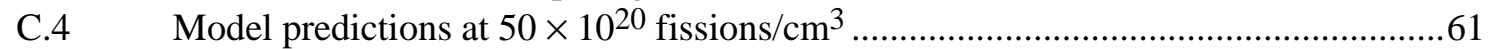

C.5 Model predictions compared with measured data ................................................62

C.6 Thermal conductivity of U-Mo alloys during irradiation at temperatures $65-300^{\circ} \mathrm{C}$ 


\section{LIST OF TABLES}

Table

2.1 Design and operating parameters of HFIR

Burnup-dependent heat transfer data-incipient boiling criteria..

Mesh definition for Fig. 2.3

Comparison of HFIR and commercial PWR operating characteristic

Neutron scattering instruments for which thermal flux should be unperturbed

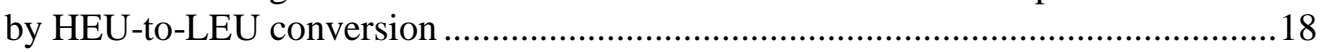

3.1 Y-12 standard chemical specification of uranium metal .........................................22

3.2 Composition of aluminum powder for filler or fuel region .................................26

4.1 Uncertainty factors in HFIR steady state heat transfer code.......................................37

4.2

SSHTC code input data..... 


\section{ACKNOWLEDGMENTS}

The authors would like to acknowledge the Reduced Enrichment for Research and Test Reactors Program (RERTR) for providing funding for this study. In particular, the assistance of Mitchell K. Meyer of the Idaho National Laboratory in expediting the transmission of funds to Oak Ridge is appreciated. The authors would like to thank John D. Sease and Larry D. Proctor, both of Oak Ridge National Laboratory (ORNL), Jim Matos, Jordi Rodlans, and Jim Snelgrove, all of Argonne National Laboratory, and Tom Newton of the Massachusetts Institute of Technology for technical reviews of this report. Finally, the authors would like to acknowledge the editing of C. C. Southmayd and document preparation of B. J. Smith, both of ORNL. 


\title{
ASSUMPTIONS AND CRITERIA FOR PERFORMING A FEASIBILITY STUDY OF THE CONVERSION OF THE HIGH FLUX ISOTOPE REACTOR CORE TO USE LOW-ENRICHED URANIUM FUEL
}

\author{
R. T. Primm III \\ R. J. Ellis \\ J. C. Gehin \\ D. L. Moses \\ J. L. Binder \\ Oak Ridge National Laboratory \\ N. Xoubi \\ University of Cincinnati
}

\begin{abstract}
A computational study will be initiated during fiscal year 2006 to examine the feasibility of converting the High Flux Isotope Reactor from highly enriched uranium fuel to low-enriched uranium. The study will be limited to steady-state, nominal operation, reactor physics and thermal-hydraulic analyses of a uranium-molybdenum alloy that would be substituted for the current fuel powder- $-\mathrm{U}_{3} \mathrm{O}_{8}$ mixed with aluminum. The purposes of this document are to (1) define the scope of studies to be conducted, (2) define the methodologies to be used to conduct the studies, (3) define the assumptions that serve as input to the methodologies, (4) provide an efficient means for communication with the Department of Energy and American research reactor operators, and (5) expedite review and commentary by those parties.
\end{abstract}




\section{INTRODUCTION AND PURPOSE OF STUDY}

The U.S. nonproliferation policy "to minimize, and to the extent possible, eliminate the use of highly enriched uranium (HEU) in civil nuclear programs throughout the world" (Ref. 1) has resulted in the conversion (or scheduled conversion) of many of the U.S. research reactors from HEU to low-enriched uranium (LEU)—low enriched meaning uranium having a ${ }^{235} \mathrm{U}$ wt \% of 20 or less. However, five high-performance reactors operating with HEU have not converted to LEU because there is currently available no suitable LEU fuel that will allow these reactors to meet their mission requirements. These reactors include the High Flux Isotope Reactor (HFIR) at Oak Ridge National Laboratory (ORNL), the Advanced Test Reactor (ATR) at the Idaho National Laboratory (INL), the National Institute of Standards and Technology (NIST) research reactor, the Missouri University Research Reactor (MURR) at the University of Missouri-Columbia, and the MITR-II reactor at the Massachusetts Institute of Technology (MIT). Of these, the highest power density core, and the most challenging to convert to LEU is the HFIR with its unique involute-curved fuel plates, The Reduced Enrichment for Research and Test Reactors (RERTR) Program has existed since 1978 to provide the technical means for reactors to convert to LEU. One of the most important activities under this program has been the development of $\mathrm{U}_{3} \mathrm{Si}_{2}$ dispersion fuel for applications requiring uranium densities up to $4.8 \mathrm{~g} / \mathrm{cc}$. Recent efforts have focused on the development uranium-molybdenum (U-Mo) alloy fuels where, as a monolithic alloy fuel, it has the potential of achieving uranium densities up to $\sim 15-16 \mathrm{gU} / \mathrm{cm}^{3}$. However, the requirements of LEU fuels in HFIR include more than just obtaining high fuel densities. Because of the high power density and fuel end-of-life exposure required in HFIR, the thermal conductivity of the fuel and irradiation behavior (including fission product retention and swelling characteristics) are extremely important in assuring fuel performance without failure.

In 1997 the RERTR Program performed a neutronics feasibility study of the conversion of HFIR (Ref. 2). The study concluded that fuels with densities of up to $9 \mathrm{gU} / \mathrm{cm}^{3}$ would be required for the conversion; however, the core power peaking was significantly higher than for the HEU core. No thermal analysis was performed to determine if the core met the required thermal margins. A more complete study is required to determine the feasibility of converting HFIR to LEU fuels.

The purpose of the current study is to assess of the feasibility of converting HFIR to a LEU fuel and determine the performance goals for the candidate LEU fuel forms. The analytical tools used to perform the current safety analysis for HFIR and the ORNL expertise most knowledgeable of HFIR operations and fuel supply will be utilized in this study.

The ORNL Research Reactor Division is committed to the DOE Office of Science and the DOE Office of Nuclear Energy, Science and Technology, by its mission statement, "to operate, maintain and support ... (HFIR) in a safe, reliable, predictable, and efficient manner and in compliance with all applicable regulations and requirements." To meet this commitment, the cognizant management and staff of HFIR have been engaged while planning for these studies. Based on the consensus of HFIR experts and management at ORNL, the key top-level assumptions that will guide the current study include the following:

- There shall be no change in the physical dimensions of the core (Ref. 3).

- There shall be no change in the fuel geometry; that is, the fuel shall be involute plates of the same physical dimensions as the current HEU core and shall have an equivalent graded fuel loading across the span of the plate as needed to achieve a radially flat power distribution across the core annulus.

- The minimum clad thickness on each side of the fuel meat in the LEU fuel plate shall be maintained at a nominal (design) value of 10 mils $(254 \mu \mathrm{m})$. 
- There shall be no reduction in core power level [85 MW(t)] or core lifetime (nominally $26 \mathrm{~d}$ at full power with no irradiation targets) from the values achievable in the current HEU core. The design reactor power level for the low enriched uranium studies will be $85 \mathrm{MW}$. An assessment will be made of the capitol improvements required to HFIR to run the reactor with the LEU fuel at $100 \mathrm{MW}$.

- The margins of safety in the bases of the currently approved Technical Safety Requirements (Ref. 4) shall be maintained.

- There shall be no change to core flow requirements or to the allocation of flow to research locations.

- The LEU core should require no changes to the control and protection systems; however, if such changes are needed, such changes shall not require a major redesign of systems. A major redesign is one that requires more than a few days to implement and verify or requires an Operational Readiness Review for restart.

- Each fresh LEU fuel element (inner or outer) separately shall have an adequate margin of subcriticality under any credible configuration. The two assembled fresh LEU fuel elements should remain subcritical when fully reflected by light water or concrete. If subcriticality is not achievable for the two assembled fresh LEU fuel elements when fully reflected by light water or concrete, simple but diverse and redundant single-failure-proof measures for assuring subcriticality shall be available.

- There shall be no change to the methods now approved for handling and storing irradiated fuel elements.

- The graded fuel in the LEU fuel plates shall be assumed to be U-10 Mo with the fuel meat composed of either (1) a shaped uranium-molybdenum (U-Mo) foil or laminate layers coated with a thin diffusion barrier, or (2) U-Mo particles either bare or with a thin diffusion barrier dispersed in an aluminum filler matrix (with silicon or other additives).

\subsection{REFERENCES}

1. http://www.nnsa.doe.gov/na-20/rertr.shtml

2. S. C. Mo and J. E. Matos, "A Neutronics Feasibility Study for LEU Conversion of the High Flux Isotope Reactor (HFIR)," 1997 International Meeting on Reduced Enrichment for Research and Test Reactors (RERTR), Jackson Hole, Wyoming, 5-10 October 1997.

3. HFIR Updated Safety Analysis Report, ORNL/HFIR/USAR-2344/R5, Oak Ridge National Laboratory, Oak Ridge, Tennessee, May 2005.

4. HFIR Technical Safety Requirements, ORNL/TM-12841, Revision 9, Oak Ridge National Laboratory, Oak Ridge, Tennessee, June 2005. 


\section{DESCRIPTION OF THE HFIR}

Reference 1 provides the following quoted summary description of the HFIR:

The HFIR is a pressurized light-water-cooled and -moderated, flux-trap type reactor that uses highly enriched ${ }^{235} \mathrm{U}$ as the fuel. The reactor core (shown in Fig. 2.1) consists of a series of concentric annular regions, each approximately $61 \mathrm{~cm}$ high (fueled height is $51 \mathrm{~cm}$ ). The center of the core is a 12.70-cm-diam cylindrical hole, referred to as the "flux trap," which contains 37 vertical experimental target sites.

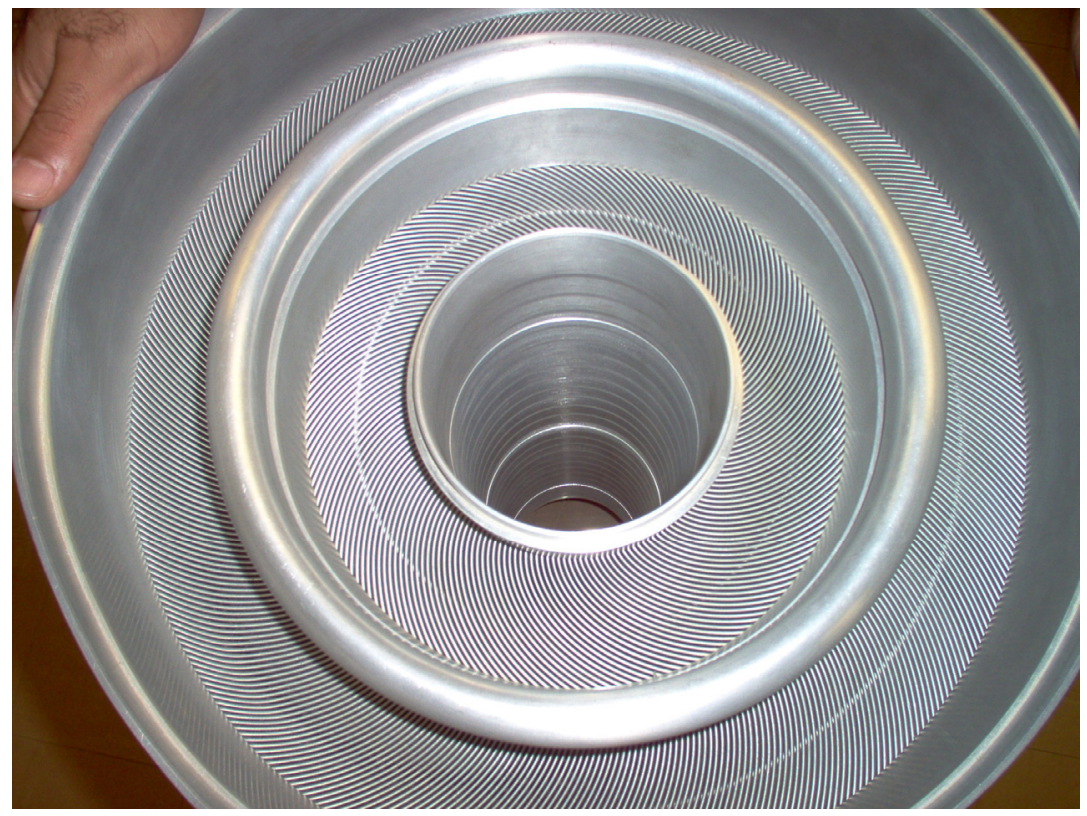

Fig. 2.1. Inner and outer HFIR elements.

Surrounding the flux trap are the two concentric fuel elements separated by a thin water region. The inner element contains 171 involute-shape fuel plates, and the outer element contains 369 involute-shape fuel plates. The fuel is aluminum-clad, highly enriched uranium oxide distributed along the arc of the involute aluminum plate $\left(\mathrm{U}_{3} \mathrm{O}_{8}-\mathrm{Al}\right.$ cermet $)$.

The inner fuel element contains boron $\left({ }^{10} \mathrm{~B}\right)$ as a burnable poison, primarily to help shift the power distribution from the inner element to the outer element. The core loading is $9.4 \mathrm{~kg}$ of ${ }^{235} \mathrm{U}$ and $2.8 \mathrm{~g}$ of ${ }^{10} \mathrm{~B}$. The average core life cycle is 19-26 days at $85 \mathrm{MW}$ (depending on quantity and type of material being irradiated).

The control plates, in the form of two thin, europium/tantalum-bearing concentric cylinders, are located in an annular region between the outer fuel element and the beryllium reflector. These plates are driven in opposite directions. Reactivity is increased by downward motion of the inner cylinder, which is used only for shimming and regulation; that is, it has no fast safety function. The outer control cylinder consists of four separate quadrants, each having an independent drive and safety release mechanism. Reactivity is increased as the outer plates are raised. All control plates have three axial regions of different poison content designed to minimize the axial peak-to-average 
power-density ratio throughout the core lifetime. Any single rod or cylinder is capable of "scramming" the reactor.

The control plates and fuel elements are surrounded by a concentric ring of beryllium that serves as a reflector and is approximately $30 \mathrm{~cm}$ thick. This, in turn, is subdivided into three regions: the removable reflector, the semipermanent reflector, and the permanent reflector, as shown in Fig. 2.2. The beryllium is surrounded by a water reflector of effectively infinite thickness. In the axial direction, the reactor is reflected by water.

The reactor core assembly is contained in a 244-cm-diameter steel pressure vessel located in a

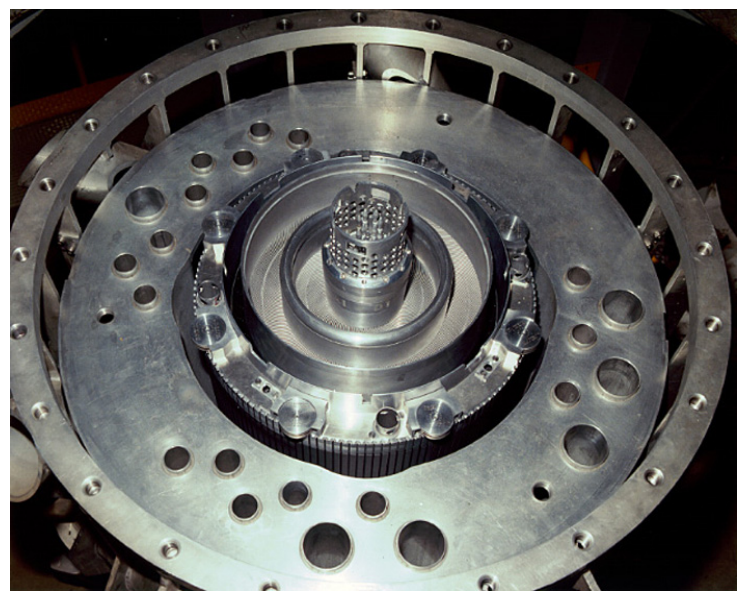

Fig. 2.2. The HFIR core with the beryllium pool of water. The top of the pressure vessel is $518 \mathrm{~cm}$ below the pool surface, and the reactor horizontal midplane is $838 \mathrm{~cm}$ below the pool surface.

HFIR spent fuel assemblies are stored on-site, in a pool adjacent to the reactor vessel. A few key parameters of HFIR are presented in Table 2.1 (Ref. 2). Significant components of the reactor are identified in (Fig. 2.3).

Table 2.1. Design and operating parameters of HFIR

\begin{tabular}{|c|c|}
\hline Reactor power, MW & 85 \\
\hline Active core height, $\mathrm{cm}$ & 50.8 \\
\hline Number of fuel elements & 2 \\
\hline Fuel type & $\mathrm{U}_{3} \mathrm{O}_{8}-\mathrm{Al}$ \\
\hline Total ${ }^{235} \mathrm{U}$ loading, $\mathrm{kg}$ & 9.43 \\
\hline Enrichment, \% & 93.1 \\
\hline Fuel cycle length; 2003-2004 fiscal years (days) & $24.3-26.2$ \\
\hline Cycle 400 length (days) & 24.6 \\
\hline Core inlet pressure, psig & $468(3.227 \mathrm{MPa})$ \\
\hline Nominal core pressure drop, psi & $100(0.689 \mathrm{MPa})$ \\
\hline Coolant (water) flow, gpm & $16,000\left(1.009 \mathrm{~m}^{3} / \mathrm{s}\right)$ \\
\hline Coolant inlet temperature, ${ }^{\circ} \mathrm{F}$ & $120(322.1 \mathrm{~K})$ \\
\hline Coolant outlet temperature (nominal), ${ }^{\circ} \mathrm{F}$ & $155-185(341.5-358.2 \mathrm{~K})$ \\
\hline Total fuel-plate heat transfer surface area $\left(\mathrm{cm}^{2}\right)$ & 398,368 \\
\hline $\begin{array}{l}\text { Average thermal flux in fuel region at } 85-\mathrm{MW} \text { operation } \\
\text { (neutrons } / \mathrm{cm}^{2} \mathrm{~s} \text { ) }\end{array}$ & $\begin{array}{l}\text { @ BOC } 2.8 \times 10^{14} \\
\text { @ EOC } 3.8 \times 10^{14}\end{array}$ \\
\hline Average power density MW/l & 1.64 \\
\hline Average heat flux Btu/h-ft ${ }^{2}$ & $6.6 \times 10^{4}\left(208.2 \mathrm{~kW} / \mathrm{m}^{2}\right)$ \\
\hline Fuel-plate heat load ( MW) & 82.9 \\
\hline $\begin{array}{l}\text { Total active fuel region volume (water and fuel plate } \\
\text { volume, l) }\end{array}$ & 50.59 \\
\hline Limiting power level, MW & 122.05 \\
\hline
\end{tabular}


Table 2.1. (continued)

\begin{tabular}{|c|c|}
\hline Power trip set point, MW [flux/flow ratio] & $106.25[1.25]$ \\
\hline Margin above scram, MW & 15.8 \\
\hline \multicolumn{2}{|l|}{ Limiting heat flux: } \\
\hline Heat flux, Btu/h-ft ${ }^{2}$ & $3.18 \times 10^{6}\left(10.03 \mathrm{MW} / \mathrm{m}^{2}\right)$ \\
\hline Bulk water temperature, ${ }^{\circ} \mathrm{F}$ & $284(413.2 \mathrm{~K})$ \\
\hline Surface temperature, ${ }^{\circ} \mathrm{F}$ & $449(504.8 \mathrm{~K})$ \\
\hline Heat transfer coefficient, Btu/h- $\mathrm{ft}^{2}-{ }^{\circ} \mathrm{F}$ & $19,270\left(109.5 \mathrm{~kW} / \mathrm{Km}^{2}\right)$ \\
\hline Flow rate, $1 \mathrm{~b} / \mathrm{s}$-in. width & $0.7471(0.133 \mathrm{~kg} / \mathrm{s}-\mathrm{cm}$ width $)$ \\
\hline Pressure, psia & $358(2.468 \mathrm{MPa})$ \\
\hline \multicolumn{2}{|c|}{ Maximum hot streak outlet bulk water temperature: } \\
\hline Magnitude, ${ }^{\circ} \mathrm{F}$ & $284(413.2 \mathrm{~K})$ \\
\hline Flow rate, lb/s-in. width & $0.7017(0.125 \mathrm{~kg} / \mathrm{s}-\mathrm{cm}$ width $)$ \\
\hline \multicolumn{2}{|l|}{ Minimum flow rate: } \\
\hline Magnitude, lb/s-in. width & $0.6843(0.122 \mathrm{~kg} / \mathrm{s}-\mathrm{cm}$ width $)$ \\
\hline Bulk water temperature at outlet, ${ }^{\circ} \mathrm{F}$ & $281(411.5 \mathrm{~K})$ \\
\hline
\end{tabular}

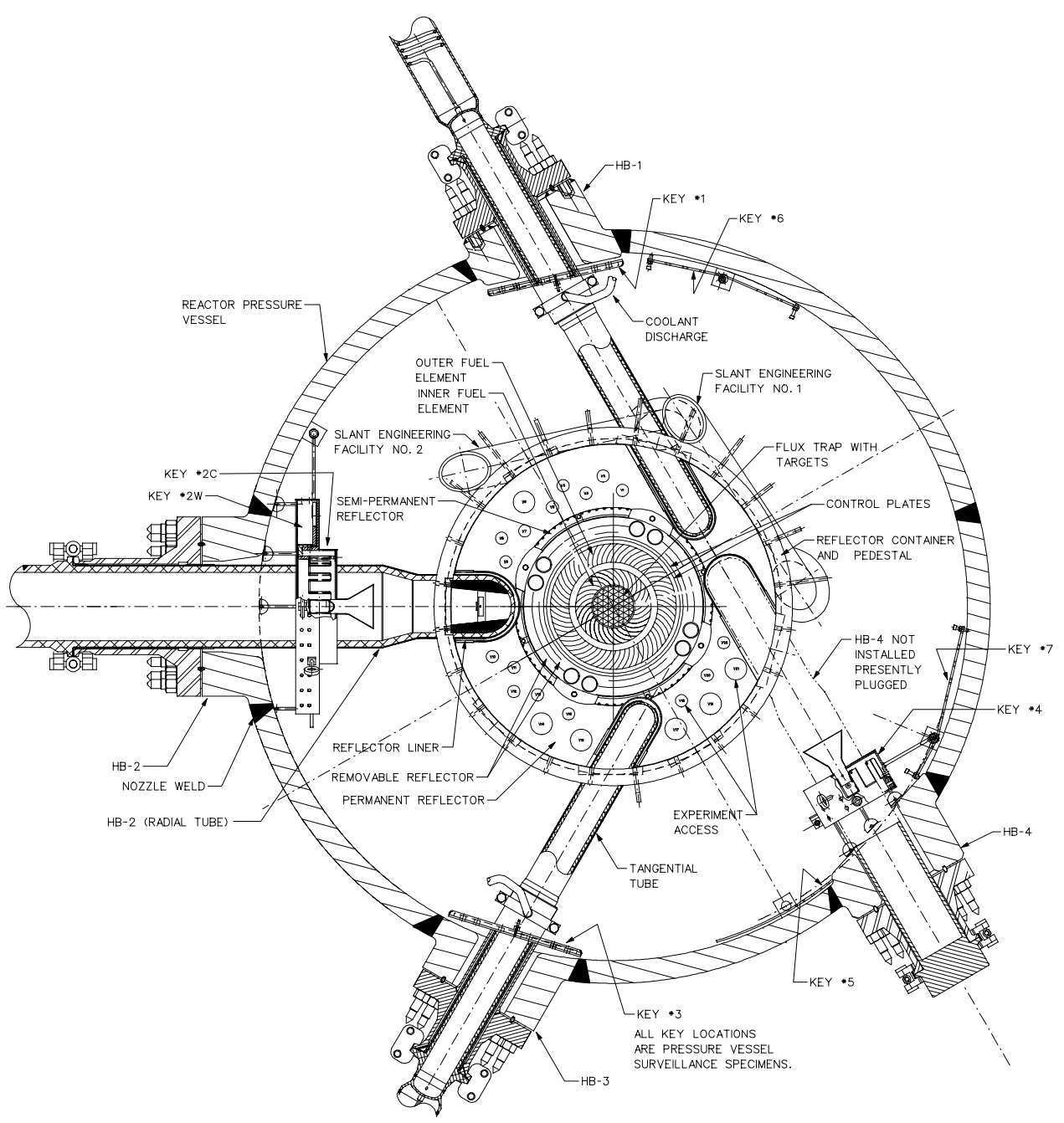

Fig. 2.3. Cross section of the HFIR reactor core at horizontal midplane. 
Table 2.2 contains various heat transfer data including notation of the peak fuel plate surface heat fluxes and temperatures at those locations. The location array indices refer to positions figuratively described in Fig. 2.3 with mesh point entries contained in Table 2.3. A comparison of HFIR to a typical power reactor is shown in Table 2.4.The values shown in Table 2.2 are determined from the HFIR steady state heat transfer code (described in Sect. 4.2.4). The methodology of combining uncertainties is described in Refs. 4 and 6. The methodology is too complex to be summarize here but an example can be found in the definition of hot spot factor from Ref. 4 (page 81). "The total hot-spot ... (factor consists) of the several individual factors indicated in the following (equation):

Hot-spot factor $=$ fuel-segregation factor $\times$ flux-distribution factor $\times$ core-volume factor $\times$ power-level factor $\times$ axial-position factor $=1.30 \times 1.10 \times 1.05 \times 1.02 \times \mathrm{E}(\mathrm{r}) "$

where $\mathrm{E}(\mathrm{r})$ is the axial power profile derived from calculations validated with experiments.

Table 2.2. Burnup-dependent heat transfer data-incipient boiling criteria

\begin{tabular}{|c|c|c|c|c|c|}
\hline Time into cycle & BOC & $1.014 \mathrm{~d}$ & $11.57 \mathrm{~d}$ & $22.72 \mathrm{~d}$ & $25.0 \mathrm{~d}$ \\
\hline Limiting power level, MW & 110.63 & 120.89 & 116.51 & 116.34 & 120.35 \\
\hline \multicolumn{6}{|l|}{ Limiting heat flux: } \\
\hline $\begin{array}{l}\text { Location, fuel element } \\
(i, j)\end{array}$ & $\begin{array}{l}\text { Outer } \\
(3,29)\end{array}$ & $\begin{array}{l}\text { Inner } \\
(5,29)\end{array}$ & $\begin{array}{l}\text { Inner } \\
(5,29)\end{array}$ & $\begin{array}{l}\text { Inner } \\
(5,29)\end{array}$ & $\begin{array}{l}\text { Outer } \\
(4,29)\end{array}$ \\
\hline Heat flux, Btu/h-ft ${ }^{2}$ & $2.80 \mathrm{E}+6$ & $2.81 \mathrm{E}+6$ & $2.79 \mathrm{E}+6$ & $2.87 \mathrm{E}+6$ & $2.70 \mathrm{E}+6$ \\
\hline Bulk water temperature, ${ }^{\circ} \mathrm{F}$ & 274 & 276 & 278 & 275 & 286 \\
\hline Surface temperature, ${ }^{\circ} \mathrm{F}$ & 422 & 422 & 422 & 422 & 422 \\
\hline $\begin{array}{l}\text { Heat transfer coefficient, } \\
\text { Btu/h-ft }{ }^{2},{ }^{\circ} \mathrm{F}\end{array}$ & 18,920 & 19,250 & 19,375 & 19,525 & 19,850 \\
\hline Flow rate, $1 \mathrm{~b} / \mathrm{s}$-in. width & 0.7473 & 0.6754 & 0.6468 & 0.6421 & 0.6684 \\
\hline Pressure, psia & 264 & 264 & 264 & 263 & 263 \\
\hline \multicolumn{6}{|l|}{$\begin{array}{l}\text { Maximum hot streak outlet } \\
\text { bulk water temperature: }\end{array}$} \\
\hline Location, fuel element $(i)$ & Outer (4) & Outer (4) & Outer (4) & Outer (4) & Outer (4) \\
\hline Magnitude, ${ }^{\circ} \mathrm{F}$ & 275 & 285 & 282 & 282 & 286 \\
\hline Flow rate, lb/s-in. width & 0.7027 & 0.6948 & 0.6650 & 0.6594 & 0.6684 \\
\hline \multicolumn{6}{|l|}{ Minimum flow rate: } \\
\hline Location, fuel element $(i)$ & Inner (4) & Inner (5) & Inner (5) & Inner (5) & Inner (5) \\
\hline Magnitude, lb/s-in. width & 0.6848 & 0.6754 & 0.6468 & 0.6421 & 0.6530 \\
\hline $\begin{array}{l}\text { Bulk water temperature at } \\
\text { outlet, }{ }^{\circ} \mathrm{F}\end{array}$ & 271 & 276 & 278 & 275 & 273 \\
\hline
\end{tabular}

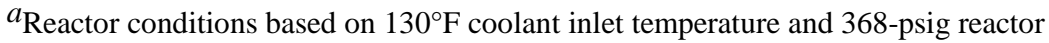
pressure (equivalent to 375 -psia fuel assembly inlet pressure). Coolant inlet temperature uncertainty factor $\mathrm{U}_{6}$ is set to 1.0 . 


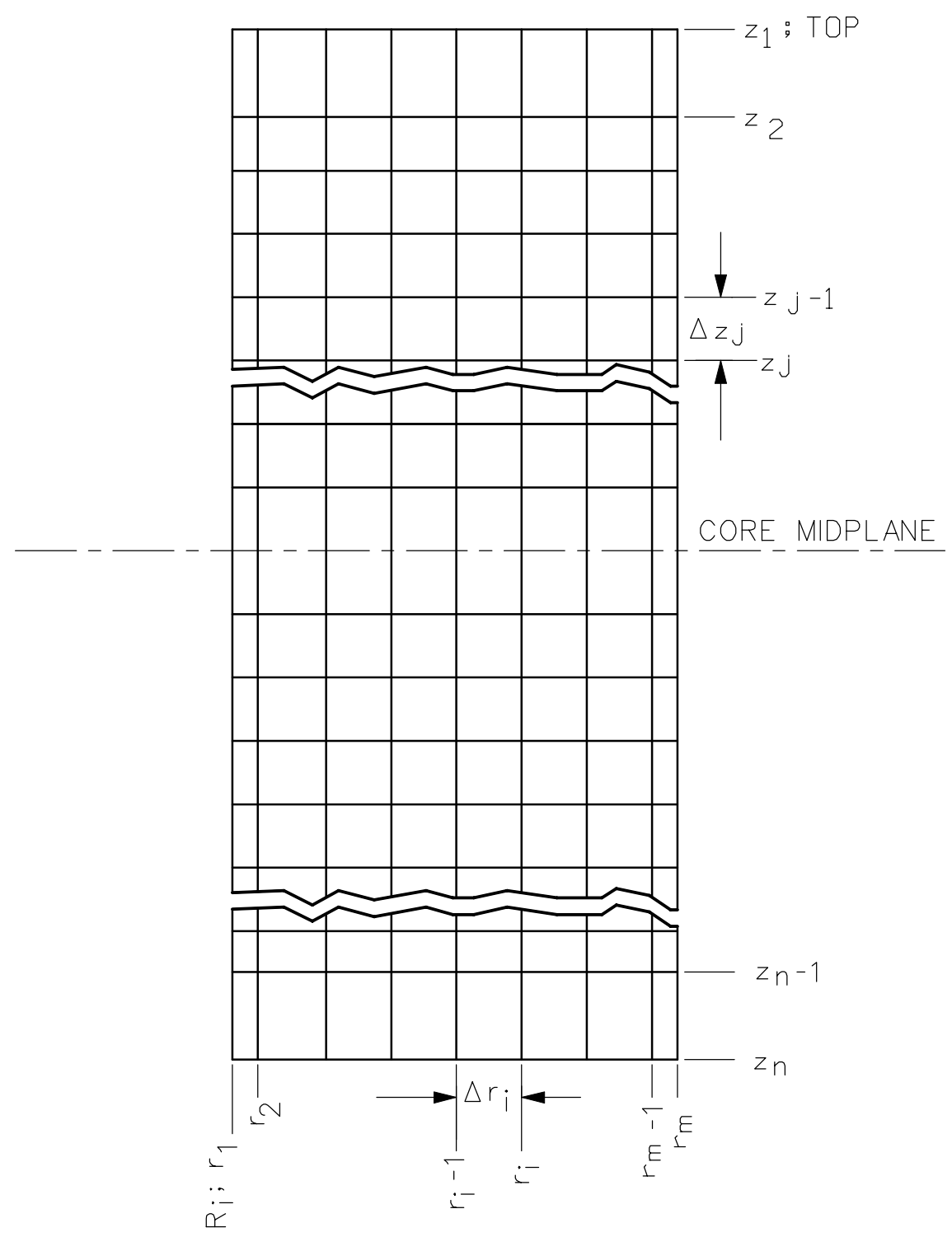

Fig. 2.4. Visualization of mesh referenced in Table 2.2. 
Table 2.3. Mesh definition for Fig. 2.3

\begin{tabular}{|c|c|c|c|}
\hline Symbol & \multicolumn{2}{|c|}{ Definition } & Typical values and units \\
\hline $\mathrm{R}$ & \multirow{2}{*}{\multicolumn{2}{|c|}{ Outside radius of inner side plate }} & 2.7215 in. for inner element \\
\hline & & & 5.8730 in. for outer element \\
\hline \multirow[t]{14}{*}{$\Delta \mathrm{r}_{\mathrm{i}}$} & \multicolumn{3}{|c|}{ Radial space increments } \\
\hline & $\underline{\text { Inner element }}$ & Outer element & \\
\hline & $\Delta \mathrm{r}_{1}=0 \mathrm{in}$ & $\Delta \mathrm{r}_{1}=0 \mathrm{in}$ & \\
\hline & $\Delta \mathrm{r}_{2}=0.0895 \mathrm{in}$. & $\Delta \mathrm{r}_{2}=0.0739 \mathrm{in}$. & \\
\hline & $\Delta \mathrm{r}_{3}=0 \mathrm{in}$ & $\Delta \mathrm{r}_{3}=0$ in & \\
\hline & $\Delta \mathrm{r}_{4}=0.3386 \mathrm{in}$. & $\Delta \mathrm{r}_{4}=0.3346 \mathrm{in}$ & \\
\hline & $\Delta \mathrm{r}_{5}=0.3937 \mathrm{in}$ & $\Delta \mathrm{r}_{5}=0.3937 \mathrm{in}$. & \\
\hline & $\Delta \mathrm{r}_{6}=0.3937 \mathrm{in}$. & $\Delta \mathrm{r}_{6}=0.3937 \mathrm{in}$. & \\
\hline & $\Delta \mathrm{r}_{7}=0.3937 \mathrm{in}$. & $\Delta \mathrm{r}_{7}=0.3937 \mathrm{in}$ & \\
\hline & $\Delta \mathrm{r}_{8}=0.3937 \mathrm{in}$. & $\Delta \mathrm{r}_{8}=0.3937 \mathrm{in}$. & \\
\hline & $\Delta \mathrm{r}_{9}=0.2362 \mathrm{in}$. & $\Delta \mathrm{r}_{9}=0.3937 \mathrm{in}$. & \\
\hline & $\Delta \mathrm{r}_{10}=0 \mathrm{in}$ & $\Delta \mathrm{r}_{10}=0 \mathrm{in}$ & \\
\hline & $\Delta \mathrm{r}_{11}=0.794 \mathrm{in}$. & $\Delta \mathrm{r}_{11}=0.0443$ & \\
\hline & & in. & \\
\hline$\Delta \mathrm{z}_{\mathrm{i}}$ & \multicolumn{3}{|c|}{ Longitudinal space increments } \\
\hline & \multicolumn{3}{|c|}{ For both elements } \\
\hline & \multicolumn{3}{|l|}{$\Delta \mathrm{z}_{1}=0$ in } \\
\hline & \multicolumn{3}{|l|}{$\Delta \mathrm{z}_{2}=2.0000 \mathrm{in}$} \\
\hline & \multicolumn{3}{|l|}{$\Delta \mathrm{z}_{3}=0$ in } \\
\hline & \multicolumn{3}{|l|}{$\Delta \mathrm{z}_{4}=0.5512 \mathrm{in}}$. \\
\hline & \multicolumn{3}{|c|}{$\Delta \mathrm{z}_{5}$ through $\Delta \mathrm{z}_{28}=0.7874 \mathrm{in}$} \\
\hline & \multicolumn{3}{|c|}{$\Delta \mathrm{z}_{30}=0 \mathrm{in}$} \\
\hline & \multicolumn{3}{|l|}{$\Delta \mathrm{z}_{31}=2.0000 \mathrm{in}$} \\
\hline
\end{tabular}


Table 2.4. Comparison of HFIR and commercial PWR operating characteristic

\begin{tabular}{|c|c|c|}
\hline Parameter & HFIR & $\begin{array}{c}\text { Commercial } \\
\text { nuclear plant }^{a}\end{array}$ \\
\hline Primary coolant pressure & $\begin{array}{l}468 \mathrm{psi} \\
(3.227 \mathrm{MPa})\end{array}$ & $\begin{array}{l}2250 \mathrm{psi} \\
(15.513 \mathrm{MPa})\end{array}$ \\
\hline Primary coolant temperature (outlet) & $156^{\circ} \mathrm{F}(342.1 \mathrm{~K})$ & $617^{\circ} \mathrm{F}(598.2 \mathrm{~K})$ \\
\hline Fuel clad surface temperature & $327^{\circ} \mathrm{F}^{b}(437.1 \mathrm{~K})$ & $657^{\circ} \mathrm{F}^{c}(620.4 \mathrm{~K})$ \\
\hline Average linear heat generation rate & $\begin{array}{l}4.25 \mathrm{MW} / \mathrm{in} . \\
(1.673 \mathrm{MW} / \mathrm{cm})\end{array}$ & $\begin{array}{l}23.7 \mathrm{MW} / \mathrm{in} . \\
(9.331 \mathrm{MW} / \mathrm{cm})\end{array}$ \\
\hline $\begin{array}{l}\text { Average linear heat generation rate } \\
\text { per plate or pin }\end{array}$ & $\begin{array}{l}7.87 \mathrm{~kW} /(\text { plate in }) \\
(3.098 \mathrm{~kW} / \text { plate-cm) }\end{array}$ & $\begin{array}{l}0.48 \mathrm{~kW} /(\text { pin in }) \\
(0.189 \mathrm{~kW} / \text { pin-cm })\end{array}$ \\
\hline Coolant velocity & $51 \mathrm{fps}(15.55 \mathrm{~m} / \mathrm{s})$ & $15.5 \mathrm{fps}(4.72 \mathrm{~m} / \mathrm{s})$ \\
\hline $\begin{array}{l}\text { Power density (volume includes fuel } \\
\text { plate/rod and associated water } \\
\text { channel) }\end{array}$ & $1.68 \mathrm{MW} / 1$ & $0.098 \mathrm{MW} / 1$ \\
\hline Operating power (thermal) & $85 \mathrm{MW}$ & $3411 \mathrm{MW}$ \\
\hline
\end{tabular}

\subsection{FUEL ELEMENTS}

The HFIR fuel region shown in Fig. 2.1 is made of two concentric annular fuel elements containing vertical, curved plates extending in the radial direction. The individual plates are of a sandwich-type construction composed of a fuel-bearing cermet bonded to cladding of type-6061 aluminum. To minimize the radial peak-to-average power density ratio, the fuel loading in each plate is varied along the arc of the involute curve as shown in Fig. 2.5. The fuel-bearing core is a dispersion of $\mathrm{U}_{3} \mathrm{O}_{8}$ particles in aluminum, approximately $30 \%$ by weight $\mathrm{U}_{3} \mathrm{O}_{8}$ in the case of the inner fuel element and $40 \%$ by weight in the case of the outer element (the inner element weights $47.2 \mathrm{~kg}$ and the outer element weights $91.7 \mathrm{kgs}$ ). The maximum thickness of the fuel-bearing core is $0.030 \mathrm{in}$., and the nominal clad thickness is $0.010 \mathrm{in}$. (minimum bound of $0.008 \mathrm{in}$.) Table 2.5 contains a description of fuel plate parameters.

\subsubsection{Inner Fuel Element}

The inner fuel element (IFE) consists of 171 fuel plates with each plate containing $15.18 \mathrm{~g}$ $\pm 1 \%$ of ${ }^{235} \mathrm{U}$ distributed along the involute arc in gradual concentration so as to reduce power peaking in the fuel plate. The plates are separated by a water-filled cooling channel, and are held together by two cylindrical aluminum side walls. The inner fuel element contains 2595.78 grams of ${ }^{235} \mathrm{U}$, and 2.8 grams of boron-10 as a burnable poison. Figure 2.6 illustrates the changes in ${ }^{235} \mathrm{U}$ grading density within the IFE. 


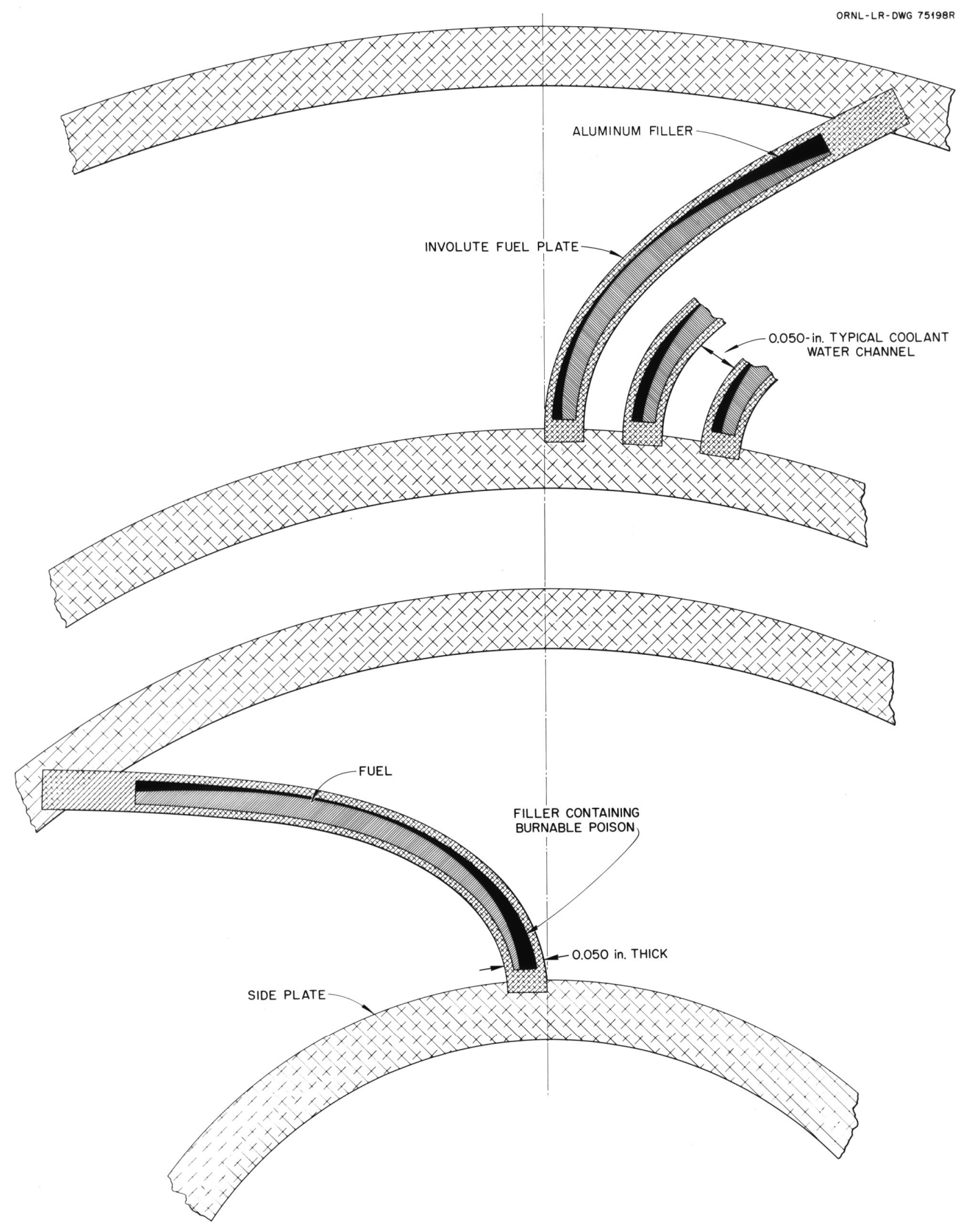

Fig. 2.5. Fuel and burnable poison distribution in the as-built element. 
Table 2.5. HFIR fuel plate specifications

\begin{tabular}{|c|c|c|}
\hline & Inner element & Outer element \\
\hline Number of fuel plates in element & 171 & 369 \\
\hline $235 \mathrm{U}$ mass per plate, $\mathrm{g}$ & 15.18 & 18.44 \\
\hline${ }^{10} \mathrm{~B}$ mass per plate, $\mathrm{g}$ & 0.0164 & 0.0 \\
\hline $\mathrm{U}_{3} \mathrm{O}_{8}$ density, $\mathrm{g} / \mathrm{cc}$ & 8.2 & 8.2 \\
\hline${ }^{235} \mathrm{U}$ loading in element, $\mathrm{kg}$ & 2.60 & 6.83 \\
\hline $\begin{array}{l}\text { Average uranium density in fuel volume (not including } \\
\text { filler volume) of interior of fuel plate (not including clad), } \\
\mathrm{g} \mathrm{U} / \mathrm{cm}^{3}\end{array}$ & 0.776 & 1.151 \\
\hline${ }^{235} \mathrm{U}$ per plate, $\mathrm{g}$ & 15.18 & 18.44 \\
\hline Total burnable poison in element, $\mathrm{g}{ }^{10} \mathrm{~B}$ & 2.8 & None \\
\hline Total boron in element, $g$ & 14.07 & None \\
\hline Fuel plate thickness, $\mathrm{cm}$ & 0.127 & 0.127 \\
\hline Coolant channel between plates, $\mathrm{cm}$ & 0.127 & 0.127 \\
\hline Nominal aluminum clad thickness, mm & 0.25 & 0.25 \\
\hline Fuel plate width, cm & 8.1 & 7.3 \\
\hline Plate fueled section $\mathrm{U}_{3} \mathrm{O}_{8}, \mathrm{~g}$ & 19.28 & 23.42 \\
\hline Plate fueled section aluminum powder, $\mathrm{g}$ & 44.59 & 35.00 \\
\hline Plate filler section $\mathrm{B}_{4} \mathrm{C}, \mathrm{g}$ & 0.105 & 0.0 \\
\hline Plate filler section aluminum powder, $\mathrm{g}$ & 21.30 & 22.64 \\
\hline Fuel plate thickness, $\mathrm{mm}$ & 1.27 & 1.27 \\
\hline Coolant channel width, mm & 1.27 & 1.27 \\
\hline Aluminum clad thickness, mm & 0.25 & 0.25 \\
\hline Fuel plate length, $\mathrm{cm}$ & 60.96 & 60.96 \\
\hline Active fuel length, $\mathrm{cm}$ & 50.80 & 50.80 \\
\hline Active fuel ID, $\mathrm{cm}$ & 14.282 & 30.259 \\
\hline Active fuel OD, cm & 25.197 & 41.867 \\
\hline Side plates ID, $\mathrm{cm}$ & 12.870 & 28.575 \\
\hline Side plates OD, $\mathrm{cm}$ & 26.899 & 43.520 \\
\hline Fuel plate centerline temperature (nominal BOC), ${ }^{\circ} \mathrm{F}\left({ }^{\circ} \mathrm{C}\right)$ & \multicolumn{2}{|c|}{$325(163)$} \\
\hline Maximum fuel-plate centerline temperature, ${ }^{\circ} \mathrm{F}\left({ }^{\circ} \mathrm{C}\right)$ & \multicolumn{2}{|c|}{$545(285)$} \\
\hline Metal oxide interface temperature (maximum), ${ }^{\circ} \mathrm{F}\left({ }^{\circ} \mathrm{C}\right)$ & \multicolumn{2}{|c|}{$519(271)$} \\
\hline Oxide water interface temperature (maximum), ${ }^{\circ} \mathrm{F}\left({ }^{\circ} \mathrm{C}\right)$ & \multicolumn{2}{|c|}{$347(175)$} \\
\hline
\end{tabular}

\footnotetext{
$a_{\text {Total for both elements. }}$
} 


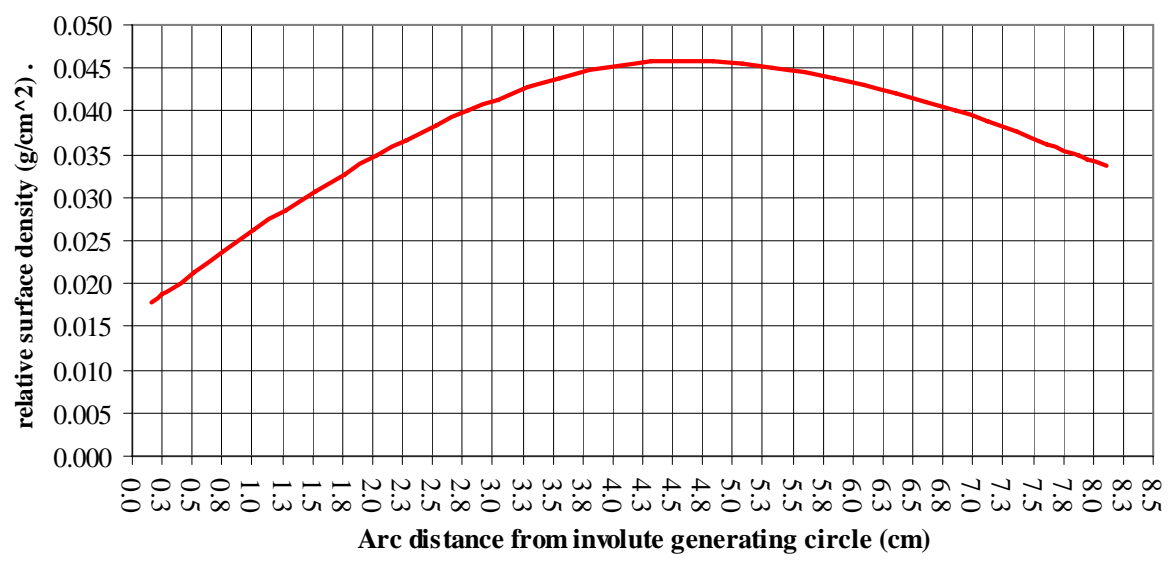

Fig. 2.6. ${ }^{235} \mathrm{U}$ Distribution in the IFE plates.

The axially averaged, measured power distributions in the inner element in critical experiments simulating beginning-of-life and end-of-life conditions in the reactor are shown in Figs. 2.7 and 2.8 (Ref. 3). The level of agreement between calculation and measurement is also shown in those figures. More measured data for a radial and axial mesh are given in Refs. 3 and 4. These power distributions are input to a steady state heat transfer code that will be described in Sect. 3. Though the "fission peak local power" is most constraining at beginning-of-cycle, the limiting thermal-hydraulic conditions actually occur at end-of-life due to oxide growth on the aluminum clad. This growth both narrows the water channel thickness and increases the fuel plate centerline temperature due to insulating properties of the oxide. For these reasons, the power

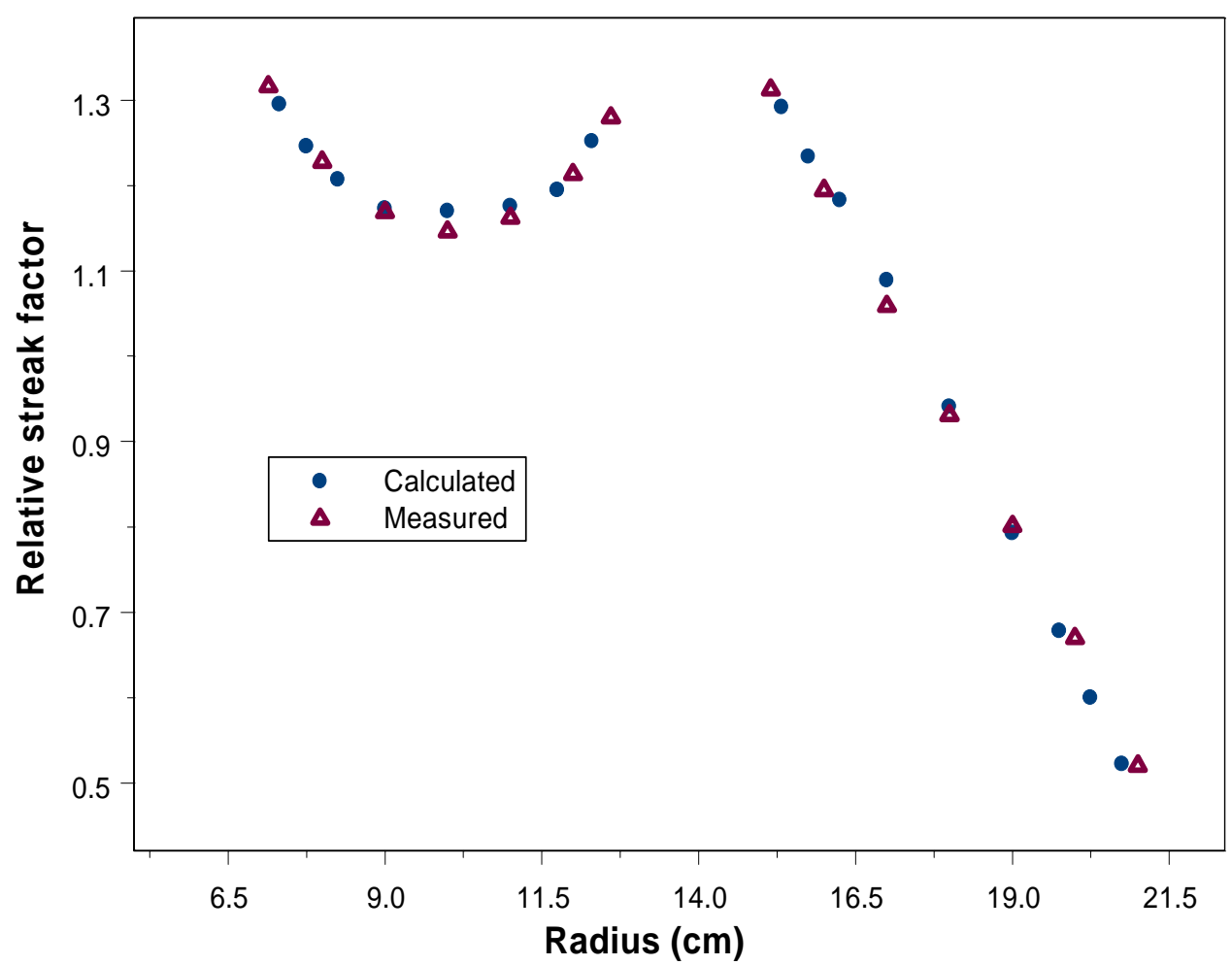

Fig. 2.7. Axially averaged radial relative power density for beginning-of-cycle. 


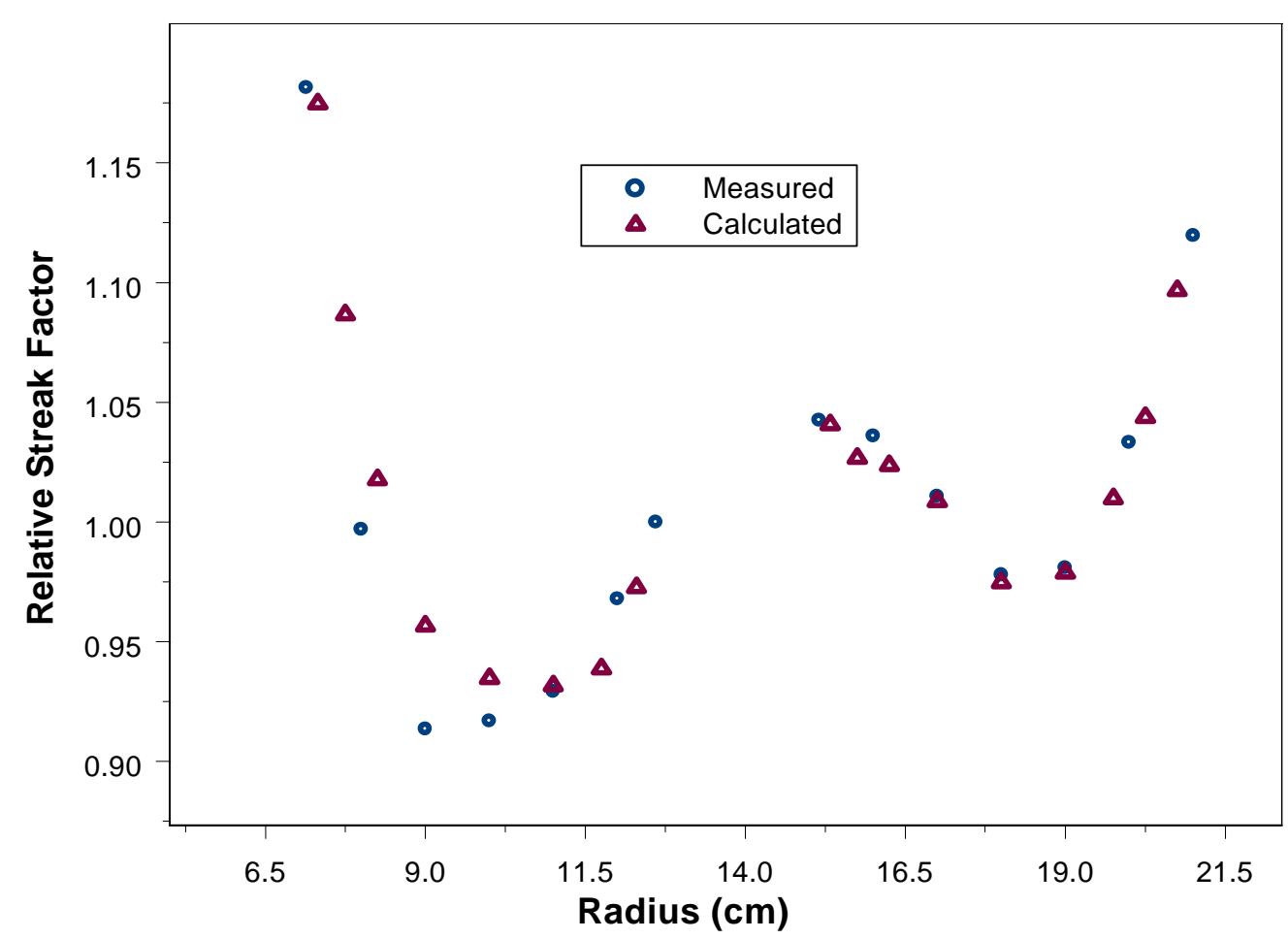

Fig. 2.8. Axially averaged radial relative power density for end-of-cycle.

distribution in the fuel must be calculated at several points during the fuel cycle as well as the end. Obtaining power distributions at each point in time for LEU fuel that are less than HEU distributions would indicate a successful fuel design. However, it is also possible to have an acceptable fuel design even if these distributions are exceeded for some points in the plates for some periods of time.

\subsubsection{Outer Fuel Element}

The outer fuel element (OFE) consists of 369 fuel plates; each plate contains $18.44 \mathrm{~g} \pm 1 \%$ of ${ }^{235} \mathrm{U}$. The outer fuel element contains 6804.36 grams of ${ }^{235} \mathrm{U}$, and no burnable poison. Figure 2.9

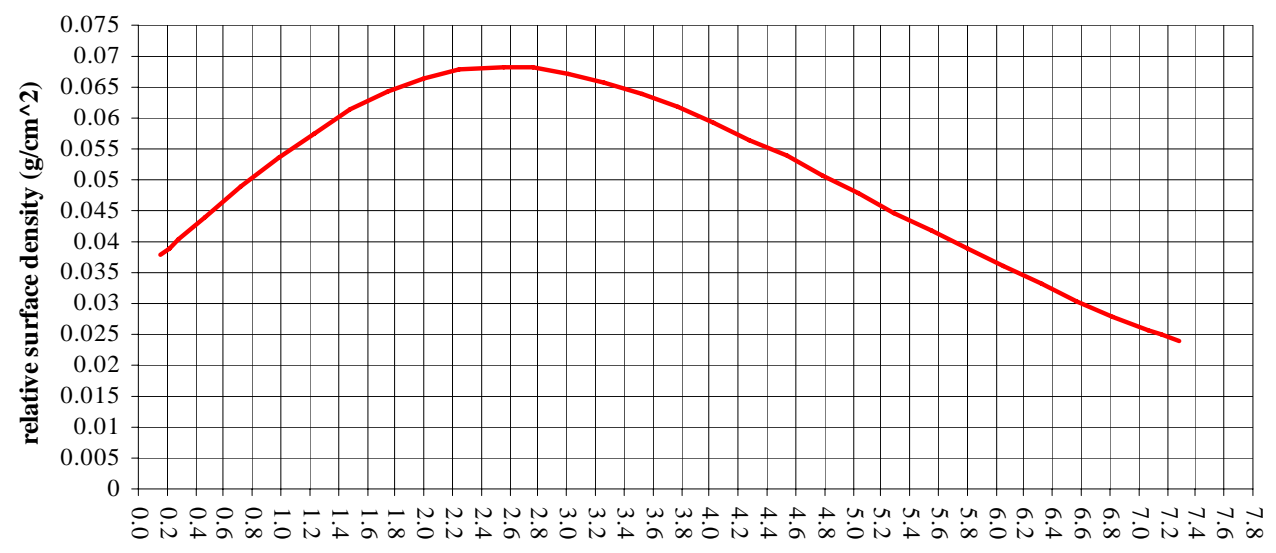

Arc distance from involute generating circle $(\mathbf{c m})$

Fig. 2.9. ${ }^{235} \mathrm{U}$ Distribution in the OFE plates. 
illustrates the changes in ${ }^{235} \mathrm{U}$ grading density within the OFE. Figures 2.7 and 2.8 show measured and calculated power distributions for the outer element.

\subsection{THERMAL-HYDRAULIC CRITERIA FOR HFIR}

Section 4.4.2.2 of Ref. 7 provides the following description of thermal-hydraulic design criteria and method of analysis:

The original HFIR protection system settings for (full power) operation were based on avoidance of incipient boiling (IB) (Ref. 4). This conservative approach was taken because of the concern that at HFIR operating conditions (high heat flux and flow rate with narrow coolant channels), local boiling in a hot channel might cause sufficient flow diversion into cooler parallel channels to lead to burnout at a power level only slightly greater than that which first causes IB. Since sufficient experimental data were not available to establish the margin between IB and burnout for these conditions, the protection system set points were chosen to prevent IB. Later in 1977, to satisfy (Energy Research and Development Administration) ERDA requirements, the [safety limits (SL), limiting safety system settings (LSSS)], now (limiting control settings) LCS, methodology was adopted for HFIR, using burnout as the acceptance criterion (Ref. 12). At this same time, the primary coolant system operating pressure was increased from 600 to 750 psi.

For current HFIR operation at 468 psi and $85 \mathrm{MW}$, the SL/LCS calculations for (full power operation, i.e., $85 \mathrm{MW}$ ) are based on the burnout criterion, consistent with the 1977 analysis and with the original ERDA requirement. In addition, to evaluate the present operating conditions against the original design basis, the calculated thermal-hydraulic conditions at the protection system set points are also compared with the IB criterion, showing that the same margin against IB is retained.

The IB correlation utilized in the HFIR steady-state heat transfer (analyses) is that derived by Bergles and Rohsenow (Ref. 13) to predict IB heat fluxes in water in the pressure range of 15 to 2000 psia (see Eq. 4.4-4 of Ref. 7). The burnout heat flux utilized in the steady-state analysis is that shown in Eq. 4.4-5 (of Ref. 7) and was developed by Gambill (Ref. 14). A more detailed discussion of these correlations and their use in the HFIR SSHTC can be found in Sect. 4.4.4.5.1 (of Ref. 7). A discussion of the peaking factors that incorporate uncertainty factors in the HFIR SSHTC can be found in Sect. 4.4.4.5.2 (of Ref. 7).

\subsubsection{Linear Heat Generation Rate}

The HFIR core has an average linear heat generation rate of $(1.67 \mathrm{MW} / \mathrm{cm})$ $51.0 \mathrm{MW} / \mathrm{ft}$. An estimate of the peak-to-average heat generation rate may be determined by the ratio of the maximum heat transfer rate along the limiting thermal track [track meaning a streak; a vertical region of thickness (radial) of approximately one centimeter] to the average heat transfer rate along the same track. Estimates for these values are obtained utilizing the HFIR SSHTC code (Ref. 4). The (maximum) peak-to-average heat generation rate (for the current HEU fuel, determined from calculations that are validated by critical experiments) is (at beginning-of-cycle and is) 1.3. 


\subsubsection{Thermal-Hydraulic Analyses at Full Power}

The normal operating sequence that is used for startup and full-power operation (maximum nominal-power level of $85 \mathrm{MW}$ ) (is termed mode 1). In this mode, the primary system is pressurized above 343 psig and the coolant system is functioning normally (nominal full flow 16,000 gpm).

The flux-to-flow ratio LCS ... (is) set equal to 1.30. A 5.95-MW uncertainty in flux-to-flow ratio (exists) for 100-MW operation, and because the analysis includes all instrumentation in the flux-to-flow safety channels, a $6 \%$ instrumentrelated uncertainty was used to specify the flux-to-flow ratio SL at 1.36 for conditions of vessel flow rate equal to, or greater than 16,000 gpm (the corresponding $100 \%$ coolant flow rate). Also, the flux-to-flow ratio scram (1.25) is set more conservative than the LCS (1.30) as recommended by the standard.

There are two action set points at coolant inlet temperatures below the LCS: a high-temperature alarm sounds at $125^{\circ} \mathrm{F}\left(5^{\circ} \mathrm{F}\right.$ above normal operating temperature), and the reactor will scram at $130^{\circ} \mathrm{F}$. Inlet coolant temperature LCS and $\mathrm{SL}$ are chosen at $5^{\circ} \mathrm{F}$ increments above the scram set point [i.e., $135^{\circ} \mathrm{F}$ (LCS) and $\left.140^{\circ} \mathrm{F}(\mathrm{SL})\right]$. Included in the thermal-hydraulic code and thus in each calculation is a $1.5 \%$ uncertainty ... for coolant inlet temperature $\left(2.0\right.$ to $2.1^{\circ} \mathrm{F}$ in the $135-140^{\circ} \mathrm{F}$ range).

\subsubsection{Thermal Evaluation}

The upper limit for the reactor power level is defined as the maximum power level at which none of the local heat fluxes in the fuel elements exceed the corresponding values of the burnout heat fluxes. Currently, the flux-to-flow ratio LCS is 1.3 times the normal operating power level as indicated by the neutron flux channels. This implies that the reactor should be able to operate at $130 \%$ of its normal power level for short periods of time without damage to the fuel elements. The normal operating power level for the HFIR is $85 \mathrm{MW}$. Therefore, the upper limit for the reactor power level should be equal to or greater than 110.5 MW in order to have confidence that the fuel elements will not be damaged during the operation of the reactor.

\subsection{COMPONENTS OF HFIR FUEL ELEMENTS IMPACTED BY CHANGE IN ENRICHMENT}

Changes in the HFIR physical plant or fuel cycle that are not related to the fuel plates and fuel elements are discussed in Appendix A and also in Sect. 5. The current operating power level for HFIR was set by a required reduction in system pressure due to possible pressure vessel embrittlement. Without changes in the HFIR physical plant (pressure vessel, pumps, etc.), the heat transfer properties of the existing HEU element should remain unchanged for LEU fuel. Heat removal requires large surface area, high surface-to-volume ratio, fuel plates and coolant channels to be as thin as can be fabricated, and a cladding material with excellent thermal conductivity. Consequently, no changes to the fuel plate dimensions or fuel element dimensions are expected for an LEU element.

The fuel meat region inside the clad is the portion of the plate that will change due to conversion to LEU. The current fuel/aluminum filler distribution is constrained by the following:

- minimum fuel thickness that can be fabricated,

- minimum aluminum filler thickness, 
- "angle of repose" for fuel powder,

- plate edge clearance to ensure that the fueled region does not extend inside the element sideplate,

- plate end clearance to ensure margin-to-boiling at coolant exit,

- minimizing rejection of fuel plates due to variability in the manufacturing process,

- minimizing the peak-to-average power density for the core.

A prior study (Ref. 5) has identified uranium-molybdenum as the fuel to be considered in the upcoming engineering studies. Criteria for fuel based on this alloy must correspond to the criteria for the current HEU fuel. The actual, numeric values for the various parameters will likely be different than for the current fuel and will be identified in future engineering studies. Further discussion of this topic is contained in Sect. 3.

The presence of ${ }^{238} \mathrm{U}$ in LEU will lead to the production of significantly greater quantities of plutonium than exist in current stored, irradiated HEU elements. While the spent LEU elements will have sufficient radiation fields to be self-protecting, the storage of spent elements at HFIR for 5-7 years would result in a large increase in the plutonium inventory at ORNL. Regulatory impacts, if any, of this change will have to be assessed.

\subsection{PERFORMANCE OF EXISTING FUEL FABRICATION TECHNOLOGY}

During 40 years of operation (406 fuel cycles each requiring an inner and an outer fuel element; 230,000 fuel plates), there have been no fuel plate or fuel element failures during reactor operation. There have been no vibration, corrosion, or erosion problems. About $10-15 \%$ of the fuel plates were typically out-of-specification when manufactured but were deemed to be acceptable for use following deviation control analyses by the HFIR staff. From 1-3\% of manufactured fuel plates are rejected at the manufacturer each year as being unacceptable for use in the reactor. When an acceptable LEU fuel element design is developed, the economic assessment of LEU conversion will require input from materials scientists and fuel fabricators as to whether comparable reliability and performance in the manufacturing processes can be attained for the LEU fuel. Economic assumptions are discussed in Sect. 5.

\subsection{POTENTIAL INDICATORS FOR JUDGING PERFORMANCE WITH LEU}

\subsubsection{Center for Neutron Scattering at HFIR}

The principal mission for HFIR for the future is to be a source of neutrons for neutronscattering measurements. There are four beam tubes that penetrate the beryllium reflector of the reactor. One of these is currently being modified to contain a vessel of liquid hydrogen and this beam line will be dedicated to studies of neutrons having energies of approximately $0.0025 \mathrm{eV}$ or lower.

\subsubsection{Cold neutron source—-beam tube HB-4}

Within the area of neutron scattering, the "cold" energy range of neutrons-energy corresponding to a temperature of $20^{\circ} \mathrm{K}$ or around $0.002 \mathrm{eV}$-is the area for which the most research proposals are currently being submitted to the Department of Energy and for which the HFIR would be the best facility for performing the measurements. The HFIR cold source is currently under construction and is scheduled to begin operation around October 1, 2006. The calculated flux of cold neutrons exiting the cold source is $10^{15}$ neutrons $/\left(\mathrm{cm}^{2} \bullet \mathrm{s}\right)$. To a first approximation, fluxes from a cold source scale as the reactor power. Competing reactor cold 
sources to the HFIR are the ILL reactor in France and the University of Munich reactor in Germany. These have power levels of $58 \mathrm{MW}$ and $20 \mathrm{MW}$, respectively, but experience less than a linear decrease in flux vs power due to the presence of heavy water reflectors as opposed to the beryllium reflector at HFIR. The flux value at the liquid moderator vessel will serve as metrics for LEU performance.

The amount of heat deposited in the cold source for the LEU core should not be greater than that expected for the HEU core. While still in the construction stage, engineering design studies have shown that very little excess capacity exists in the refrigeration equipment already purchased for the cold source.

\subsubsection{Thermal neutron sources-beam tubes HB-1, -2 , and -3}

Figure 2.10 provides a brief description of the currently installed neutron scattering devices on beam tubes HB-1, -2 , and -3 . The thermal fluxes available at the instrument locations at a reactor power of $85 \mathrm{MW}$ are provided in Table 2.6. For these neutron-scattering applications that employ thermal neutrons, the thermal (energy less than or equal to $0.625 \mathrm{eV}$ ) neutron flux at the origin of the beam tubes-meaning the tip of the tube at the point closest to the reactor core-is $8\left(10^{14}\right)$ neutrons $/\left(\mathrm{cm}^{2} \bullet \mathrm{s}\right)$. The impact of conversion to LEU on the thermal flux at the points in the beam tubes closest to the reactor core will be quantified, and estimates of the impact on fluxes at the instrument locations will be developed.

\section{HFIR Center for Neutron Scattering}

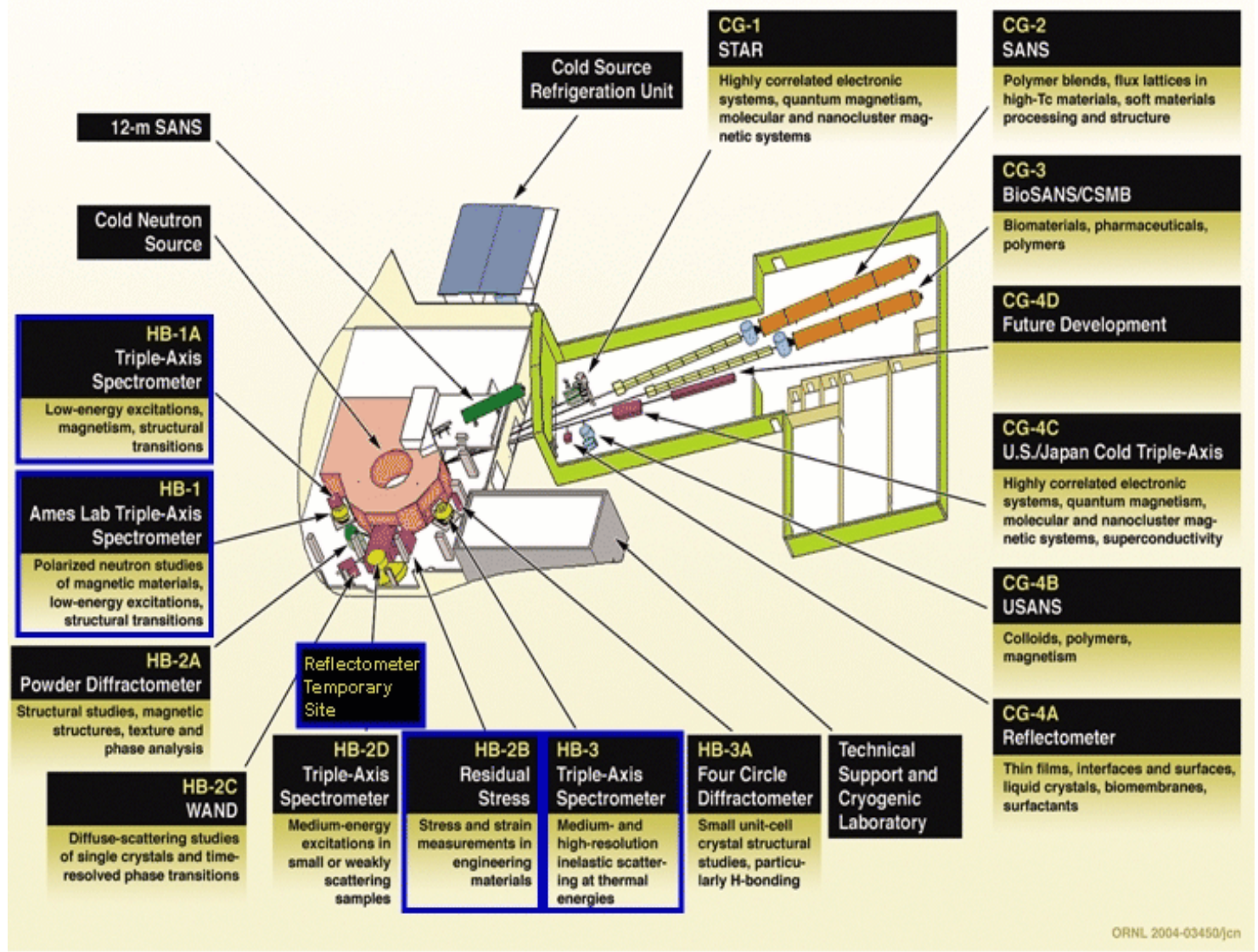

Fig. 2.10. Neutron scattering instrumentation existing or under construction at HFIR. 


\begin{tabular}{|l|l|}
\hline \multicolumn{2}{|c|}{$\begin{array}{c}\text { Table 2.6. Neutron scattering instruments for which } \\
\text { thermal flux should be unperturbed } \\
\text { by HEU-to-LEU conversion }\end{array}$} \\
\hline $\begin{array}{c}\text { Instrument } \\
\text { designation }\end{array}$ & \multicolumn{1}{c|}{ Instrument name } \\
\hline HB-1A & Triple-axis spectrometer \\
\hline HB-1 & Ames lab triple-axis spectrometer \\
\hline HB-2A & Powder diffractometer \\
\hline HB-2B & Residual stress \\
\hline HB-2C & WAND \\
\hline HB-2D & Triple-axis spectrometer \\
\hline Reflectometer & Reflectometer \\
\hline HB-3 & Triple-axis spectrometer \\
\hline HB-3A & Four circle diffractometer \\
\hline
\end{tabular}

\subsubsection{Isotope Production and Materials Irradiation}

Secondary missions of HFIR, in terms of fractional financial support to the operating expenses of the facility, are the production of trans-plutonium isotopes, principally californium, medical isotopes, and uninstrumented, small sample material irradiations. The perturbed thermal flux in the central target region-the location for these missions-is $2.6\left(10^{15}\right)$ neutrons $/\left(\mathrm{cm}^{2} \bullet \mathrm{s}\right)$ and the total flux is $5\left(10^{15}\right)$ neutrons $/\left(\mathrm{cm}^{2} \bullet \mathrm{s}\right)$. The Advanced Test Reactor (ATR) is the only domestic reactor that achieves fluxes close to these values but would require facility modifications, additional transportation costs for sample transit to Oak Ridge, and most importantly, would likely experience the same modifications in performance due to conversion from HEU to LEU as would HFIR. While international purchase and shipment of irradiated specimens is conceivable, procurement time for short-lived isotopes would make some of the current missions unachievable. The metrics for evaluating the impact of LEU on these secondary missions would likely be the production rate for isotopes, the time-to-achieve-fluence-goal for materials irradiations, and minimizing any perturbation to the neutron spectra. Currently, about $25 \%$ of the central target locations in HFIR are unused-aluminum rods are substituted for isotope production rods.

A tertiary mission of the HFIR, in terms of financial support to the operation of the reactor, is the use of the reactor as a neutron source for activation analyses. This mission, while small (financially), is growing. Fluxes of $10^{14}$ neutrons $/\left(\mathrm{cm}^{2} \bullet\right.$ s) are not currently achievable in U.S.based LEU reactors. A similar facility with this flux level does not exist at other, currently HEUfueled, U.S. reactors. Due to the short half-lives of the activated nuclides, performance of this mission at reactors outside the United State is not possible. The metric of evaluating the impact of LEU on this mission will be a review of irradiations conducted over the lifetime of the activation analysis facility to determine if the perturbation in flux level due to LEU would have precluded or hindered any of these measurements.

While not a current mission of HFIR, a fourth category would be consideration of the impact of LEU on the potential to perform larger-sample-size (relative to the central target region) and/or instrumented irradiations in various locations in the beryllium reflector. Since these facilities are currently unused and since the ATR was specifically constructed as a materials irradiation facility, the impact of LEU on this potential mission capability would not seem to be a metric for evaluation of performance. 


\subsubsection{Availability Factor}

Both the availability factor-defined as the fraction of time that the reactor is operating during a calendar year-and the length of time of an operating cycle will be important metrics for comparing LEU to HEU performance. The "down time" between operating cycles will likely be independent of the use of HEU or LEU fuel but will be assessed. The length of the fuel cycle may be strongly dependent on the type of fuel and could increase from the current value. The current fuel cycle length is 19-26 d depending on the loading of experiments to the central target and beryllium reflector positions. As noted in Sect. 1.0, the operating power of the reactor and the minimum cycle length — that being the current value — are not variables in these studies.

\subsection{REFERENCES}

1. N. Xoubi and R. T. Primm, III, Modeling of the High Flux Isotope Reactor Cycle 400, ORNL/TM-2004/251, Oak Ridge National Laboratory, Oak Ridge, Tennessee, August 2005.

2. HFIR Updated Safety Analysis Report, ORNL/HFIR/USAR/2344, Rev. 5, May 2005.

3. R. T. Primm III, Reactor Physics Studies of Reduced-Tantalum-Content Control and Safety Elements for the High Flux Isotope Rector, ORNL/TM-2003/65, Oak Ridge National Laboratory, Oak Ridge, Tennessee, December 2003.

4. R. D. Cheverton and T. M. Sims, HFIR Core Nuclear Design, ORNL-4621, Oak Ridge National Laboratory, Oak Ridge, Tennessee, July 1971.

5. S. C. Mo and J. E. Matos, "A Neutronic Feasibility Study for LEU Conversion of the High Flux Isotope Reactor (HFIR)," Proceedings of the 1997 International Reduced Enrichment for Research and Test Reactors (RERTR) Meeting, 1997, available at http://www.rertr.anl.gov/Analysis97/SCMOpaper97.html.

6. H. A. McLain, HFIR Fuel Element Steady State Heat Transfer Analysis, Revised Version, ORNL/TM-1904, Oak Ridge National Laboratory, Oak Ridge, Tennessee, December 1967 as appended by T. E. Cole, L. F. Parsly, and W. E. Thomas, Revisions to the HFIR Steady State Heat Transfer Analysis Code, ORNL/CF-85/68, April 7, 1986. 


\section{LEU USE IN FUEL/FILLER REGION OF FUEL PLATES}

As discussed in Sect. 2.0, the fuel thickness inside the fuel plates in the current HFIR plate is a function of position along the plate (see Fig. 3.1). The fuel thickness is thinner at the inner and outer edges of the fuel plates - for both inner and outer plates - in order to reduce local power density along the edges of the plates. ${ }^{*}$ This single-fuel-mixture/single filler-mixture-otherwise termed single compact fuel plate-is the basis for fabrication of plates for the LEU fuel elements. ${ }^{\dagger}$
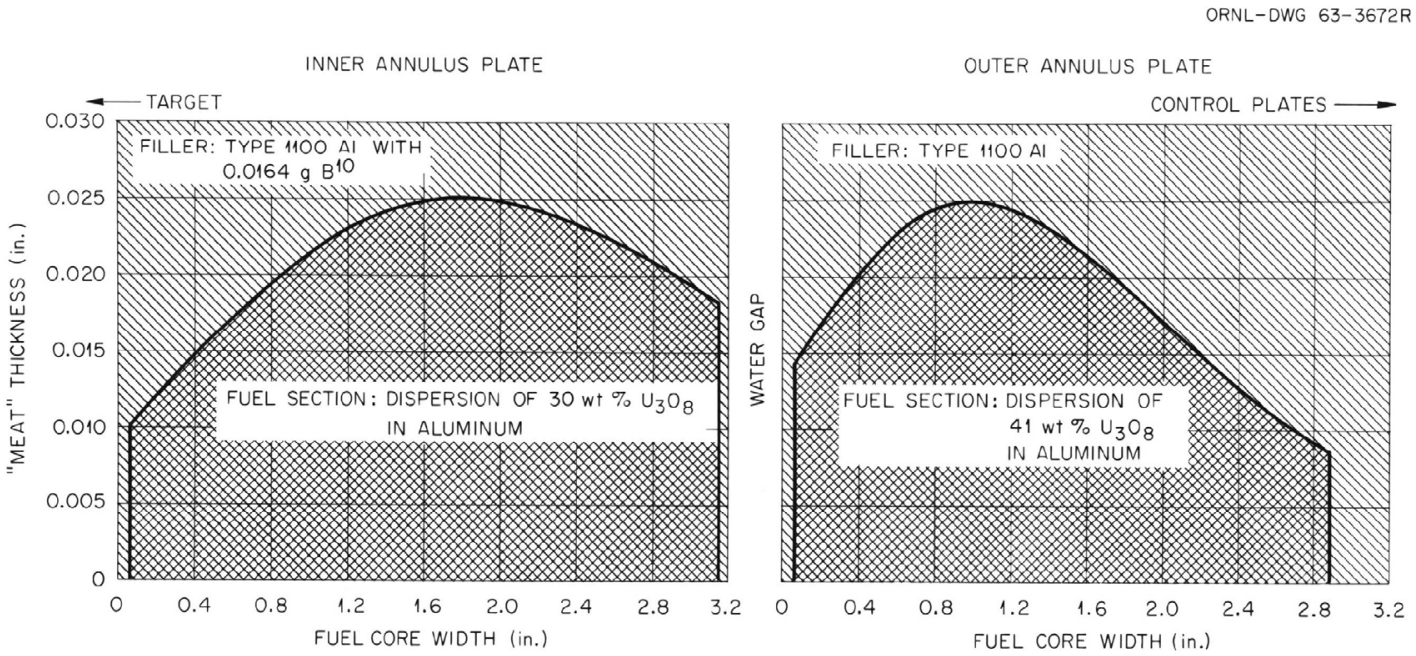

Fig. 3.1. Fuel and aluminum filler distribution inside inner element and outer element fuel plates for current HFIR elements.

Figure 3.1 shows the fuel/filler distribution in the current HFIR fuel plates. The aluminum filler in the inner element plates has $2.8 \mathrm{~g}$ of ${ }^{10} \mathrm{~B}$ (nominally $14.1 \mathrm{~g}$ of natural boron as $\mathrm{B}_{4} \mathrm{C}$ ) added to the aluminum filler for suppression of the local power density in the inner element fuel plate. At any particular fuel core width value, shown in Fig. 3.1, the variation in thickness from the profiles shown can be as much as $\pm 12 \%$. A complete set of fabrication specifications is provided in Ref. 7. Though each plate is formed from a single compact, different uranium dispersions exist in the inner element fuel plate compact than exist in the outer element fuel plate compact. The same type of aluminum filler material is used in each plate. Though the materials

\footnotetext{
* The thermal neutron flux is higher at the edges of the plates (due to reflection from the target region for the inner plate and reflection from the beryllium reflector for the outer plates and due to a small water gap between the inner and outer fuel elements) so to reduce the power density, the local aerial density of uranium (volumetric uranium content corresponding to a unit surface area of a fuel plate) must be reduced by thinning the fuel-bearing region.

†ther methods are available for reducing the local power density at a given location in a fuel plate. All of the methods entail zoning the fuel region and/or filler region by creating more than one compact per fuel plate. That is, instead of a single compact for each fuel plate, multiple, smaller compacts would be loaded to a plate frame and rolled. The multiple compacts would allow for variation of physical properties along a plate by varying the contents of the compacts. Properties that could be varied include varying the density of uranium by compact, increasing the local burnable poison content in selected filler regions of compacts, or using different burnable poisons in the filler regions of different compacts. All three of these options would require the fabrication of multiple compacts for each plate. Such a modification, even if found to be feasible, would require significant revision of the fabrication process and unquestionably higher production costs. Preliminary studies for multicompact, no-filler region fuel for the existing $\mathrm{U}_{3} \mathrm{O}_{8}$ fuel but with $25 \%$ greater uranium loading showed that an acceptable power distribution could not be found if the number of compacts was limited to three. For all of these reasons, multicompact fuel designs will not be considered in the following engineering study.
} 
composing the filler and fuel regions are independent, the relative thicknesses of the two regions at any given point along the width of a plate are obviously dependent.

\subsection{FUEL ALLOY}

For LEU studies, the current uranium form, $\mathrm{U}_{3} \mathrm{O}_{8}$, will be replaced by a uranium molybdenum alloy. Specifications for the uranium component of the alloy are shown in Table 3.1 from Ref. 1. The molybdenum component of the alloy is assumed to have natural molybdenum isotopic ratios and no impurities.

Table 3.1. Y-12 Standard chemical specification of uranium metal

\begin{tabular}{|c|c|c|c|c|}
\hline Element & Symbol & Units & LEU & EBC factor \\
\hline Uranium (metal) & $\mathrm{U}$ & wt $\%$ & $99.880 \%$ & \\
\hline $232 \mathrm{U}^{a}$ & ${ }^{232} \mathrm{U}$ & $\mu \mathrm{g} / \mathrm{gU}$ & 0.002 & \\
\hline $234 \mathrm{U}$ & ${ }^{234} \mathrm{U}$ & wt $\%$ & $0.260 \%$ & \\
\hline $235 \mathrm{U} \pm 0.20 \mathrm{wt} \%$ & $235 \mathrm{U}$ & wt $\%$ & $19.75 \%$ & \\
\hline${ }^{236} \mathrm{U}$ & $236 \mathrm{U}$ & $\mu \mathrm{g} / \mathrm{gU}$ & 4600 & \\
\hline Trans-U (alpha) & TRU & $\mathrm{Bq} / \mathrm{gU}$ & 100.0 & \\
\hline Activation product & ActProd & $\mathrm{Bq} / \mathrm{gU}$ & 100.0 & \\
\hline Fission products & Gamma & $\mathrm{Bq} / \mathrm{gU}$ & 600.0 & \\
\hline Aluminum & $\mathrm{Al}$ & $\mu \mathrm{g} / \mathrm{gU}$ & 150.0 & 0.0000 \\
\hline Arsenic & As & $\mu \mathrm{g} / \mathrm{gU}$ & $\mathrm{TBR}^{b}$ & 0.0008 \\
\hline Beryllium & $\mathrm{Be}$ & $\mu \mathrm{g} / \mathrm{gU}$ & 1.0 & 0.0000 \\
\hline Boron & $\mathrm{B}$ & $\mu \mathrm{g} / \mathrm{gU}$ & 1.0 & 1.0000 \\
\hline Cadmium & $\mathrm{Cd}$ & $\mu \mathrm{g} / \mathrm{gU}$ & 1.0 & 0.3172 \\
\hline Calcium & $\mathrm{Ca}$ & $\mu \mathrm{g} / \mathrm{gU}$ & 100.0 & 0.0002 \\
\hline Carbon & $\mathrm{C}$ & $\mu \mathrm{g} / \mathrm{gU}$ & 350.0 & 0.0000 \\
\hline Chromium & $\mathrm{Cr}$ & $\mu \mathrm{g} / \mathrm{gU}$ & 50.0 & 0.0008 \\
\hline Cobalt & $\mathrm{Co}$ & $\mu \mathrm{g} / \mathrm{gU}$ & 5.0 & 0.0089 \\
\hline Copper & $\mathrm{Cu}$ & $\mu \mathrm{g} / \mathrm{gU}$ & 50.0 & 0.0008 \\
\hline Dysprosium & Dy & $\mu \mathrm{g} / \mathrm{gU}$ & 5.0 & 0.0818 \\
\hline Europium & Ey & $\mu \mathrm{g} / \mathrm{gU}$ & 5.0 & 0.4250 \\
\hline Gadolinium & $\mathrm{Gd}$ & $\mu \mathrm{g} / \mathrm{gU}$ & 5.0 & 4.3991 \\
\hline Iron & $\mathrm{Fe}$ & $\mu \mathrm{g} / \mathrm{gU}$ & 250.0 & 0.0006 \\
\hline Lead & $\mathrm{Pb}$ & $\mu \mathrm{g} / \mathrm{gU}$ & 5.0 & 0.0000 \\
\hline Lithium & $\mathrm{Li}$ & $\mu \mathrm{g} / \mathrm{gU}$ & 2.0 & 0.1439 \\
\hline Magnesium & $\mathrm{Mg}$ & $\mu \mathrm{g} / \mathrm{gU}$ & 50.0 & 0.0000 \\
\hline Manganese & $\mathrm{Mn}$ & $\mu \mathrm{g} / \mathrm{gU}$ & 24.0 & 0.0034 \\
\hline Molybdenum & Mo & $\mu \mathrm{g} / \mathrm{gU}$ & 100.0 & 0.0004 \\
\hline Nickel & $\mathrm{Ni}$ & $\mu \mathrm{g} / \mathrm{gU}$ & 100.0 & 0.0011 \\
\hline Niobium & $\mathrm{Nb}$ & $\mu \mathrm{g} / \mathrm{gU}$ & TBR & 0.0002 \\
\hline Nitrogen & $\mathrm{N}$ & $\mu \mathrm{g} / \mathrm{gU}$ & TBR & 0.0019 \\
\hline Phosphorus & $\mathrm{P}$ & $\mu \mathrm{g} / \mathrm{gU}$ & 50.0 & 0.0000 \\
\hline Potassium & $\mathrm{K}$ & $\mu \mathrm{g} / \mathrm{gU}$ & TBR & 0.0006 \\
\hline Samarium & $\mathrm{Sm}$ & $\mu \mathrm{g} / \mathrm{gU}$ & 5.0 & 0.5336 \\
\hline Silicon & $\mathrm{Si}$ & $\mu \mathrm{g} / \mathrm{gU}$ & 100.0 & 0.0000 \\
\hline Silver & $\mathrm{Ag}$ & $\mu \mathrm{g} / \mathrm{gU}$ & TBR & 0.0083 \\
\hline
\end{tabular}


Table 3.1. (continued)

\begin{tabular}{|l|l|l|l|c|}
\hline \multicolumn{1}{|c|}{ Element } & Symbol & Units & LEU & EBC factor \\
\hline Sodium & $\mathrm{Na}$ & $\mu \mathrm{g} / \mathrm{gU}$ & 25.0 & 0.0003 \\
\hline Tin & $\mathrm{Sn}$ & $\mu \mathrm{g} / \mathrm{gU}$ & 100.0 & 0.0000 \\
\hline Tungsten & $\mathrm{W}$ & $\mu \mathrm{g} / \mathrm{gU}$ & 100.0 & 0.0014 \\
\hline Vanadium & $\mathrm{V}$ & $\mu \mathrm{g} / \mathrm{gU}$ & 30.0 & 0.0014 \\
\hline Zinc & $\mathrm{Zn}$ & $\mu \mathrm{g} / \mathrm{gU}$ & $\mathrm{TBR}$ & 0.0002 \\
\hline Zirconium & $\mathrm{Zr}$ & $\mu \mathrm{g} / \mathrm{gU}$ & 250.0 & 0.0000 \\
\hline Total impurities & $\mu \mathrm{g} / \mathrm{gU}$ & 1200 & \\
\hline Equivalent boron content ${ }^{c}$ & & 3.0 & \\
\hline
\end{tabular}

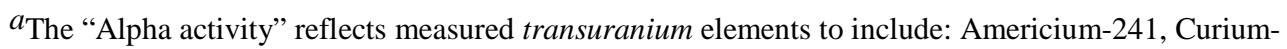
243/244, Neptunium-237, Plutonium-238, and Plutonium-239/240. Such measurement will be in picocuries per gram (pCi/g). An arithmetic conversion will result in a converted upper limit of $6757 \mathrm{pCi} / \mathrm{g}$.

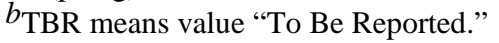

${ }^{c}$ EBC Factors are taken from ASTM C1233-97, "Standard Practice for Determining Equivalent Boron Contents of Nuclear Materials." EBC calculation will include boron, cadmium, dysprosium, europium, gadolinium, lithium, and samarium.

A variety of uranium molybdenum alloys exist, and their properties are summarized in Appendix B. Thomas Newton, Massachusetts Institute of Technology (MIT), reports that, "(RERTR reports show) fuels from U-10Mo to U-6Mo have faired well in irradiation tests, but anything below $6 \%$ molybdenum fails." Newton reports that he has focused on U-7Mo in his studies of the MIT reactor. Per the direction of the RERTR Program Office, the neutronics/thermal-hydraulics studies that are to be conducted for considering LEU fuel in HFIR will be based on the assumption that U-10Mo is the fuel (density of $17.02 \mathrm{~g} / \mathrm{cm}^{3}$ ).

\subsection{FUEL FORM}

Today most aluminum plate fuel for research reactors is made with the fuel as discrete angular particles dispersed in an aluminum matrix by hot rolling. This type of fuel form-termed dispersion fuel - has been demonstrated for fuel densities up to $\sim 4.8 \mathrm{~g} / \mathrm{cc}$ with $\mathrm{U}_{3} \mathrm{Si}_{2}$ fuel particles and higher densities could be obtained using U-10Mo fuel particles. Dispersion fuel plates are typically fabricated by mixing fuel particles with an aluminum powder matrix, cold pressing a compact, loading the compact into an aluminum metal frame with covers and hot rolling at a reduction ratio of $\sim 8: 1$ to form a flat plate. In this type of process, the loading of angular fuel particles is limited to about 40 volume percent of the fuel core. ${ }^{*}$ In a dispersion fuel based on U/Mo alloy, reactions between the aluminum matrix with the fuel particles have been mitigated by using spherical fuel particles to reduce the surface to volume ratio and coating the fuel particles with an $\mathrm{Nb}$ diffusion barrier have been used to increase the performance of a U/Mo dispersion fuel. The coating of particles is developed technology but the integrity of such a coating with a high loading after rolling is an unknown.

A plate with the fuel in monolithic alloy sheet and clad with aluminum can achieve fuel loading in excess of $9 \mathrm{~g} / \mathrm{cc}$. The required monolithic fuel form with a fuel gradient likely can be formed either by casting or by stacking foils of different widths to achieve the desired fuel

\footnotetext{
*With $17.1 \mathrm{~g} / \mathrm{cc}$ U-10Mo fuel particles, the maximum loading would be limited $\sim 7 \mathrm{~g} / \mathrm{cc}$; with spherical particles a maximum loading slightly higher might be achievable. At high volume loadings, little experience for making the required fuel gradient and cold forming the plate to the required shape exists. Furthermore, at a high volume loading, the core become more fragile and forming the required involute shape by conventional cold forming processes may not be feasible.
} 
gradient. In both cases, different fabrication processes than those being used in production today would be required. The irradiation performance of the candidate alloy fuels is unknown.*

Neutronics studies will be conducted for four types of LEU fuel. All four types will contain uranium-molybdenum alloy. Two concepts will employ a monolithic alloy, monolith meaning cast as a single piece. In one case, a single casting of the to-be-determined thickness profile will be made. In the other, a series of foils of varying lengths will be stacked to achieve a stepwise graded thickness profile. In both cases, the fabricated monoliths will be assumed to be coated with a thin niobium diffusion barrier. The other two fuel concepts will employ dispersion fuel, meaning fuel particles of approximately the same diameter as $\mathrm{U}_{3} \mathrm{O}_{8}$ particles in the current $\mathrm{HEU}$ fuel and intermixed with a silicon-stabilized aluminum powder. Because it is not currently known if a diffusion barrier is required or desired, in one case, the dispersion particles will be assumed to have no diffusion barrier coating, only spherical U-10Mo particles. In the second case, a diffusion barrier coating will encase the U-10Mo particles.

\subsubsection{Monolithic}

A potentially significant difference between monolithic and dispersion fuels is that it will be assumed that a zero filler thickness is allowed for monolithic fuels. Because the fuel zone will be solid, the fabrication step in which the silicon-stabilized aluminum filler is added to the fuel contour is simplified. With a solid fuel region, rather than a powder fuel, there is not a concern of disrupting the fuel profile during addition of the aluminum powder filler. The assumption of allowable zero-filler-region thickness applies to both the single cast and foil monolithic cases. All monolithic fuels are assumed to be U-10Mo with a density of $17.02 \mathrm{~g} / \mathrm{cm}^{3}$. The thermal conductivity of the fuel portion of the plate will be based on the derivation provided in Appendix C. ${ }^{\dagger}$

\subsubsection{Single cast}

The "after rolling" minimum allowable thickness of a single cast alloy is assumed to be 0.005 in. ( 5 mils, $0.127 \mathrm{~mm}$ ) per specification by the RERTR Program Office. The maximum thickness is $0.762 \mathrm{~mm}$ (30 mils). The cast alloy is assumed to be coated with an 8 - $\mu \mathrm{m}$-thick diffusion barrier (expected range of coatings would be $6-8 \mu \mathrm{m}$ ). Reference 2 notes that "when the (niobium) coating thickness is approximately $8.5 \mu \mathrm{m}$, the porosity of the film is essentially zero.

\footnotetext{
*Fuel densities in excess of $9 \mathrm{~g} / \mathrm{cc}$ required for a HFIR LEU fuel can potentially be achieved in a monolithic fuel form, but bonding the cladding to the fuel core by hot rolling has not been particularly successful. A technique using a "stir melt" process has shown promise in achieving the required bonding, but irradiation performance has not been determined. The reaction of fuel core alloy fuel with the aluminum matrix during irradiation is also a concern. In current development activities, a $\mathrm{Nb}$ diffusion barrier applied as a thin coating over the fuel core section is being considered to minimize this reaction. The use of a cladding other than aluminum-of consideration of concerns with the fuel/clad reaction-is out of the scope of this study.

${ }^{\dagger}$ S. J. Zinkle notes that the effect of fission transmutation products on the thermal conductivity for burnups in excess of $10 \%$ has not been included in the discussion in Appendix C. Also, consideration should be given as to whether there are data to support the assumed decrease in fuel swelling at temperatures above $450^{\circ} \mathrm{C}$. A basis should be established for assuming the conductivity of the two-phase $\mathrm{U}-27 \mathrm{Mo}\left(\mathrm{Mo}+\mathrm{MoU}_{2}\right)$ will be similar or equivalent to the conductivity of the two-phase $\mathrm{U}-29 \mathrm{Zr}\left(\mathrm{U}+\mathrm{UZr}_{2}\right)$ alloy. Due to uncertainty in the derivation of thermal conductivity, the HFIR steady state heat transfer code will be modified to allow for user input to override values derived from the methodology in Appendix C (with warning messages issued to the user). Sensitivity studies of temperature profile as a function of assumed conductivity will be performed.
} 


\subsubsection{Foils}

The minimum thickness of an after-rolled foil is assumed to be the same as the minimum thickness for the as-rolled fuel bearing region in the current HFIR fuel plate, $0.127 \mathrm{~mm}$. Given the thickness of the fuel/filler region, the maximum number of foils available for constructing the grading distribution is six. The uncertainty in the placement of the foils is assumed to be bounded by the uncertainty in the fuel thickness, i.e., fuel homogeneity bounds. Those bounds are discussed in a subsequent section.

The foils need not have their centerpoints be collinear. While three thicknesses are possible, five zone widths are achievable by varying the location of the centerpoints of the foils and the lengths of the foils. The foils will be assumed to be hot-pressed to form one stair-stepped foil and then coated with a thin $(8-\mu \mathrm{m})$ diffusion barrier of niobium. Filler aluminum (see Sect. 3.3) is assumed to contain silicon to minimize $\mathrm{UAl}_{4}$ due to contact between the aluminum and $\mathrm{U}-10 \mathrm{Mo}$ resulting from any discontinuities in the niobium diffusion barrier.

\subsubsection{Dispersion}

Dispersion fuel refers to a mixture of particles in the fuel zone rather than a continuous metal casting. In the current fuel design, this mixture is $\mathrm{U}_{3} \mathrm{O}_{8}$ and aluminum metal powder (see Fig. 3.1). Dispersion LEU fuels are conceptually the same; particles of U-10Mo or U-10Mo mixed with silicon-stabilized aluminum metal would be pressed into a compact.

The size of the U-10Mo particles will be assumed to be the same as for the target specification for $\mathrm{U}_{3} \mathrm{O}_{8}$ particles in the current HFIR fuel-a distribution with a mean diameter of approximately $250 \mu \mathrm{m}$. The particles will be assumed to be spherical in shape. The particle size for the aluminum powder will also be assumed to be the same as for the current HFIR fuel plate mixture-a distribution with a mean diameter of approximately $70 \mu \mathrm{m}$.

The maximum uranium density for a dispersion fuel would occur if no aluminum were added to the LEU powder. Assuming hexagonal closest packed geometry would yield a packing fraction of 0.7405. In practice, a maximum packing fraction of 0.6 is found (Ref. 3 ). Reference 3 also reports that for distributions of similarly sized spheres the packing fraction is approximately 0.5. This derivation in Ref. 3 agrees with powder production experience at Research Reactors Division, ORNL (J. D. Sease), and a packing fraction of 0.5 will be assumed.

The thermal conductivity of the fuel region will be enhanced by the presence of aluminum in interstitial positions between the U-10Mo matrix. The amount of aluminum needed to meet thermal criteria will be a subject of study in subsequent engineering analyses. However these analyses will be constrained by the assumption that as aluminum is added or removed, there is a particle for particle substitution (nominal $70-\mu \mathrm{m}$ aluminum metal particle for $250-\mu \mathrm{m}$ LEU particle). Clearly such an assumption is appropriate only over a limited range of aluminum contents. As such, as a part of subsequent engineering analyses, the assumption will be reviewed for validity.

The thermal conductivity of the dispersion fuels will be assumed to be the same as that of monolithic U-10Mo. As with the packing fraction for aluminum and LEU particles, this assumption will be reviewed for validity as a part of subsequent engineering analyses.

The minimum thickness of an after-rolled fuel region is assumed to be $0.127 \mathrm{~mm}$. The maximum thickness is assumed to be the same as for the current HFIR fuel, $0.635 \mathrm{~mm}(0.025 \mathrm{in}$., see Fig. 3.1), different from that of the monolithic fuels due to expected differences in the fabrication processes. 


\subsubsection{Uncoated particles}

For uncoated U-10Mo particles, a maximum U-10Mo density is assumed to be half of the nominal U-10Mo density, $8.51 \mathrm{~g} / \mathrm{cm}^{3}$ due to a packing fraction of 0.5 . There is assumed to be no intermixing of the filler and fuel regions before or after rolling.

\subsubsection{Coated particles}

Reference 4 reports the results of studies of applying a niobium coating to uranium molybdenum particles as a diffusion barrier. The barrier is intended to inhibit the interdiffusion of uranium and aluminum; "this interdiffusion leads to the formation of low density, brittle intermetallics, which result in swelling and potential failure of the fuel plate clad" (Ref. 4). The potential use of these coatings is applicable to current studies both when considering the filler/fuel interface and also the U-10Mo aluminum interaction inside the fuel region if aluminum powder is mixed with U-10Mo particles.

Assuming that the outer diameter of a coated U-10Mo particle remains the same as an uncoated particle (nominally $250 \mu \mathrm{m}$ ), then if the coating is assumed to be $8 \mu \mathrm{m}$ thick, the diameter of the U-10Mo particle would be reduced to $234 \mu \mathrm{m}$. Consequently, for coated particles, the maximum uranium density will be reduced from the value of the uncoated particles by the ratio of the cube of the fuel radius to the cube of the coated particle radius. Hence, for coated particles, the maximum U-10Mo density will be $(8.78 \times 0.82)=6.98 \mathrm{~g} / \mathrm{cm}^{3}$. The niobium will be assumed to have naturally occurring isotopic ratios.

\subsection{ALUMINUM FILLER/FUEL DISPERSION AGENT}

The aluminum in the filler region (and fuel region if present) is assumed to be ATA 101 aluminum powder with a $3 \mathrm{wt} \%$ silicon addition, resulting in the composition shown in Table 3.2. An aluminum matrix with a silicon content in the range of $3-12 \mathrm{wt} \%$ is needed to preclude $\mathrm{UAl}_{4}$ formation with uncoated, decoated, or failed-coating U-Mo particles. Because both silicon and aluminum are generally transparent to neutrons, the exact concentration is not necessary to be specified for the upcoming engineering studies. Table 3.2 shows that at least

Table 3.2. Composition of aluminum powder for filler or fuel region

\begin{tabular}{|l|l|}
\hline \multicolumn{1}{|c|}{ Element } & \multicolumn{1}{|c|}{ wt $\%$} \\
\hline Aluminum (metallic) & 96.30 minimum \\
\hline Silicon & 3.0 minimum \\
\hline Cadmium & 0.002 maximum \\
\hline Copper & 0.200 maximum \\
\hline Lithium & 0.008 maximum \\
\hline Iron & 0.250 maximum \\
\hline Zinc & 0.100 maximum \\
\hline Other (single) & 0.050 maximum \\
\hline $\mathrm{Al}_{2} \mathrm{O}_{3}$ & 0.700 maximum \\
\hline Boron & 0.001 maximum \\
\hline
\end{tabular}


$3 \mathrm{wt} \%$ silicon is added to an $\mathrm{Al}-101$ mix to preclude $\mathrm{UAl}_{4}$ formation in any exposed U-Mo. Neutronics calculations will assume 3 wt $\%$.

The post-rolled density in the filler region will be assumed to be that of aluminum metal, $2.70 \mathrm{~g} / \mathrm{cm}^{3}$. If present in dispersion fuel, the aluminum density will be a variable in the upcoming engineering studies.

In the current HFIR fuel plates, boron is added to the aluminum filler for the inner element fuel plates. For LEU engineering studies, boron content will be considered a variable. Potential limits on boron concentration would be the criteria of maintaining the same cycle length as the current HEU fuel cycle and assurance that helium generation due to neutron absorption does not lead to clad failure.

\subsection{UNCERTAINTIES IN FABRICATION PROCESSES}

To determine that an LEU fuel design has not reduced the margin of safety for the HFIR from that currently documented in the Updated Safety Analysis Report (Ref. 5), deviations in physical parameters due to manufacturing processes or measurement uncertainty must be quantified. Because the goal of the following engineering study is to determine a design for a fuel that is not in commercial production, it is obvious that none of these deviations can be known. Yet uncertainties in fuel plate constituents and configuration cannot be ignored as these parameters are required input to the determination of the margin of safety (Ref. 6).

For subsequent engineering studies, the fuel homogeneity and inspection requirements that are documented in Ref. 7 and discussed in Sect. 4 will be applied, as appropriate, to U-10Mo fuels. Furthermore, fuel element fabrication parameters such as minimum and maximum plate thicknesses, minimum and maximum coolant channel thicknesses, etc., that are documented in Refs. 5 and 6 and discussed in Sect. 4 will be assumed to apply to LEU fuels.

\section{REFERENCES}

1. M. E. Hassler and E. M. Parker, "Y-12 Product Improvements Expected to Reduce Metal Production Costs and Decrease Fabrication Losses," Transactions of the 2004 RERTR Meeting, November 7-12, 2004, http://www.rertr.anl.gov/RERTR26/pdf/46-Hassler.pdf.

2. J. M. Blocher, Jr., N. D. Viegel, J. H. Oxley, V. M. Secrest, and E. E. Rose, Fluidized Bed Coating of $\mathrm{UO}_{2}$ Powder with Niobium and Other Elements, BMI-1440, May 25, 1960.

3. J. A. Elliott, A. Kelly, and A. H. Windle, "Recursive Packing of Dense Particle Mixtures," Journal of Materials Science Letters, 21, 1249-1251 (2002), http://www.cus.cam.ac.uk/ jae1001/research/packing/Elliott_Kelly_Windle_JMatSciLett_2002_c orrected.pdf.

4. B. N. Briggs and W. H. Friske, Development of Niobium Diffusion Barriers for Aluminum-Clad Uranium Alloy Fuel Elements, NAA-SR-7973, 1963.

5. HFIR Updated Safety Analysis Report, ORNL/HFIR/USAR/2344, Oak Ridge National Laboratory, Oak Ridge, Tennessee, Rev. 5, May 2005.

6. H. A. McLain, HFIR Fuel Element Steady State Heat Transfer Analysis, Revised Version, ORNL/TM-1904, Oak Ridge National Laboratory, Oak Ridge, Tennessee, December 1967, as appended by T. E. Cole, L. F. Parsly, and W. E. Thomas, Revisions to the HFIR Steady State Heat Transfer Analysis Code, ORNL/CF-85/68, April 7, 1986.

7. R. B. Rothrock and J. D. Sease, Homogeneity Requirements and Inspection of HFIR Fuel Plates, ORNL/TM-2000/309, Oak Ridge National Laboratory, Oak Ridge, Tennessee, February 2001. 


\section{COMPUTER CODES, DATA, AND MODELS}

The performance of HFIR with LEU fuel will be analyzed using the standard set of computational tools that are currently used to support the operation of the reactor. These tools include those for neutronics, thermal-hydraulics, and dose assessments. The following subsections include a description of the computer codes and models and provide information on their past usage for similar analyses performed at Oak Ridge National Laboratory (ORNL). The methods and computer codes are an extension of the experience base at ORNL for the earlier conceptual core design for the Advanced Neutron Source (ANS) project.

\subsection{COMPUTER CODES AND DATA}

The computer codes that will be used for the analysis include MCNP (Ref. 1), SCALE (Ref. 2), and BOLD VENTURE (Ref. 3) for use in reactor physics analyses and assessments. The HFIR steady-state thermal-hydraulics code SSHTC (Steady State Heat Transfer Code) (Ref. 4) is used by HFIR staff in modeling operational behavior of the reactor. These codes are the production codes to be used in the overall assessment and analyses of the HFIR LEU fuel designs. For quality assurance purposes, the codes MONTEBURNS (Ref. 5) and ATTILA (Ref. 6) are to be used for independent assessment and review of the neutronics analyses with the reactor physics production codes. In addition to these codes, the accident analyses performed for the HFIR Safety Analysis Report (SAR) are performed with RELAP5 (Ref. 7); however, the calculations to update the SAR will not be performed in this study.

The nuclear data libraries to be used with the neutronics codes for this work will be the most recent data available. These data libraries will generally be based on ENDF/B-VI nuclear data. The libraries used with BOLD VENTURE will be prepared using the SCALE/AMPX crosssection generation sequences. Previously, the AMPX (Ref. 8) code system was used separately, but the modules have now been incorporated into the SCALE system.

\subsubsection{Production Codes and Methods}

\subsubsection{MCNP}

MCNP5 (Ref. 1) is a general-purpose three-dimensional, continuous-energy, Monte Carlo N-Particle transport code system that can be used for neutron, photon, electron, or coupled neutron/photon/electron transport. The code can perform transport calculations in either continuous or multigroup modes and has the capability to calculate eigenvalues for critical systems, reaction rates, reactivity effects, flux levels, fixed source calculations, etc. Many tallies of desired output parameters are available and definable in the case models.

The MCNP5 code treats an arbitrary three-dimensional configuration of materials in geometric cells bounded by first- and second-degree surfaces and fourth-degree elliptical tori. Pointwise cross-section data are used. For neutrons, all reactions given in a particular cross-section evaluation (such as ENDF/B-VI) are accounted. Thermal neutrons are described by both the free gas and $S(\alpha, \beta)$ models. For photons, the code accounts for incoherent and coherent scattering, the possibility of fluorescent emission after photoelectric absorption, absorption in pair production with local emission of annihilation radiation, and bremsstrahlung. Important standard features that make MCNP very versatile and easy to use include a general source, criticality source, and surface source; both geometry and output tally plotters; a collection of variance reduction techniques; a flexible tally structure; and an extensive collection of cross-section data. 
The analysis performed in this study will be based on the existing, detailed HFIR MCNP model (Refs. 9 and 10), which uses the standard ENDF/B-VI point cross section library that is distributed with the code.

In this study, MCNP will be used as a reference code and since it can model the detailed components of the reactor, will be used to determine the specific impacts on key neutron fluxes as outlined in the performance criteria.

\subsubsection{SCALE}

SCALE (Standardized Computer Analyses for Licensing Evaluation) (Ref. 2) is a modular code system that is developed and maintained by ORNL for the U.S. Nuclear Regulatory Commission (NRC) and the Department of Energy (DOE). The SCALE system utilizes wellestablished computer codes and methods within standard analysis sequences that (1) provide an input format designed for the occasional user and/or novice, (2) automate the data processing and coupling between modules, and (3) provide accurate and reliable results. System development has been directed at problem-dependent cross-section processing and analysis of criticality safety, shielding, depletion/decay, and heat transfer problems.

SCALE 5.0 was released in 2004, and SCALE 5.1 is planned for release in early 2006. The standard cross section libraries for SCALE 5.0 include a 238 and 44 group ENDF/B-V library. A new ENDF/B-VI data library has been developed and released with SCALE 5.1. Currently, SCALE 5.0 has been approved for use through the HFIR software quality assurance process and will be used for the analysis. However, depending upon the release of SCALE 5.1 and the need for ENDF/B-VI based cross sections, SCALE 5.1 may also be utilized.

The role of the SCALE code system in this study is to (1) provide few-group cross section libraries for use with BOLD VENTURE; (2) perform detailed isotopic analyses for source terms and decay heat; (3) perform dose assessments as needed; and (4) provide for criticality safety analyses. Note that in order to perform the cross section preparation, some utility routines from the AMPX system that are not currently part of SCALE may be needed as well.

\subsubsection{BOLD VENTURE}

BOLD VENTURE (Ref. 3) is a three-dimensional multigroup diffusion-theory neutronics code based on finite-difference diffusion theory. The BOLD VENTURE code system includes the BURNER burnup code allowing for the analysis of reactor performance over fuel cycles. The BOLD VENTURE code system can solve for nuclear reactor core static neutronics and reactor history exposure problems. BOLD VENTURE is used to calculate the neutronics eigenvalue, adjoint, fixed source, and criticality search problems. BOLD VENTURE was developed at ORNL over a long term and has been validated against benchmark problem studies and analytical solutions in addition to experimental data for numerous applications. In reactor core analysis, BOLD VENTURE applies the finite-difference neutron diffusion method ( $\mathrm{P}_{1}$ approximation) in an outer-inner iteration strategy, with several different data handling techniques. The code solves the finite-difference mesh-centered formulation of the neutron diffusion equations in one, two, or three dimensions: Cartesian cylindrical, spherical, and triangular geometry. BOLD VENTURE models have been used extensively for the High Flux Isotope Reactor (e.g., Ref. 11).

BOLD VENTURE will be used to perform the detailed fuel grading studies needed to arrive at a suitable fuel distribution and loading to meet the power peaking and cycle length requirements. The reactor core will be modeled using R-Z geometry with approximately 20 energy groups. 


\subsubsection{HFIR steady-state thermal-hydraulics analysis code (SSHTC)}

Section 4.4.2.2 of Ref. 7 provides the following description of thermal-hydraulic design criteria and method of analysis:

To define an integral thermal-hydraulic model of the operating reactor, the following factors must be considered simultaneously:

1. plant operating conditions,

2. power density distributions during the fuel cycle,

3. oxide film buildup on the fuel plates,

4. fuel plate deflections induced by differential pressures and temperatures,

5. coolant flow distribution within the fuel elements,

6. fuel segregation and cladding-fuel nonbonds, and

7. heat transfer and burnout characteristics.

McLain developed an integrated thermal-hydraulic model for the steadystate operation of the HFIR, taking into consideration all the factors listed above [Ref. 4]. The basic approach used in the analysis is to calculate the thermalhydraulic history of the fuel elements at some specified power level for all time increments prior to the time at which the reactor power level is raised to the maximum value. This accounts for the burnup of the fuel and for the buildup of the oxide on the fuel plates. Then the power level is raised to a value consistent with the IB or the burnout criteria.

The computer code for HFIR fuel element steady-state heat transfer analyses was originally written in the mid-1960s in connection with the design of the HFIR [Refs. 12, 13], and it employs an integral thermal-hydraulics model that simultaneously accounts for the nuclear, hydraulic, heat transfer, mechanical, and corrosion history of the operating reactor.

Beginning in 1984, and as support of a new research reactor concept being studied at ORNL, the code was updated. The primary changes involved:

1. expanding the capability of the code to analyze either light- or heavy-water reactors,

2. the Bernath burnout correlation was replaced by the Ivey and Morris correlation for saturation temperatures above $254^{\circ} \mathrm{F}$ (pressure above 32 psia), and

3. the thermal-hydraulics code was slightly modified to utilize a more current version of the Hausen heat transfer coefficient equation, as described in the following.

The HFIR thermal-hydraulics analysis code is used to calculate the power level at which the relevant thermal-hydraulic criterion (IB or burnout) is reached as a function of inlet coolant temperature $\left({ }^{\circ} \mathrm{F}\right)$ and fuel assembly inlet pressure (psia). The IB (burnout) power level (MW) is that reactor power level at which the hot spot surface heat flux numerically equals the surface heat flux required to cause IB (burnout), and is determined as a function of axial position (top to bottom) in each coolant channel. The hydraulic calculations include entry losses at the top of the fuel assembly, exit losses from the assembly, and frictional losses down the length of the coolant passage. The flow through a fuel element cooling channel is calculated from the Moody relation, with allowances for inlet and exit pressure losses. The friction factor used for the fuel plate surface is 
based on surface roughness measurements from out-of-reactor flow and corrosion tests at HFIR conditions using type-6061 aluminum and is approximated in the analysis code as a function of fluid conditions using the (Reynolds $\mathrm{Nr})^{-0.2}$ representation.

The mechanics of the thermal-hydraulics analysis code are designed so that the heat transfer coefficient at any point in the iterative solution is calculated by using properties based on previous estimates for bulk water temperature and fuel plate surface temperature. The IB power level is also determined by iterative solution. The reactor power level is adjusted until the surface heat flux predicted by the IB equation equals the hot spot heat flux. This condition occurs at only one "spot" on the entire fuel assembly, out of 682 mesh points in the calculation. The mesh points employed in the calculation are given in Ref. 4.

The code also calculates the incipient burnout power level by using coolant inlet pressure and temperature conditions. These calculations are performed by the code while automatically adjusting the reactor power until the surface heat flux predicted by the burnout correlation equals the hot spot heat flux. The resultant power level, or incipient burnout power, is used in selecting the HFIR SL.

Discussion of the application of uncertainty factors in the heat transfer code is presented in Sect. 4.2.4.

\subsubsection{Methods for Quality Assurance}

Some methods will be used to provide "independent" confirmation of the results of analyses performed with previously described diffusion and transport methods. These methods will be used in the initial stage of the engineering analyses to develop/confirm selection of number of energy groups and energy group boundaries and to develop/confirm the adequacy of the spatial mesh in deterministic calculations. They will be used again at the completion of the engineering evaluation to confirm the final results of the "production" diffusion and transport methods.

\subsubsection{MONTEBURNS}

The MONTEBURNS code (Ref. 5) is actually not a distinct methodology. It is an automated coupling of MCNP and ORIGEN2 for depletion purposes. Burnup calculations will be performed using MONTEBURNS studies currently being documented (Ph.D. dissertation by N. Xoubi, University of Cincinnati) have shown that inherent limitations of MONTEBURNS require that the existing HFIR MCNP model (Refs. 9, 10,14) had to be simplified to accommodate zone limitations of the MONTEBURNS code.

Because MONTEBURNS affords the capability of performing continuous energy calculations as a function of time, this code package will be used to assess level of agreement among computational methods for calculated power distributions for time periods after beginning-of-cycle. By this comparison, confidence in the selection of number and span of energy groups for deterministic codes can be gained. The code package will also be used to assess the level of agreement among codes for the production of plutonium and transplutonium actinides-phenomena that will be enhanced in an LEU cycle relative to an HEU cycle.

The MCNP model input to MONTEBURNS will likely be the same as being currently documented by Xoubi but with fuel/filler zones changed to match, as closely as possible, that of the "production" MCNP. Actinides and major fission products—approximately thirty—will be 
updated in the ORIGEN2 portion of the MONTEBURNS input and are expected to be the same as selected for recent study by Xoubi.

\subsubsection{ATTILA}

The inherent (coding) limitation on the spatial resolution obtainable from MONTEBURNS leads to the inclusion of the ATTILA code (Ref. 6) in the suite of quality assurance methods. ATTILA is a commercially available radiation transport and depletion program. Algorithms in ATTILA solve the particle transport equations on unstructured tetrahedral elements. Smaller elements can be used when a higher level of resolution is required, and larger elsewhere. The spatial mesh is generated by the program. The number and span of energy groups can be set by the user.

ATTILA accepts a variety of computer-aided-design (CAD) input formats and as such, can provide an exact representation of an involute-shaped fuel plate and the fuel profile inside the plate while also having the capability to perform burnup calculations. Size and distribution of spatial mesh can be changed rapidly and easily. Both the cylindrical geometry approximations of the production diffusion and transport models and the adequacy of the production spatial mesh will be assessed with ATTILA calculations.

During the evaluation phase for the purchase of ATTILA by ORNL, a model of the HFIR was developed but not with an involute-shaped fuel plate explicitly represented. Cross-section data input to ATTILA will be the same as used for production diffusion and transport programs.

\subsection{DESCRIPTION OF THE AVAILABLE HFIR MODELS}

The models used with the identified neutronics codes are based on the technical details from the 1971 HFIR description report (Ref. 13), updated as required to represent the current configuration and design of the reactor.

\subsubsection{MCNP}

The MCNP model of HFIR represents the reactor as-built and includes all redesigns, modifications, and upgrades since its 1965 first approach to criticality. The HFIR MCNP model (HFV4.0) (Refs. 9 and 10) explicitly represents six sections, each pertaining to a specific region or structure of the reactor:

1. flux trap target region,

2. inner fuel element region,

3. outer fuel element region,

4. control element region,

5. removable reflector region, and

6. permanent beryllium reflector region.

This model has been modified and updated to represent the latest HFIR configuration representative of cycle 400, including target loading pattern, reflector experiments, and reflector beam tube design changes. Figure 4.1 is a horizontal planar cross section view of the HFIR MCNP model, as depicted in Ref. 9. In addition, a detailed representation of the cold source is available to allow the calculation of potential impacts on the cold source to be performed. The calculations are performed with continuous energy ENDF/B-VI neutron cross-section data libraries. 


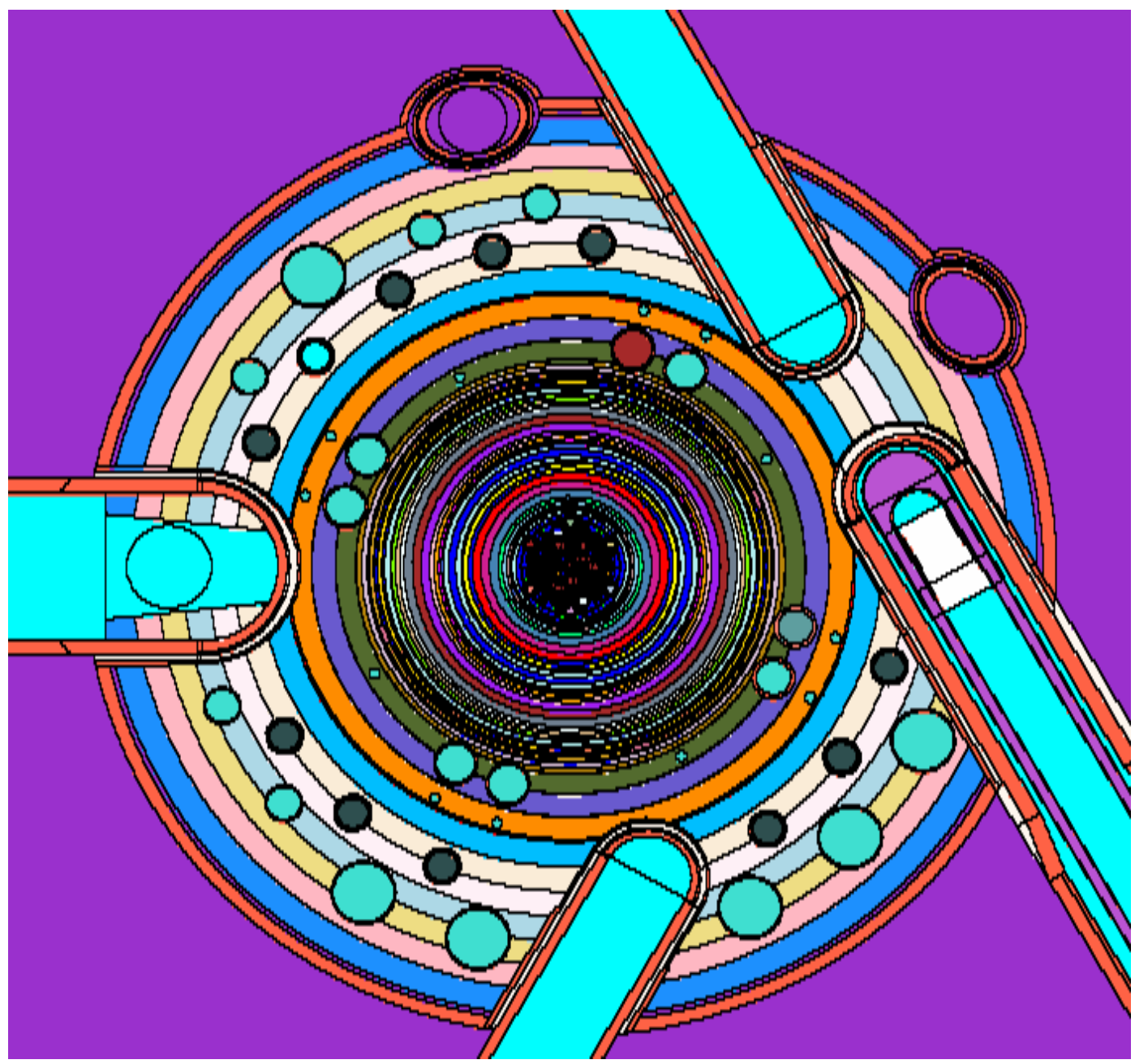

Fig. 4.1. MCNP model of HFIR: cross section of reactor core at horizontal midplane.

\subsubsection{SCALE}

A BOLD VENTURE model had been developed in support of the safety analysis report to provide estimates of the core power distributions, cycle length, and reactivity coefficients (Refs. 11 and 15). This model, described below, requires few-group cross sections that were obtained using AMPX (Ref. 8) and SCALE. As mentioned above, the modules and utility codes of AMPX are included in the latest version of SCALE (Ref. 2). The cross-section library previously used with BOLD VENTURE is the 99-group ANSL-V (Ref. 16) library (based on ENDF/B-V nuclear data) developed for the Advanced Neutron Source (ANS) project.

The few-group cross section library for the BOLD VENTURE analysis is created using the BONAMI and NITAWL modules for resonance processing and the XSDRNPM module to perform a one-dimensional radial calculation to obtain the appropriate neutron flux spectrum for collapsing the cross sections to seven energy groups. Because of the use of HEU with thin fuel plates, the homogenization of the fuel region is performed with volume weighting. Figure 4.2 presents a calculational flow diagram of the procedure for producing the appropriate working library for BOLD VENTURE for use with the ANS model. The SCALE/AMPX sequence for producing the relevant library for BOLD VENTURE for use in the HFIR LEU fuel design assessments will be similar, but with a different upgraded neutron energy group partitioning, and without the indicated degree of group collapse. 


\section{Calculation Flow Diagram}

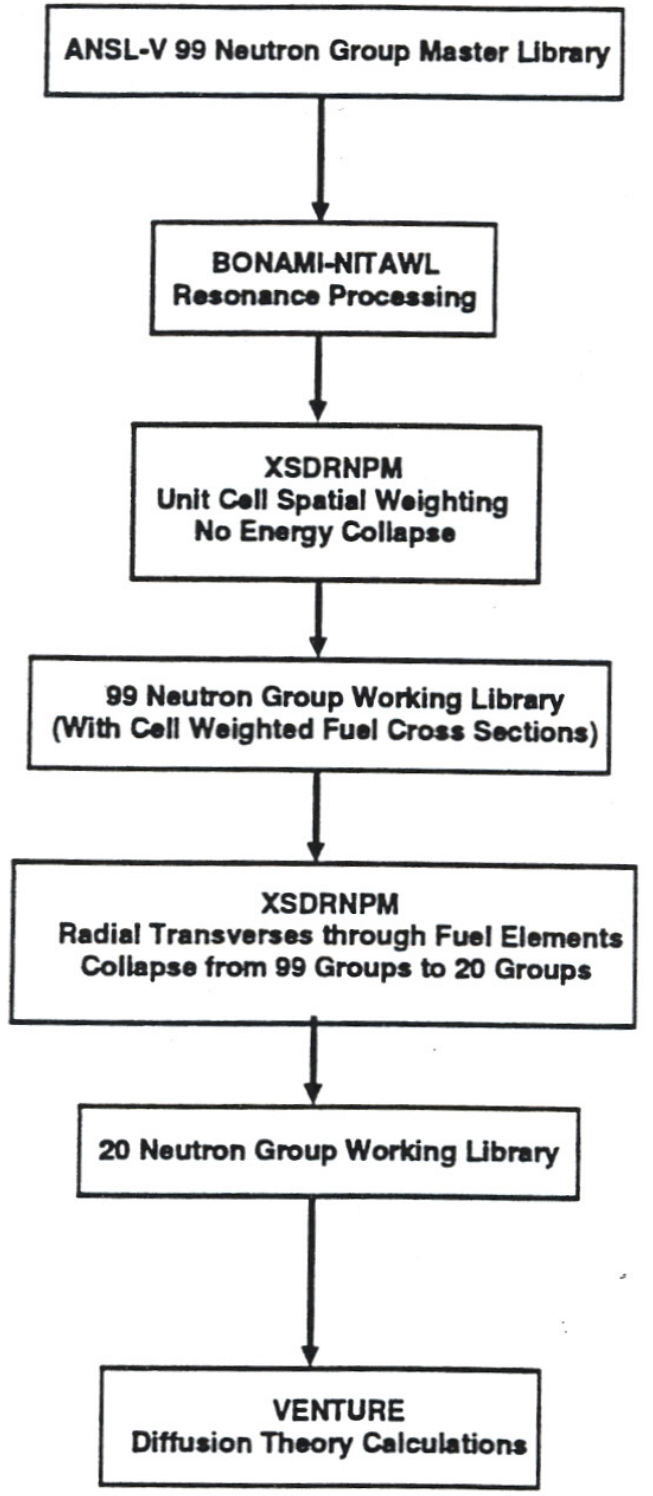

Fig. 4.2. Flow diagram of an example representative SCALE/AMPX cross-section generation sequence.

For the LEU fuel design analyses, it is expected that this model will be revised to use the 238-group cross section library distributed with the SCALE Version 5.1 code system. The same resonance processing and one-dimensional radial model will be used to obtain few-group cross sections in approximately 20 energy groups. If necessary for LEU fuel design analysis calculations and assessments, an additional step to perform a flux-weighted collapse of the fuel plate can be added to obtain the homogenized fuel cross sections. This process will be repeated for the different fuel loadings and enrichments (LEU/HEU) to obtain problem-dependent libraries for the core analyses. 


\subsubsection{BOLD VENTURE}

The BOLD VENTURE model of HFIR (Refs. 11 and 15) provides the ability to perform the depletion calculations of the HFIR core, using the BURNER module, and to provide detailed power distributions based on the input fuel distribution. The current model has a homogenized representation of the central target region, multiple fuel regions in the two fuel elements, control elements, and the beryllium reflector without the experimental facilities. The reactor is modeled in R-Z geometry, although R-Theta-Z models have been developed for special purposes. As described above, the multigroup neutron cross-section libraries are obtained using SCALE/AMPX.

The fuel depletion calculations are performed using multiple depletion regions in the fuel element and with several depletion steps involving the solution of the detailed burnup chains. The control rod position is adjusted to provide an approximate critical configuration. The output of the calculation is the detailed power distribution in the fuel region, the isotopic composition of the fuel, neutron flux distribution, and the effective multiplication factor. Since these calculations are very fast, they can be used to perform the numerous fuel grading calculations needed to provide the flat power profile, as well as provide impacts on the peak fluxes in the target and reflector regions.

\subsubsection{HFIR Steady-State Thermal-Hydraulics Code}

Measurement, calibration, correlation, and fabrication uncertainties are included in the IB calculation through the use of uncertainty factors in the SSHTC. These uncertainty factors and their values for the current HEU fuel are reported in Table 4.1. An explanation of the use of these factors is contained in Refs. 4 and 7. However, one application and a useful example are excerpted below from Ref. 7, Sects. 4.4.4.5.1 and 4.4.4.5.3.

The thermal-hydraulic code calculates the fuel hot spot heat flux by using an equation of the form:

$$
\phi_{H S}=\left(3.413 \times 10^{6}\right)\left(Q \frac{f}{A}\right) \phi(i, j) U_{1} U_{2} U_{3} U_{25} U_{x}
$$

where

$$
\begin{aligned}
A Q= & \text { eactor power level, } \mathrm{MW} \\
f= & \text { fraction of heat deposited in the fuel assembly }(0.975) ; \\
= & \text { nominal fuel assembly heat transfer area, } \mathrm{ft}^{2} ; \\
\varphi(i, j)= & \text { normalized power density distribution at each radial and axial } \\
& \text { location. }
\end{aligned}
$$

The definition of and representative values for the $U_{1}, U_{2}, U_{3}$, and $U_{25}$ uncertainties are contained in Table 4.1. $U_{x}$ is derived from:

$$
U_{x}=1.0+(\bar{U}-1)\left[\frac{H(i, j)}{15,000}\right]\left[\frac{T_{s}(i, j)}{T(i, j)}\right]^{0.163}
$$


where

$$
\begin{aligned}
\bar{U}= & \text { an uncertainty factor to account for fuel segregation and } \\
& \text { nonbonds in the fuel plates; } \\
H(i, j)= & \text { hot spot heat transfer coefficient from Hausen equation, } \\
& \text { Btu/h-ft- }{ }^{\circ} \mathrm{F} ; \\
T(i, j)= & \text { hot streak bulk water temperature, }{ }^{\circ} \mathrm{F} ; \\
T_{S}(i, j)= & \text { hot spot surface temperature, }{ }^{\circ} \mathrm{F}
\end{aligned}
$$

The (U) factors, when used in the (HFIR safety analyses), result in a high degree of conservatism, as illustrated in the following example.

It is recalled that the HFIR scram set points are selected such that no incipient boiling occurs when the system pressure, coolant inlet temperature, and flux-toflow ratio are concurrently held at their respective scram set points. In the selected example, the uncertainties given in Table 4.1 are used in the calculation of the IB power level, assuming the following conditions:

1. System pressure at the scram set point of 368 psig (100 psi below the normal operating pressure).

2. Coolant inlet temperature at the scram set point of $130^{\circ} \mathrm{F}\left(10^{\circ} \mathrm{F}\right.$ above the normal operating temperature).

3. Reactor coolant flow at $16,000 \mathrm{gpm}$ (nominal $100 \%$ flow condition).

4. Flux-to-flow ratio at the scram set point of 1.25 (106.25 MW at $100 \%$ flow).

The resulting IB power level is 110.6 MW. In comparison, if all uncertainties were set to unity (1.0), a recalculation of the IB power level yields a reactor

\begin{tabular}{|c|c|c|}
\hline Symbol & Definition & Typical values \\
\hline$U_{1}$ & Uncertainty in the reactor power level & 1.02 \\
\hline$U_{2}$ & Uncertainty in the total heat transfer area & 1.045 \\
\hline$U_{3}$ & Uncertainty in the power density distribution & 1.155 \\
\hline$U_{4}$ & $\begin{array}{l}\text { Uncertainty in the "average" fuel concentration in } \\
\text { the hot plate } a\end{array}$ & $\begin{array}{r}0.92 \text { for } 1 \leq \mathrm{j} \leq 16 \\
1.10 \text { for } 17 \leq \mathrm{j} \leq 31\end{array}$ \\
\hline$U_{5}$ & $\begin{array}{l}\text { Uncertainty in the "average" fuel concentration in } \\
\text { the cold plate } a\end{array}$ & $\begin{array}{l}1.08 \text { for } 1 \leq \mathrm{j} \leq 16 \\
0.90 \text { for } 17 \mathrm{j} \leq 31\end{array}$ \\
\hline$U_{6}$ & Uncertainty in the inlet coolant temperature & 1.015 \\
\hline$U_{7}$ & Uncertainty in the friction factor & 1.05 \\
\hline$U_{8}$ & Uncertainty in the local heat transfer correlation & 0.90 \\
\hline$U_{9}$ & Uncertainty in the oxide film correlation & 1.25 \\
\hline$U_{10}$ & $\begin{array}{l}\text { Uncertainty in the relationship for deflection as a } \\
\text { result of the differential pressure across the } \\
\text { plate }\end{array}$ & 1.10 \\
\hline
\end{tabular}
power of 190.3 MW, which is $79.7 \mathrm{MW}$ above the uncertainty-burdened calculation. In other words, the conservatism in the IB power associated with the uncertainty factors alone is $79.7 \mathrm{MW}$, when compared to the nominal or best estimate calculation of core behavior.

Table 4.1. Uncertainty factors in HFIR steady state heat transfer code 
Table 4.1. (continued)

\begin{tabular}{|c|c|c|c|}
\hline Symbol & \multicolumn{2}{|c|}{ Definition } & Typical values \\
\hline$U_{11}$ & \multicolumn{2}{|c|}{$\begin{array}{l}\text { Uncertainty in the relationship for deflection of plate } \\
\text { being considered in reference to an average plate } \\
\text { as a result of temperature differences }\end{array}$} & 1.10 \\
\hline$U_{12}$ & \multicolumn{2}{|c|}{$\begin{array}{l}\text { Uncertainty in the increase in the fuel plate thickness } \\
\text { as a result of thermal expansion }\end{array}$} & 2.00 \\
\hline$U_{13}$ & \multicolumn{2}{|c|}{$\begin{array}{l}\text { Uncertainty in the increase in the fuel plate thickness } \\
\text { as a result of radiation damage }\end{array}$} & 1.00 \\
\hline$U_{14}$ & \multicolumn{2}{|c|}{$\begin{array}{l}\text { Uncertainty in the longitudinal buckling of the fuel } \\
\text { plate as a result of the temperature differences } \\
\text { between the fuel plate and the side plates }\end{array}$} & 1.00 \\
\hline$U_{15}$ & \multicolumn{2}{|c|}{$\begin{array}{l}\text { Uncertainty in the longitudinal buckling of the fuel } \\
\text { plate as a result of the radiation damage }\end{array}$} & 1.00 \\
\hline$U_{16}$ & \multicolumn{2}{|c|}{$\begin{array}{l}\text { Uncertainty in the side plate heat generation rate at } \\
100 \mathrm{MW}\end{array}$} & 1.00 \\
\hline$U_{17}$ & \multicolumn{2}{|c|}{$\begin{array}{l}\text { Uncertainty in the coolant heat generation rate } 100 \\
\text { MW }\end{array}$} & 1.00 \\
\hline$U_{18}$ & \multicolumn{2}{|c|}{$\begin{array}{l}\text { Fuel segregation flux peaking on the hot side of the } \\
\text { fuel plate }\end{array}$} & 1.30 \\
\hline$U_{19}$ & \multicolumn{2}{|c|}{$\begin{array}{l}\text { Fuel segregation flux peaking on the cold side of the } \\
\text { fuel plate (a) }\end{array}$} & 1.30 \\
\hline$U_{23}$ & \multicolumn{2}{|c|}{ Uncertainty in the IB correlation } & 1.00 \\
\hline$U_{24}$ & \multicolumn{2}{|c|}{ Hot streak factor ${ }^{a}$} & 1.10 \\
\hline$U_{25}$ & \multicolumn{2}{|c|}{$\begin{array}{l}\text { Flux peaking for fuel extending beyond normal } \\
\text { boundaries }\end{array}$} & \\
\hline & \multicolumn{2}{|c|}{ For $\mathrm{j}, 1$ through 28,30 , and 31} & 1.00 \\
\hline & \multicolumn{2}{|c|}{ For j, 29: } & See below \\
\hline & & Inner element & Outer element \\
\hline & 1 & 1.00 & 1.00 \\
\hline & 2 & 1.00 & 1.00 \\
\hline & 3 & 1.00 & 1.23 \\
\hline & 4 & 1.25 & 1.23 \\
\hline & 5 & 1.41 & 1.26 \\
\hline & 6 & 1.44 & 1.35 \\
\hline & 7 & 1.43 & 1.31 \\
\hline & 8 & 1.30 & 1.23 \\
\hline & 9 & 1.20 & 1.00 \\
\hline & 10 & 1.00 & 1.00 \\
\hline & 11 & 1.00 & 1.00 \\
\hline
\end{tabular}

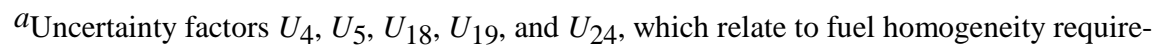
ments, were revised by Ref. 22 and subsequent fuel specifications as follows:

$U_{4}$, min. average over $1 / 2$ hot plate/maximum average over $1 / 2$ hot plate: $0.90 / 1.12$

$U_{5}$, maximum average over $1 / 2$ cold plate/min. average over $1 / 2$ cold plate: $1.10 / 0.88$

$U_{18}, U_{19}$, max local fuel density: 1.27

$U_{24}$, maximum fuel density averaged over $\sim 1 / 2$-in. track: 1.12 
Other input data to the SSHTC—currently used solution grid, etc.—some of which could be varied for an LEU fuel are identified in Table 4.2. Dimensions and tolerances relevant to the

Table 4.2. SSHTC code input data

\begin{tabular}{|c|c|c|c|}
\hline Symbol & \multicolumn{2}{|c|}{ Definition } & Typical values and units \\
\hline \multirow[t]{2}{*}{$\mathrm{R}$} & \multicolumn{2}{|c|}{ Outside radius of inner side plate } & 2.7215 in. for inner element \\
\hline & & & $5.8730 \mathrm{in}$. for outer element \\
\hline \multirow[t]{13}{*}{$\Delta \mathrm{r}_{\mathrm{i}}$} & \multicolumn{3}{|c|}{ Radial space increments } \\
\hline & Inner Element & Outer Element & \\
\hline & $\Delta \mathrm{r}_{1}=0 \mathrm{in}$ & $\Delta \mathrm{r}_{1}=0 \mathrm{in}$ & \\
\hline & $\Delta \mathrm{r}_{2}=0.0895 \mathrm{in}$. & $\Delta \mathrm{r}_{2}=0.0739 \mathrm{in}$ & \\
\hline & $\Delta \mathrm{r}_{3}=0 \mathrm{in}$ & $\Delta \mathrm{r}_{3}=0 \mathrm{in}$ & \\
\hline & $\Delta \mathrm{r}_{4}=0.3386 \mathrm{in}$ & $\Delta \mathrm{r}_{4}=0.3346 \mathrm{in}$ & \\
\hline & $\Delta \mathrm{r}_{5}=0.3937 \mathrm{in}$ & $\Delta \mathrm{r}_{5}=0.3937 \mathrm{in}$ & \\
\hline & $\Delta \mathrm{r}_{6}=0.3937 \mathrm{in}$. & $\Delta \mathrm{r}_{6}=0.3937 \mathrm{in}$ & \\
\hline & $\Delta \mathrm{r}_{7}=0.3937 \mathrm{in}$. & $\Delta \mathrm{r}_{7}=0.3937 \mathrm{in}$ & \\
\hline & $\Delta \mathrm{r}_{8}=0.3937 \mathrm{in}$. & $\Delta \mathrm{r}_{8}=0.3937 \mathrm{in}$ & \\
\hline & $\Delta \mathrm{r}_{9}=0.2362 \mathrm{in}$. & $\Delta \mathrm{r}_{9}=0.3937 \mathrm{in}$ & \\
\hline & $\Delta \mathrm{r}_{10}=0 \mathrm{in}$ & $\Delta \mathrm{r}_{10}=0 \mathrm{in}$ & \\
\hline & $\Delta \mathrm{r}_{11}=0.794 \mathrm{in}$ & $\Delta \mathrm{r}_{11}=0.0443 \mathrm{in}$ & \\
\hline \multirow[t]{9}{*}{$\Delta \mathrm{z}_{\mathrm{i}}$} & \multicolumn{3}{|c|}{ Longitudinal space increments } \\
\hline & \multicolumn{3}{|c|}{$\underline{\text { For both elements }}$} \\
\hline & \multicolumn{3}{|l|}{$\Delta \mathrm{z}_{1}=0$ in. } \\
\hline & \multicolumn{3}{|l|}{$\Delta \mathrm{z}_{2}=2.0000 \mathrm{in}$} \\
\hline & \multicolumn{3}{|l|}{$\Delta z_{3}=0$ in. } \\
\hline & \multicolumn{3}{|c|}{$\Delta \mathrm{z}_{4}=0.5512 \mathrm{in}$} \\
\hline & \multicolumn{3}{|c|}{$\Delta \mathrm{z}_{5}$ through $\Delta \mathrm{z}_{28}=0.7874 \mathrm{in}}$. \\
\hline & \multicolumn{3}{|l|}{$\Delta \mathrm{z}_{30}=0$ in. } \\
\hline & \multicolumn{3}{|l|}{$\Delta \mathrm{z}_{31}=2.0000 \mathrm{in}$} \\
\hline$\varphi_{\mathrm{i}, \mathrm{j}}$ & \multicolumn{2}{|c|}{ Normalized power density distribution } & $\begin{array}{l}\text { To be calculated in follow-on } \\
\text { engineering study }\end{array}$ \\
\hline \multirow[t]{6}{*}{$\theta_{\mathrm{k}}$} & \multicolumn{3}{|l|}{ Time increment } \\
\hline & \multicolumn{3}{|l|}{$\theta_{1}=24.33 \mathrm{~h}$} \\
\hline & \multicolumn{3}{|l|}{$\theta_{2}=253.23 \mathrm{~h}$} \\
\hline & \multicolumn{3}{|l|}{$\theta_{3}=267.68 \mathrm{~h}$} \\
\hline & \multicolumn{3}{|l|}{$\theta_{4}=54.78 \mathrm{~h}$} \\
\hline & \multicolumn{3}{|l|}{$\theta_{5}=0 \mathrm{~h}$} \\
\hline
\end{tabular}


Table 4.2. (continued)

\begin{tabular}{|c|c|c|}
\hline Symbol & Definition & Typical values and units \\
\hline$Q$ & Specified reactor power level & $85 \mathrm{MW}$ \\
\hline$f$ & Fraction of heat deposited in the fuel assembly & 0.975 \\
\hline$A$ & Nominal fuel assembly heat transfer area & $428.8 \mathrm{ft}^{2}$ \\
\hline$t$ & Fuel plate thickness & $51 \mathrm{mils}$ \\
\hline$e_{A}$ & $\begin{array}{l}\text { Average fuel element coolant channel thickness prior to } \\
\text { reactor operation }\end{array}$ & 49 mils for both fuel elements \\
\hline$e_{n}$ & $\begin{array}{l}\text { Average thickness of the narrow coolant channel prior to } \\
\text { reactor operation }\end{array}$ & 44 mils for both fuel elements \\
\hline$e_{w}$ & $\begin{array}{l}\text { Average thickness of the wide coolant channel prior to } \\
\text { reactor operation }\end{array}$ & 56 mils for both fuel elements \\
\hline$e_{n e}$ & $\begin{array}{l}\text { Thickness of the inlet and exit of the narrow coolant } \\
\text { channel prior to reactor operation }\end{array}$ & 44 mils for both fuel elements \\
\hline$e_{w e}$ & $\begin{array}{l}\text { Thickness of the inlet and exit of the wide coolant } \\
\text { channel prior to reactor operation }\end{array}$ & 56 mils for both fuel elements \\
\hline$e_{n, \min }$ & $\begin{array}{l}\text { Minimum thickness of the narrow coolant channel prior } \\
\text { to reactor operation }\end{array}$ & 40 mils for both fuel elements \\
\hline$e_{w, \min }$ & $\begin{array}{l}\text { Minimum thickness of the wide coolant channel prior to } \\
\text { reactor operation }\end{array}$ & 40 mils for both fuel elements \\
\hline$T_{\text {in. }}$ & Inlet coolant temperature & $120^{\circ} \mathrm{F}$ \\
\hline$P$ & Reactor vessel pressure (nominal) & 468 psig \\
\hline$\Delta P_{F}$ & Fuel element pressure drop & $108 \mathrm{psi}$ \\
\hline$F$ & Constant in the friction factor relation $f=F /(\mathrm{Re})^{0.2}$ & 0.235 \\
\hline
\end{tabular}

thermal-hydraulics analyses are specified in Table 4.3. The SSHTC code will be modified for LEU fuel design analyses to include the proper thermal-hydraulics and material parameters (thermal conductivity, heat capacity, etc.) for U-10Mo fuel that are documented in Appendix B of Sect. 3 .

\subsection{EXPERIENCE AND VALIDATION}

In addition to the analysis of HFIR, MCNP, SCALE, and BOLD VENTURE were used extensively on the ANS project at ORNL, which was terminated in 1995. The ANS was a highpower (330-MW), high-flux reactor designed for both isotope production and neutron science. The core consisted of multiple fuel assemblies with a very similar geometrical configuration as HFIR but with heavy water coolant and reflector. The original configuration consisted of two axially offset fuel elements with HEU, but was later modified to three elements to accommodate the use of a reduced enrichment fuel (50 wt $\left.\%{ }^{235} \mathrm{U}\right)$.

\subsubsection{HFIR}

The MCNP and BOLD VENTURE models have been used for the analysis of the HFIR, particularly for the assessment of the experimental facilities and designs. Recently, the MCNP model has been updated to provide a representation of cycle 400 (Ref. 9). A comparison of the 
Table 4.3. Pertinent HFIR dimensions and tolerances

$\begin{array}{ll}\text { Length of fuel plates } & 24 \mathrm{in} . \\ \text { Nominal fuel plate thickness } & 0.050 \mathrm{in} . \\ \text { Maximum fuel plate thickness } & 0.051 \mathrm{in} . \\ \text { Nominal coolant channel thickness } & 0.050 \mathrm{in} . \\ \text { Maximum coolant channel thickness averaged across width of plate at any given elevation } & 0.056 \mathrm{in} . \\ \text { Minimum coolant channel thickness averaged across width of plate at any given elevation } & 0.044 \mathrm{in} . \\ \text { Maximum local coolant channel thickness } & 0.060 \mathrm{in} . \\ \text { Minimum local coolant channel thickness } & 0.040 \mathrm{in} . \\ \text { Nominal distance of fuel bearing portion from upper and lower edges of the fuel plate } & 2 \mathrm{in} . \\ \text { Maximum distance of fuel bearing portion from upper and lower edges of the fuel plate } & 21 / 4 \mathrm{in} . \\ \text { Minimum distance of fuel bearing portion from upper and lower edges of the fuel plate } & 13 / 4 \mathrm{in} . \\ \text { Minimum radial distance of the fuel bearing portion of the fuel plate from the side plate } & 0.045 \mathrm{in} . \\ \text { Nominal heat transfer area } & 428.7 \mathrm{ft}^{2} \\ \text { Minimum heat transfer area } & 410.3 \mathrm{ft} \\ \text { Maximum diameter of non-bond between fuel and clad } & 1 / 16 \mathrm{in} . \\ \text { Tolerance on total fuel loading within an individual fuel plate } & \pm 1.0 \% \\ \text { Tolerance on fuel loading within a 5/64-in. diameter spot } & +27 \% \\ \text { Average tolerance on fuel loading within a rectangular area } 5 / 64 \text { in. } \times 1 / 2 \text { in. } & -100 \%\end{array}$

fresh core configuration critical control rod position provides an indication of the accuracy of the model. In addition, some comparisons have been made with measurements in experimental positions.

\subsubsection{ANS}

The same codes proposed for this work were used extensively in the design of the ANS reactor (Refs. 17-19). Detailed calculations and comparisons were performed with MCNP and BOLD VENTURE to provide a measure of the consistency of the models and the accuracy of the diffusion theory results for the high flux reactor. In addition, the tools were used to perform a study of the use of LEU fuels, and the results were compared with those performed by ANL.

This work provided extensive experience upon which the current HFIR models were developed, and all codes were found to perform very well. The level of accuracy of the diffusion theory analysis was found to be very good and suitable for the design and scoping studies performed. In addition, validation with experiments, described in the next section, provide confidence in the results.

\subsubsection{FOEHN Critical Experiment}

MCNP (22) and BOLD VENTURE (23), and their associated nuclear data libraries, were validated during the ANS conceptual core design efforts through benchmark analyses of the FOEHN critical experiment configurations. FOEHN was deemed appropriate for validation of neutronics methods in the now-defunct ANS reactor because of similarities with the High Flux Reactor (HFR). The similarities of HFR to HFIR support the use of FOEHN in the validation of the neutronics methods and nuclear data for the HFIR LEU fuel design assessment project. 


\subsubsection{Description of the FOEHN critical experiment}

The FOEHN critical experiment was performed at the CEN-Cadarache EOLE reactor facility, as part of design process to validate the calculational methods used by the FrenchGerman team designing the HFR at the Institut Laue-Langevin (ILL) in Grenoble. The core was a hollow cylinder of $90 \%$ HEU U-Al alloy in involute-shaped fuel plates. The core is HW moderated and reflected.

\subsubsection{Results from FOEHN benchmark studies}

In the FOEHN critical configurations analyzed during the ANS CCD phase, the results showed good agreement between measured experimental data and code calculations for eigenvalue and power density profiles. The FOEHN critical experiment involved configurations of three planned levels of complexity: simplest configuration, intermediate configuration, and the complex configuration.

In the MCNP validation calculations (Ref. 20) of the FOEHN critical experiment, there was good agreement between code predictions, and experiment. For all levels of configuration complexity, the MCNP calculations of the effective multiplication eigenvalues $\mathrm{k}_{\text {eff }}$ were within $2 \sigma$ or $3 \sigma$ error bars of the experimentally determined critical values (1.000). The MCNP power distributions with $2 \sigma$ error bars were within $4 \%$ of the experimental values. A similar high level of agreement was observed for thermal neutron flux calculations and for the calculation of the rendement ratio.

In the calculations performed with BOLD VENTURE (Ref. 21), the determinations of the effective multiplication factors were within $1.1 \%$ of the experimental critical values of 1 for the simple FOEHN configuration, and within $1.4 \%$ for the intermediate configuration. Depending on the modeling assumptions and techniques, the $\mathrm{k}_{\mathrm{eff}}$ calculations with BOLD VENTURE for the complex FOEHN configuration differed from the experimental critical values ranging from less than $0.5 \%$ to $2 \%$. The average percent difference between the experimental measured power distributions and the BOLD VENTURE calculations ranged from just under $3 \%$ for the simple configuration to about $4 \%$ for the complex configuration.

\subsection{REFERENCES}

1. MCNP-A General Monte Carlo N-Particle Transport Code, Version 5, LA-CP-03-0245, Los Alamos National Laboratory, April 2003.

2. SCALE: A Modular Code System for Performing Standardized Computer Analyses for Licensing Evaluations, ORNL/TM-2005/39, Version 5, Vols. I-III, Oak Ridge National Laboratory, Oak Ridge, Tennessee, April 2005. [Available from Radiation Safety Information Computational Center (RSICC) at Oak Ridge National Laboratory as CCC-725.]

3. D. R. Vondy, T. B. Fowler, and G. W. Cunningham III, The Bold Venture Computation System for Nuclear Reactor Core Analysis, Version III, ORNL-5711, Oak Ridge National Laboratory, Oak Ridge, Tennessee, June 1981.

4. H. A. McLain, HFIR Fuel Element Steady State Heat Transfer Analysis, Revised Version, ORNL/TM-1904, Oak Ridge National Laboratory, Oak Ridge, Tennessee, December 1967 as appended by T. E. Cole, L. F. Parsly, and W. E. Thomas, Revisions to the HFIR Steady State Heat Transfer Analysis Code, ORNL/CF-85/68, April 7, 1986.

5. D. L. Poston and H. R. Trellue, User's Manual, Version 2.0 for MONTEBURNS

Version 1.0, Los Alamos National Laboratory, LA-UR-99-4999 (September 1999).

6. ATTILA computer code Web page: http://www.radiative.com/software.htm 
7. HFIR Updated Safety Analysis Report, ORNL/HFIR/USAR/2344, Rev. 5, Oak Ridge National Laboratory, Oak Ridge, Tennessee, May 2005.

8. N. M. Greene et al., AMPX-A Modular Code System to Generate Coupled Multigroup Neutron-Gamma Cross Sections from ENDF/B, ORNL/TM-3706, Oak Ridge National Laboratory, Oak Ridge, Tennessee, March 1976.

9. N. Xoubi and R. T. Primm III, Modeling of the High Flux Isotope Reactor Cycle 400, ORNL/TM-2004/251, Oak Ridge National Laboratory, Oak Ridge, Tennessee, August 2005.

10. D. E. Peplow, A Computational Model of the High Flux Isotope Reactor for the Calculation of Cold Source, Beam Tube, and Guide Hall Nuclear Parameters, ORNL/ TM-2004/237, Oak Ridge National Laboratory, Oak Ridge, Tennessee, November 2004.

11. N. Xoubi, R. T. Primm III, and G. I. Maldonado, "A Computational Model of the High

Flux Isotope Reactor-Validation and Application to Low Enriched Uranium Fuels,"

Proceedings of the Joint Conference, International Group on Research Reactors and Test, Research, and Training Reactors, 2005.

12. W. R. Gambill, Design Curves for Burnout Heat Flux in Forced-Convection Subcooled Light-Water Systems, ORNL/TM-2421, Oak Ridge National Laboratory, Oak Ridge, Tennessee, November 14, 1968.

13. HFIR Core Nuclear Design, ORNL-4621, Oak Ridge National Laboratory, Oak Ridge, Tennessee, 1971.

14. C. O. Slater and R. T. Primm III, Calculation of Rabbit and Simulator Worth in the HFIR Hydraulic Tube and Comparison with Measured Values, ORNL/TM-2005/94, Oak Ridge National Laboratory, Oak Ridge, Tennessee, September 2005.

15. R. T. Primm III, Reactor Physics Input to the Safety Analysis Report for the High Flux Isotope Reactor, ORNL/TM-11956, Oak Ridge National Laboratory, Oak Ridge, Tennessee, March 1992.

16. ANSL-V: ENDF/B-V Based Multigroup Cross-Section Libraries for Advanced Neutron Source (ANS) Reactor Studies, ORNL-6618, Oak Ridge National Laboratory, Oak Ridge, Tennessee, September 1990.

17. E. E. Alston, J. C. Gehin, and C. D. West, Fuel Density, Uranium Enrichment, and Performance Studies for the Advanced Neutron Source Reactor, ORNL/TM-12775, Oak Ridge National Laboratory, Oak Ridge, Tennessee, June 1994.

18. J. C. Gehin, Reactor Physics Analysis of the Advanced Neutron Source Three-Element Core, ORNL/M-4604, Oak Ridge National Laboratory, Oak Ridge, Tennessee, August 1995.

19. J. C. Gehin, B. A. Worley, J. P. Renier, C. A. Wemple, S. N. Jahshan, and J. M. Ryskamp, Reactor Physics Methods, Models, and Applications Used to Support the Conceptual Design of the Advanced Neutron Source, ORNL/TM-12966, Oak Ridge National Laboratory, Oak Ridge, Tennessee, August 1995.

20. A. M. Ougouag, C. A. Wemple, G. A. Rubio, and J. M. Ryskamp, MCNP Analysis of the FOEHN Critical Experiment, ORNL/TM-12466, Oak Ridge National Laboratory, Oak Ridge, Tennessee, October 1993.

21. L. A. Smith, J. C. Gehin, F. X. Gallmeier, J. P. Renier, and B. A. Worley, Validation of Multigroup Neutron Cross Sections and Calculational Methods for the ANS Against the FOEHN Critical Experiments, ORNL/TM-12829, Oak Ridge National Laboratory, Oak Ridge, Tennessee, May 1995. 


\section{ENGINEERING/ECONOMIC ASSESSMENT ASSUMPTIONS}

Based upon the results of the neutronic and thermal-hydraulic analyses of the available and near-term fuel options for a HFIR LEU core design, this section of the final report will provide an overall engineering assessment reflecting materials selections, structural-mechanical issues, safety impacts, cost impacts, and operations considerations. The assessment in the final report will revisit this initial "Assumptions and Criteria" report to assure consistency in specifying a set of requirements and criteria for subsequent fuel development and qualification necessary for the conversion of HFIR to LEU. The assessment will provide a preliminary evaluation of performance impacts and trade-offs in design options and a preliminary cost estimate of the required safety analysis updates, changes to Technical Safety Requirements, procedural modifications, and required training to support the implementation of core conversion. An assessment will be made of the capitol improvements required to HFIR to run the reactor with the LEU fuel at $100 \mathrm{MW}$. The assumptions for this portion of the assessment follow:

- The need and anticipated cost to change fresh fuel storage facilities at the Y-12 plant if weight or criticality concerns necessitate such changes.

- The need and anticipated cost to change tools used to handle the core movement in the pool shall be addressed since the LEU core mass will increase over that of the current HEU core.

- An assessment of the structural-mechanical impact of the more massive core on current invessel supports and, if appropriate, reactor vessel supports shall be performed along with a cost estimate for corrective or mitigative actions.

- An assessment of the structural-mechanical impact of the more massive core on current inpool spent fuel storage racks shall be performed along with a cost estimate for corrective or mitigative action.

- If the margins of subcriticality are reduced for the fresh core, an assessment of the impacts on both core handling during refueling and in-pool storage of a defueled partially-irradiated core (that is, as bounded by the unirradiated isotopics) shall be performed along with a cost estimate for corrective or mitigative action.

- An assessment shall be performed of the scope of changes to the safety analysis report and Technical Safety Requirements for DOE approval of LEU core operations along with a cost estimate for performing needed analyses and the production of required documentation.

- An assessment shall be performed of the scope of procedural changes and training requirements for implementation of LEU core operations along with a cost estimate for implementation.

- An assessment shall be performed of the scope and cost of any "start-up" or prototypic tests required for the certification of the use of LEU fuel in HFIR.

- Criteria shall be developed as required for the acceptance of appropriate experimental data needed for fuel qualification to satisfy the needs of the safety analysis report to be reviewed by DOE, the Technical Safety Requirements, and the ORNL ability to assure the customer of the continued mission accomplishment by HFIR.

- An assessment of the incremental cost impacts shall be performed for changes in the fuel manufacturing procedures including: down-blending of HEU to LEU; development of new production equipment for fabricating uranium-molybdenum foils or powders and applying diffusion barriers; development of new fuel plate manufacturing procedures (rolling, bending) including quality assurance procedures, for example, assessment of continued applicability of homogeneity and radiography scanners, and changes in safeguards/security requirements.

- An assessment of cost impact on fuel fabrication due to changing from HEU/oxide to LEU/U-10Mo is planned to be performed by the fuel fabricator. An assessment of the incremental cost impacts shall be performed in this study for any ORNL site specific changes due to the use of LEU and for any new waste disposal considerations, that is, spent fuel disposition, including need for additional spent fuel shipping cask analyses. 
- An assessment of the acceptability of uranium-molybdenum for shipping and storage of spent fuel.

Some additional considerations for this portion of the assessment are provided in Appendix A. 


\section{CORE LEU CONVERSION ANALYSIS METHODOLOGY}

The design of a HFIR LEU core will be performed using the tools described in Sect. 4 and requires the determination of the appropriate fuel loading and grading profiles as well as the assessment of the impact of the reactor operations and performance. The fuel loading will be determined such that the primary requirement for power level $(85 \mathrm{MW})$ and cycle length $(26 \mathrm{~d})$ are met. As discussed in Sect. 3, a variety of high-density fuels are available, and therefore, these calculations will be computed for a limited number of different fuels.

Given that a suitable core loading is determined, auxiliary criteria to assess the impact of the core conversion on operations and performance will be performed. This approach is similar to that used in the assessment of the conversion of the ANS to LEU (Refs. 1-3).

\subsection{REFERENCE HEU CALCULATIONS}

Reference cases using existing MCNP (Refs. 4 and 5) and BOLD VENTURE (Refs. 6 and 7) models for the current HEU design will be re-executed to obtain reference parameters to which the corresponding values from the LEU analyses will be compared, that is, software quality assurance. This approach will ensure that consistent models are used for the comparison and that the differences in performance are not the result of modeling differences. The results can also be compared to recent operating cycles to ensure that the models are accurate [such comparisons have been performed for cycle 400 (Ref. 4) using the MCNP model].

\subsection{FUEL LOADING DESIGN PROCESS}

The fuel loading design will be performed using the BOLD VENTURE model with a detailed core model to provide a nearly continuous representation of the fuel loading. The cross sections for this process will be obtained using the SCALE (Ref. 8) system as previously discussed in Sect. 4 and will be updated as needed to reflect changes in the fuel loading and fuel types. The calculations will be performed with approximately 20 neutron energy groups using $\mathrm{R}-\mathrm{Z}$ geometry with a homogenized central target region and a bare beryllium reflector.

The determination of the distribution of the fuel in the fuel plate requires an iterative calculation process that is similar to the fuel management calculations performed for commercial power reactors. A reasonably efficient process was developed for the two-dimensional grading for the ANS core, and the same process should work very well for the one-dimensional radial fuel grading determination for the HFIR LEU fuels (Ref. 9).

The approach is as follows:

a. An initial fuel loading profile is assumed (starting with a uniform profile, for example).

b. A fuel cycle calculation is performed with BOLD VENTURE to obtain the cycle length and power distribution.

c. If the fuel cycle length criterion is not met, the overall fuel loading will be increased (but will not exceed the maximum local loading).

d. If the power distribution exhibits too much peaking, the relative loading of fuel in the local region will be reduced.

e. Steps $b$ through $d$ are repeated for a number of iterations resulting in the best grading profile for the fuel being considered.

Upon obtaining a fuel grading profile, the power distribution will be used as input in the steady-state thermal-hydraulics code (SSHTC) to obtain the thermal margins. The goal in obtaining the power distribution is to maintain the current thermal margins. In addition to the thermal calculations, a representation of the fuel grading will be used in the HFIR MCNP model 
for comparison of the criticality and power distribution results with the BOLD VENTURE model, as well as to perform detailed assessments of the core performance.

Initial calculations may be performed with BOLD VENTURE with the control elements withdrawn to determine the approximate core loading to meet the cycle length requirement. However, for calculations of the power distribution, a criticality search will be performed to ensure that the influence of the control elements on the power distribution is taken into account.

The use of boron $\left({ }^{10} \mathrm{~B}\right)$ as a burnable absorber to flatten the power profiles and to minimize the control rod movements may also be considered. This depends upon the ability to incorporate boron in the fuel plate manufacturing process and will only be considered for those fuels in which boron can be placed within the fuel region of the plate.

\subsubsection{Optimal Grading}

The optimal grading will be obtained for a fuel material by allowing the fuel loading to vary continuously in the radial direction in the fuel elements. The minimum and maximum fuel meat thickness and maximum density will be used for the particular fuel being considered. The steps outlined above will be used to obtain the optimum grading profile. However, given the geometric limits, it may not be possible to obtain a truly optimal grading profile because it may be necessary to have the fuel at its maximum loading in some regions to meet the fuel cycle length requirement.

\subsubsection{Multiregion Grading}

Some of the fuel materials, such as the monolithic U-Mo fuel, may be in a form such that fuel grading will consist of several regions each of which have a uniform fuel loading. The impact of such a multiregion fuel loading will be assessed by representing the optimal grading profile as several uniform fuel regions. The number of regions can be varied, but will likely range from three up to a maximum of nine. The detailed power distribution for this multiregion design will also be analyzed with the steady-state thermal-hydraulics code SSHTC to assess the reactor performance.

\subsection{ADDITIONAL CALCULATIONS TO ASSESS LEU CORE DESIGNS}

Once a suitable LEU core design is obtained (that is, a design meeting the core power and cycle length requirements), additional parameters will be computed to assess additional safety requirements, impact on performance, and safeguards. Table 6.1 contains a list of the parameters that will be computed in each of these areas. The BOLD VENTURE and MCNP models will both be used to compute these parameters with MCNP being used primarily for BOC values and the BOLD VENTURE model being used for values throughout the fuel cycle.

\subsubsection{Reactivity Coefficients}

The primary reactivity coefficients of interest for HFIR are the Doppler reactivity coefficient and the coolant void coefficient. Both of these quantities are used in the HFIR safety analyses. They will be computed using BOLD VENTURE at BOC and EOC and compared to the MCNP BOC values. 
Table 6.1. Quantities to be computed in HFIR LEU study

\author{
Safety parameters \\ - Doppler reactivity coefficient \\ - Void reactivity coefficient \\ - Control element differential reactivity worth \\ - Safety rod reactivity worth (with one stuck element) \\ - Central void maximum reactivity worth \\ - Fuel element criticality (elements together and separate \\ in light water and reflected by concrete) \\ - Fuel element decay heat
}

\title{
Performance parameters
}

- Cycle length

- Power distribution

- Neutron flux in the central target region

- Peak unperturbed thermal flux in the reflector

- Thermal flux at the HB-2 beam tube

- Thermal flux at the NAA irradiation location

- Cold source flux

Other parameters (safeguards and environmental)

- Plutonium content in spent fuel elements

- Fuel element dose rates

- Fuel element isotopic compositions

\subsubsection{Control Element Reactivity Worth}

The reactivity worth of the control elements as a function of element position will change when the fuel enrichment is changed and as plutonium is produced during the fuel cycle with the LEU fuel design. The differential control rod worth curves are used in the safety analysis at the negative reactivity insertion in a reactor SCRAM. In addition, HFIR shutdown is required to meet specific shutdown criteria with one control blade withdrawn.

\subsubsection{Central Element Void Reactivity Worth}

The insertion of a void in the central region results in a positive reactivity insertion that must be offset by the negative reactivity insertion from the inserted control rods. Using the current criteria of maximum worth void in the central target region, the maximum void reactivity will be computed and compared to the current value as well as the appropriate SCRAM reactivity worth.

\subsubsection{Fuel Element Criticality}

Each fresh HFIR LEU fuel element (inner or outer) separately shall have an adequate margin of subcriticality under any credible configuration. The two assembled fresh LEU fuel elements should remain subcritical when fully reflected by light water or concrete. If subcriticality is not achievable for the two assembled fresh LEU fuel elements when fully reflected by light water or concrete, simple but diverse and redundant single-failure-proof measures for assuring subcriticality shall be available. In this study, fuel element criticality calculations will be performed with fresh fuel in light water to ensure that they meet the current requirements. 


\subsubsection{Decay Heat}

The decay heat from discharged cores, as a function of cooling time, will be assessed to assess potential impact of the operations and fuel storage. The decay heat vs cooling time is dependent on the actinide and fission product composition of the discharged fuel. These calculations can be performed using SCALE/ORIGEN-S.

\subsubsection{Fuel Cycle Length}

The effective multiplication factor $\mathrm{k}_{\mathrm{eff}}$ will be calculated throughout the HFIR fuel cycles to ensure the core has sufficient reactivity at BOC and that the reactor will remain critical for the full fuel cycle. For fuel cycle length determination, the depletion calculations can be performed with the control rods withdrawn for comparison purposes. A target EOC multiplication factor of 1.025 will be used to ensure that there is a sufficient reactivity margin. For the final calculations, the critical control rod position throughout the fuel cycle will be used to obtain an accurate estimate of the core power distribution with the end-of-life multiplication factor being the same as for the reference HEU core. The multiplication factors from BOLD VENTURE will be compared with those computed with MCNP at BOC.

\subsubsection{Core Power Distribution}

As an important assessment in the LEU fuel analyses, the power density distributions will be determined for relevant LEU cores, as appropriate. The linear power ratings and potential hot spot locations will be assessed to ensure that the reactor performance will be within specifications.

\subsubsection{Neutron Flux}

The neutron flux levels and spectrum in the central targets and in the reflector irradiation sites will be calculated for comparison to HEU core values. The neutron fluxes in the central target region provide an indication of the impact on the isotope production and target irradiation capabilities. The fluxes in the reflector region provide a measure of the impact on the neutron scattering facilities. In the reflector, the thermal neutron flux at the beam tube tips, the cold source flux (at a specified neutron energy at some location down the beam tube) and the flux at the location used for neutron activation analyses will be computed.

\subsubsection{Plutonium Composition}

The presence of ${ }^{238} \mathrm{U}$ in LEU at large fractions will lead to the production of greater quantities of plutonium than exist in current stored, irradiated HEU fuel elements. The storage of spent elements at HFIR for 5-7 years would result in a large increase in the plutonium inventory at ORNL. Regulatory impacts, if any, of this increased plutonium inventory will be assessed.

\subsubsection{Fuel Element Dose Rates}

The radiation fields associated with discharged HFIR LEU cores will be calculated to assess fuel element handling and storage issues. The dose rate for a bare fuel element in air will be computed and compared to identify any increase in radiation fields. 


\subsubsection{Isotopic Compositions}

The isotopic composition of the spent HFIR fuel has an impact on the environmental consequences for severe accidents as outlined in the HFIR SAR (Ref. 10). The isotopic composition of the spent fuel will change when converting from HEU to LEU HFIR cores. Calculations will be performed with BOLD VENTURE and SCALE to provide an estimate of the isotopic composition (actinides and fission products) of the spent fuel elements. The HEU and LEU compositions will be compared to identify any potential impact on the safety analysis.

\subsection{CALCULATIONS WITH OTHER CODES}

As discussed in Sect. 4, other codes are available at ORNL to perform verification calculations for the results obtained with MCNP and BOLD VENTURE. These additional codes will be used as needed to provide assurance that the results obtained are accurate. In particular, independent means of assuring adequate energy resolution in the group structure of the cross section libraries throughout the fuel cycle and accurate calculation of local power densities at the edges of the fuel elements will be assured by comparison to MONTEBURNS or ATTILA as appropriate.

\subsection{ASSESSMENT OF LEU CORES}

Based on the calculations outlined in this section, the performance of the LEU core designs will be compared to the criteria outlined in Sect. 2. A comparison table will be developed to compare the results of the analyses with these criteria to allow for an assessment of the suitability of the LEU core design. Some of the safety parameters presented in Table 6.1 will have to be assessed in lieu of performance of a complete safety analysis (HFIR SAR Chap. 15) (Ref. 10). For example, should the control element worth be outside of that used in the SAR safety analysis, the potential impact will be assessed qualitatively without performing the safety calculations. The overall assessment will clearly indicate any criteria that are not met, quantify impacts on the performance criteria, and provide an assessment of the impact on safety criteria.

\subsection{SUMMARY}

Computer codes, nuclear data, and methods in use at ORNL will be used to assess the LEU fuel design options for HFIR LEU core conversion. The optimum fuel grading will be determined within the constraints that the requirements of HFIR power and operational specifications and criteria are fully met.

\subsection{REFERENCES}

1. E.E. Alston, J. C. Gehin, and C. D. West, Fuel Density, Uranium Enrichment, and Performance Studies for the Advanced Neutron Source Reactor, ORNL/TM-12775, Oak Ridge National Laboratory, Oak Ridge, Tennessee, June 1994.

2. J. C. Gehin, Reactor Physics Analysis of the Advanced Neutron Source Three-Element Core, ORNL/M-4604, Oak Ridge National Laboratory, Oak Ridge, Tennessee, August 1995.

3. J. C. Gehin, B. A. Worley, J. P. Renier, C. A. Wemple, S. N. Jahshan, and J. M. Ryskamp, Reactor Physics Methods, Models, and Applications Used to Support the Conceptual Design of the Advanced Neutron Source, ORNL/TM-12966, Oak Ridge National Laboratory, Oak Ridge, Tennessee, August 1995. 
4. N. Xoubi, and R. T. Primm III, Modeling of the High Flux Isotope Reactor Cycle 400, ORNL/TM-2004/251, Oak Ridge National Laboratory, Oak Ridge, Tennessee, August 2005

5. D. E. Peplow, A Computational Model of the High Flux Isotope Reactor for the Calculation of Cold Source, Beam Tube, and Guide Hall Nuclear Parameters, ORNL/ TM-2004/237, Oak Ridge National Laboratory, Oak Ridge, Tennessee, November 2004

6. N. Xoubi, R. T. Primm III, and G. I. Maldonado, "A Computational Model of the High Flux Isotope Reactor-Validation and Application to Low Enriched Uranium Fuels," Proceedings of the Joint Conference, International Group on Research Reactors and Test, Research, and Training Reactors, 2005.

7. R. T. Primm III, Reactor Physics Input to the Safety Analysis Report for the High Flux Isotope Reactor, ORNL/TM-11956, Oak Ridge National Laboratory, Oak Ridge, Tennessee, March 1992.

8. SCALE: A Modular Code System for Performing Standardized Computer Analyses for Licensing Evaluations, ORNL/TM-2005/39, Version 5, Vols. I-III, Oak Ridge National Laboratory, Oak Ridge, Tennessee, April 2005. [Available from Radiation Safety Information Computational Center (RSICC) at Oak Ridge National Laboratory as CCC-725.]

9. J. C. Gehin, "The Advanced Neutron Source Three-Element Core Fuel Grading," Trans. Am. Nucl. Soc., 73, 394-395 (November 1995).

10. HFIR Updated Safety Analysis Report, ORNL/HFIR/USAR/2344, Rev. 5, Oak Ridge National Laboratory, Oak Ridge, Tennessee, May 2005. 


\section{Appendix A CRITERIA TO BE CONSIDERED QUALITATIVELY IN THIS STUDY}

The follow-on economic and engineering study (see Sect. 5) shall consider in a rigorous quantitative manner the results of the neutronic and thermal-hydraulic analyses. Many other criteria are important in considering a transition from LEU to HEU, but these other criteria can likely only be assessed in a qualitative or semiquantitative manner at this juncture. The following specifies those aspects of the follow-on economic and engineering assessment that will provide at most a preliminary assessment subject to further study and analyses.

\section{A.1 COMPONENTS OF THE HFIR PHYSICAL PLANT IMPACTED BY CHANGE IN ENRICHMENT}

Because of the construction of the reactor, the dimensions of the HFIR fuel elements could not be modified for LEU without prohibitively high cost and outage time to make reactor plant modifications. A criterion of future engineering studies is that there shall be no change to the physical dimensions of the core. However, simply changing the fuel from HEU to LEU will increase the uranium loading by a factor of 5 . An inner fuel element has a mass of $47.2 \mathrm{~kg}$, and an outer element has a mass of $91.7 \mathrm{~kg}$. A consequence of changing to LEU would be that the mass of an inner fuel element would increase by at least $22 \%$ and that of an outer element by at least $30 \%$. Maintaining an equivalent cycle length for the LEU fuels will almost certainly lead to fuel element mass increases greater than these values.

The mass or weight of the HFIR fuel elements directly impacts fuel handling operations during fuel fabrication, transportation of fresh fuel to Oak Ridge, fresh fuel storage, handling operations between the fresh fuel storage and the reactor core, handling operations between the core and spent fuel storage, and finally transportation by shipping cask to the spent fuel storage site. Fuel handling tools, seismic qualification of storage arrays, and other weight-related analyses will have to be performed when an acceptable LEU fuel design has been developed. Fuel handling operations are performed several times a year because HFIR typically is refueled eight times per year.

The physical support structure of the reactor core inside the reactor pressure vessel should be sufficient for the increase in weight accompanying LEU fuel. Nevertheless, the physical plant would have to be reviewed and qualified for the added weight, especially for seismic events.

Irradiated HFIR elements are stored in relatively close-packed, three-dimensional arrays at the reactor site until sufficiently decayed for shipment (typically 5-7 years). Approximately 60 assemblies (combinations of inner and outer elements) are currently stored at HFIR, and anticipated future operation would add 8 assemblies per year. The physical support structure of the array should be sufficient for the increase in weight accompanying LEU fuel but would have to be reviewed and qualified. Currently, operations at HFIR are limited to the storage of a maximum of 90 cores due to a lack of structural analyses of the pool floor.

Increased ${ }^{235} \mathrm{U}$ content (since studies will likely show that an increase in fissile content is necessary to compensate for parasitic capture in the fertile fuel) and change of enrichment level will mandate new criticality safety analyses for the spent fuel storage array. The current safety approval for the spent fuel storage is based on a series of cadmium-poisoned arrays of fresh, HEU fuel elements (no burnup credit). New analyses would be required for LEU, and it will have to be determined if a change to LEU would require new critical experiments and/or a larger fuel element spacing.

The radiation source term from spent HFIR fuel is the basis for accident source terms for some ORNL hot cell facilities as well as for the HFIR itself. This source term will be different due to the enhanced plutonium and trans-plutonium isotope content of spent LEU fuel as 
compared to HEU (for comparable energy generation) and due to differing fission product distribution in LEU fuel (a significant number of fissions will occur in plutonium produced from ${ }^{238} \mathrm{U}$ due to the high burnup of HFIR elements-200,000 MWd/MTHM for HEU fuel). Changes to the physical plant due to variation in the radiation source term would seem unlikely, but modification of safety documentation would extend beyond HFIR to other ORNL facilities.

\section{A.2 CHANGES IN THE DOCUMENTED SAFETY BASIS DUE TO CONVERSION TO LEU}

The steady-state operation of the reactor (reactor physics and thermal hydraulics) is described in Chap. 4 of the HFIR Updated Safety Analysis Report (USAR) (Ref. 1). Analyses of the reactor power distribution, inlet and outlet coolant temperatures, margin to incipient boiling, hot spot temperatures, clad oxide thickness, etc., will be performed using existing HFIR methodologies and models. While it is expected that values different from those in the current safety analysis report will be obtained, the goal for the engineering design studies will be to obtain a design such that the margin of safety is not reduced from that documented in the USAR. Such a philosophy has been successfully followed in recent design changes (Ref. 4).

The performance of the reactor under anticipated transients is described in Chap. 15 of the USAR. No new transients are expected to be identified due to a change in fuel material and fuel enrichment, but input will be needed from materials specialists to confirm performance of uranium-molybdenum alloy relative to the current fuel that is a mixture of $\mathrm{U}_{3} \mathrm{O}_{8}$ and aluminum. However, the reactivity worth of the control elements as a function of element position will change when the fuel enrichment is changed and as plutonium is produced during the fuel cycle. When a fuel design has been developed that satisfies steady-state operating criteria, existing methods and models (Ref. 3) will be used to examine the transient performance of the reactor. As for steady state, the goal for the engineering design studies will be to obtain a design such that the margin of safety is not reduced from that documented in the USAR.

\section{A.3 REFERENCES}

1. HFIR Updated Safety Analysis Report, ORNL/HFIR/USAR/2344, Rev. 5, Oak Ridge National Laboratory, Oak Ridge, Tennessee, May 2005.

2. Howard A. McLain, HFIR Fuel Element Steady State Heat Transfer Analysis, Revised Version, ORNL/TM-1904, Oak Ridge National Laboratory, Oak Ridge, Tennessee, December 1967 as appended by T. E. Cole, L. F. Parsly, and W. E. Thomas, Revisions to the HFIR Steady State Heat Transfer Analysis Code, ORNL/CF-85/68, Oak Ridge National Laboratory, Oak Ridge, Tennessee, April 7, 1986.

3. D. G. Morris and M. W. Wendel, High Flux Isotope Reactor System RELAP5 Input Model, ORNL/TM-11647, Oak Ridge National Laboratory, Oak Ridge, Tennessee, January 1993.

4. R. T. Primm, III, Reactor Physics Studies of Reduced-Tantalum-Content Control and Safety Elements for the High Flux Isotope Reactor, ORNL/TM-2003/65, December 2003. 


\section{Appendix B \\ FUEL CHARACTERISTICS FOR SELECTED FUEL FORMS}

(Thomas Newton, MIT)

\begin{tabular}{|c|c|c|c|c|}
\hline Fuel alloy & $\begin{array}{l}\text { Matrix } \\
\text { material }\end{array}$ & $\begin{array}{l}\text { Alloy density } \\
\left(\text { Rho }_{d}, \mathbf{g} / \mathbf{c m}^{3}\right)\end{array}$ & $\mathbf{W}_{\mathbf{d}} \mathbf{u}$ & 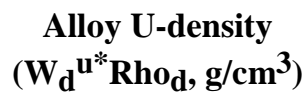 \\
\hline $\mathrm{Al}$ & & 2.7 & - & - \\
\hline $\mathrm{Al}_{2} \mathrm{O}_{3}$ & & 3.94 & - & - \\
\hline $\mathrm{UAl}_{4}$ & $\mathrm{Al}$ & 5.7 & 0.653 & 3.72 \\
\hline $\mathrm{UAl}_{3}$ & $\mathrm{Al}$ & 6.8 & 0.746 & 5.07 \\
\hline $\mathrm{UAl}_{2}$ & $\mathrm{Al}$ & 8.14 & 0.815 & 6.63 \\
\hline $\mathrm{UAl}_{\mathrm{x}}{ }^{a}$ & $\mathrm{Al}$ & 6.42 & 0.717 & 4.60 \\
\hline $\mathrm{UO}_{2}$ & $\mathrm{Al}$ & 10.96 & 0.882 & 9.67 \\
\hline $\mathrm{U}_{3} \mathrm{O}_{8}$ & $\mathrm{Al}$ & 8.30 & 0.848 & 7.04 \\
\hline $\mathrm{U}_{4} \mathrm{O}_{9}$ & $\mathrm{Al}$ & 11.19 & 0.869 & 9.72 \\
\hline Russian oxide $b$ & $\mathrm{Al}$ & 9.50 & 0.869 & 8.26 \\
\hline USi & $\mathrm{Al}$ & 10.96 & 0.895 & 9.81 \\
\hline Compd $\mathrm{U}_{3} \mathrm{Si}_{2}$ & $\mathrm{Al}$ & 12.20 & 0.927 & 11.31 \\
\hline $\mathrm{U}_{3} \mathrm{Si}$ & $\mathrm{Al}$ & 15.30 & 0.960 & 14.69 \\
\hline U-10Mo & $\mathrm{Al}$ & 17.02 & 0.90 & 15.32 \\
\hline U-9Mo & $\mathrm{Al}$ & 17.20 & 0.91 & 15.65 \\
\hline $\mathrm{U}-8 \mathrm{Mo}$ & $\mathrm{Al}$ & 17.36 & 0.92 & 15.97 \\
\hline U-7Mo & $\mathrm{Al}$ & 17.55 & 0.93 & 16.32 \\
\hline U-6Mo & $\mathrm{Al}$ & 17.72 & 0.94 & 16.66 \\
\hline U-4Mo & $\mathrm{Al}$ & 18.09 & 0.96 & 17.37 \\
\hline Compd $\mathrm{U}_{2} \mathrm{Mo}$ & $\mathrm{Al}$ & 16.60 & & 13.81 \\
\hline U-6Mo-1Pt & $\mathrm{Al}$ & 17.74 & & 16.50 \\
\hline U-6Mo-0.6Ru & $\mathrm{Al}$ & 17.64 & & 16.48 \\
\hline $\mathrm{U}-6 \mathrm{Mo}-0.1 \mathrm{Si}$ & $\mathrm{Al}$ & 17.59 & & 16.52 \\
\hline U-10Mo-0.05Sn & $\mathrm{Al}$ & 17.01 & & 15.30 \\
\hline $\mathrm{U}-9 \mathrm{Nb}-3 \mathrm{Zr}$ & $\mathrm{Al}$ & 16.08 & & 14.15 \\
\hline $\mathrm{U}-6 \mathrm{Nb}-4 \mathrm{Zr}$ & $\mathrm{Al}$ & 16.41 & & 14.77 \\
\hline $\mathrm{U}-5 \mathrm{Nb}-3 \mathrm{Zr}$ & $\mathrm{Al}$ & 16.86 & & 15.51 \\
\hline $\mathrm{U}-2 \mathrm{Mo}-1 \mathrm{Nb}-1 \mathrm{Zr}$ & $\mathrm{Al}$ & 17.94 & & 17.22 \\
\hline $\mathrm{U}_{6} \mathrm{Fe}$ & $\mathrm{Al}$ & 17.40 & 0.962 & 16.74 \\
\hline UN & $\mathrm{Al}$ & 14.30 & 0.944 & 13.50 \\
\hline $\mathrm{U}$ & - & 19.05 & 1.00 & 19.05 \\
\hline
\end{tabular}

Note: Rho $_{\mathrm{d}}=$ density of dispersed phase

$\mathrm{W}_{\mathrm{d}} \mathrm{u}=$ weight fraction of uranium in dispersed phase

$\mathrm{W}_{\mathrm{d}}^{\mathrm{u}} * \mathrm{Rho}_{\mathrm{d}}=$ density of uranium in dispersed phase

${ }^{a}$ Assumed to consist of $69 \mathrm{wt} \% \mathrm{UAl}_{3}$ and $31 \mathrm{wt} \% \mathrm{UAl}_{4}$ after fabrication.

${ }^{b}$ Russian oxide powder is commonly referred to as $\mathrm{UO}_{2}$, but is actually $\mathrm{U}_{4} \mathrm{O}_{9}$. Actual density of this oxide powder is $9-10 \mathrm{~g} / \mathrm{cm}^{3}$. Here a density of $9.5 \mathrm{~g} / \mathrm{cm}^{3}$ is assumed. 


\section{Appendix C \\ URANIUM-MOLYBDENUM THERMAL CONDUCTIVITY DURING IRRADIATION}

(Yeon Soo Kim and G. L. Hofman, Argonne National Laboratory)

\section{C.1 INTRODUCTION}

A model correlation for the thermal conductivity of (monolithic) $U$-Mo alloys as a function of molybdenum content, temperature, and burnup was developed.

\section{C.2 THERMAL CONDUCTIVITY OF UNIRRADIATED U-MO ALLOY}

Touloukian et al. (Ref. 1) summarized the thermal conductivity data for uranium metal available before 1970 . The only data accumulated since then were by Takahashi et al. (Ref. 2). For the temperature range $255 \leq T \leq 1173 \mathrm{~K}$, the thermal conductivity increased monotonically as temperature increased. A parabolic function of temperature was used to fit the data. Consequently, the thermal conductivity of uranium metal takes the form

$$
k_{U}(T)=21.73+1.591 \times 10^{-2} \mathrm{~T}+5.907 \times 10^{-6} \mathrm{~T}^{2},
$$

where $k$ is the thermal conductivity in $\mathrm{W} / \mathrm{m}-\mathrm{K}$ and $\mathrm{T}$ the temperature in $\mathrm{K}$. The temperature range for Eq. (1) was $255 \leq T \leq 1173 \mathrm{~K}$.

For the thermal conductivity of molybdenum metal, Touloukian et al. (Ref. 1) tabulated the recommended values based on assessment of data in the literature. The recommended values showed that the thermal conductivity of molybdenum decreased linearly as temperature increased for the temperature range of $300 \leq \mathrm{T} \leq 800 \mathrm{~K}$. A linear function of temperature was selected to fit the data. By fitting the data, the thermal conductivity of molybdenum was obtained as

$$
k_{M o}(T)=150.0-4.0 \times 10^{-2} \mathrm{~T}
$$

The temperature range for Eq.(2) was $300 \leq \mathrm{T} \leq 800 \mathrm{~K}$.

Thermal conductivity data of U-Mo alloy were available from Refs. 1 and 3-5 for the molybdenum content range of 5-10.7 wt \%. The U-Mo system has the second-phase metallic compound, $\gamma^{\prime}-\mathrm{U}_{2} \mathrm{Mo}$, at $300-800 \mathrm{~K}$, which approximately corresponds to U-17Mo. At this composition, the alloy would have the lowest thermal conductivity. However, because no data were available for the composition and a more conservative approach was deemed necessary, it was assumed that the thermal conductivity reached its minimum at 50 at. $\%$ molybdenum (or 29 wt \% molybdenum) in the alloy. Because no data for U-29Mo were available, U-29Zr data were adopted among U-based alloys with available thermal conductivity (Ref. 6). By fitting the data accumulated and prepared above to the following correlation, the thermal conductivity of unirradiated U-Mo fuel was modeled:

$$
k_{U-M o}^{0}=\left(1-\sqrt{1-x_{M o}}\right) k_{M o}+\sqrt{1-x_{M o}}\left\{\left(1-x_{M o}\right) k_{U}+x_{M o} k_{c, M o}\right\},
$$


where $k_{U-M o}^{0}$ is in $\mathrm{W} / \mathrm{m}-\mathrm{K}, x_{M o}$ is the molybdenum content in weight fraction. $k_{U}$ is given by Eq. (1), and $k_{M o}$ by Eq. (2). $k_{\mathrm{c}, \text { Mo }}$ is a result of the regression analysis of the data to Eq. (3) and takes the form

$$
\begin{aligned}
k_{c, M o}=-274.4+985.2 x_{M o}-1.941 & \times 10^{3} x_{M o}{ }^{2} \\
& +3.640 \times 10^{-2} T+7.365 \times 10^{-5} T^{2}+5.793 \times 10^{-2} x_{M o} T
\end{aligned}
$$

where $\mathrm{T}$ is in $\mathrm{K}$. The valid temperature range is $300 \leq \mathrm{T} \leq 800 \mathrm{~K}$.

No initial porosity was assumed in the unirradiated fuel. Therefore, Eq. (3) was not intended to be applicable to a porous U-Mo alloy.

Figure C.1 compares the data used for correlation fitting with the model predictions. The prediction for U-17Mo was also included for comparison. The predictions are generally close to the data.

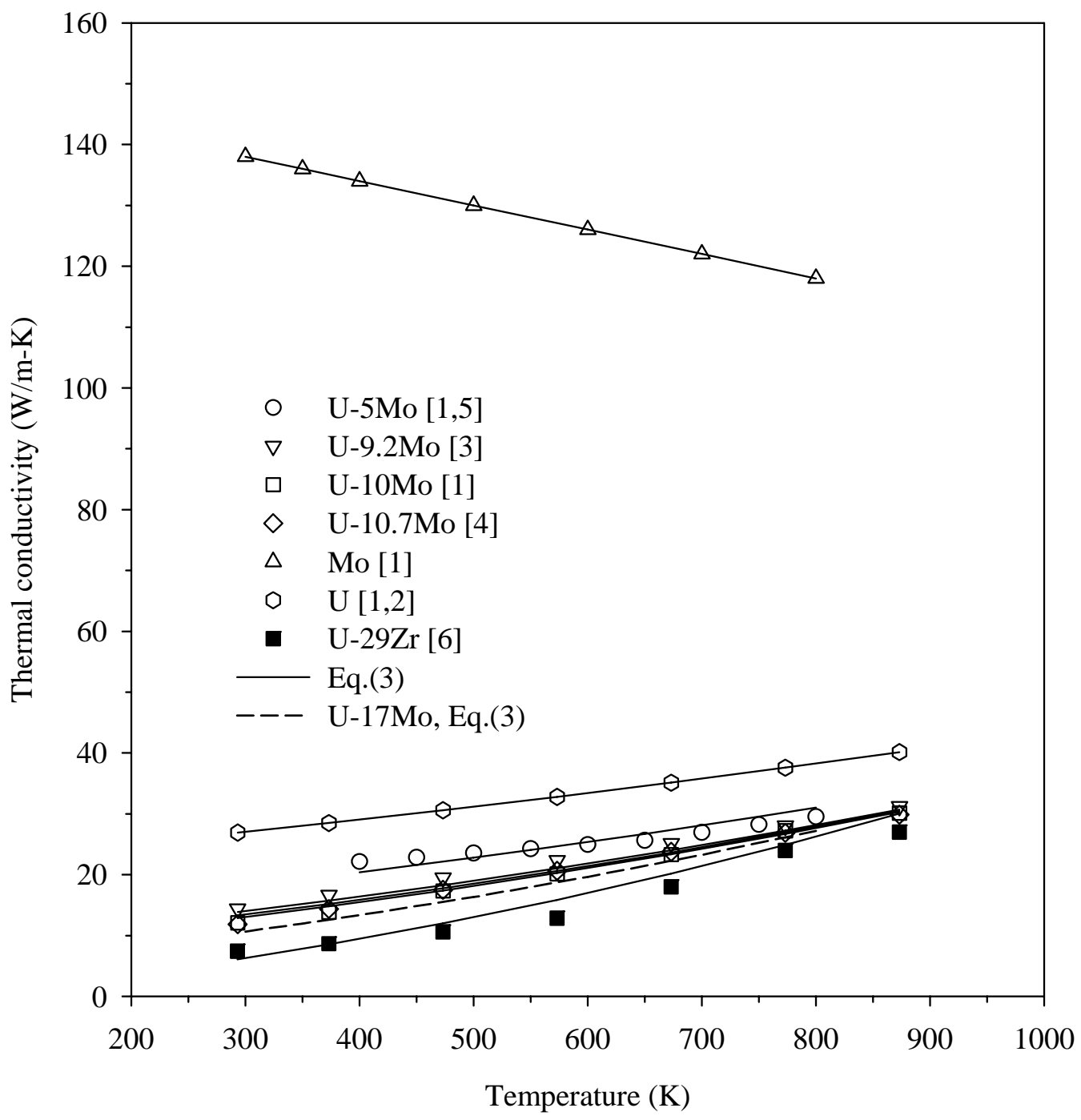

Fig. C.1. Measured data and model predictions for unirradiated U-Mo alloys. The numbers in front of molybdenum indicate the molybdenum content in weight percent. 


\section{C.3 THERMAL CONDUCTIVITY OF U-MO ALLOY DURING IRRADIATION}

The thermal conductivity of U-Mo alloy decreases during irradiation due to increase in porosity by gaseous swelling and buildup of fission products in the fuel. The impurity effect by fission products is considered negligible if compared with the U-Mo alloying effect. The pores (i.e., fission gas bubbles) are generated during irradiation and filled with fission gases. Except the initial stage of bubbles, the internal pressure of the bubbles is low so that the existence of pores significantly hampers heat flow. The fission gases are composed of xenon and krypton with a ratio of nine xenon atoms per one krypton atom. The thermal conductivity of fuel during irradiation is modeled by considering the fuel as a composite of U-Mo metal and gas-filled pores.

\section{C.3.1 U-Mo Swelling Model}

The data for U-Mo swelling in the literature were available (Refs. 7-14). Among them, only monolithic U-Mo data were useful; data for U-Mo dispersion-type fuel were excluded because the volume increase of the interaction layer between fuel particles and the matrix was difficult to separate from that by swelling. The data obtained at low temperatures $\left(<600^{\circ} \mathrm{C}\right)$ were used.

The total swelling is composed of two elements: swelling due to solid fission product, including liquid phase fission products, and swelling due to gas phase fission products. The former is solely proportional to burnup; it is independent on temperature and alloying conditions such as molybdenum content and fabrication processes. Therefore, this type of swelling is usually given by a linear function of burnup. However, the latter is in principle a thermally activated phenomenon. It depends on fuel temperature and molybdenum content as well as burnup.

\section{Solid swelling}

Based on the data given by Hofman (Ref. 7), the swelling due to solid fission products was formulated as follows:

$$
\left(\frac{\Delta V}{V_{0}}\right)_{S}=0.356 B
$$

where $\left(\Delta V / V_{0}\right)_{S}$ is the solid-swelling volume change in percent, and $B$ is burnup in $10^{20}$ fissions $/ \mathrm{cm}^{3}$.

\section{Gas bubble swelling}

An empirical model for swelling due to gaseous fission products was developed by fitting the data found in the literature (Refs. 7-16). The gas swelling values were estimated by subtracting the solid swelling from the data. The model correlation was obtained by fitting the gaseous swelling values. After reviewing the data, the characteristics of U-Mo alloy gaseous swelling and corresponding modeling scheme can be summarized as follows:

1. At the lower burnup stages, swelling follows a linear function of burnup. As recrystalization begins at $\sim 30 \times 10^{20}$ fissions $/ \mathrm{cm}^{3}$, fuel switches to a higher swelling mode. This burnup dependence can be correlated by a cubic function (see Fig. C.2).

2. The effect of molybdenum content manifests itself as a parabolic function of molybdenum content with a minimum at $10 \%$ molybdenum (see Fig. C.3). 


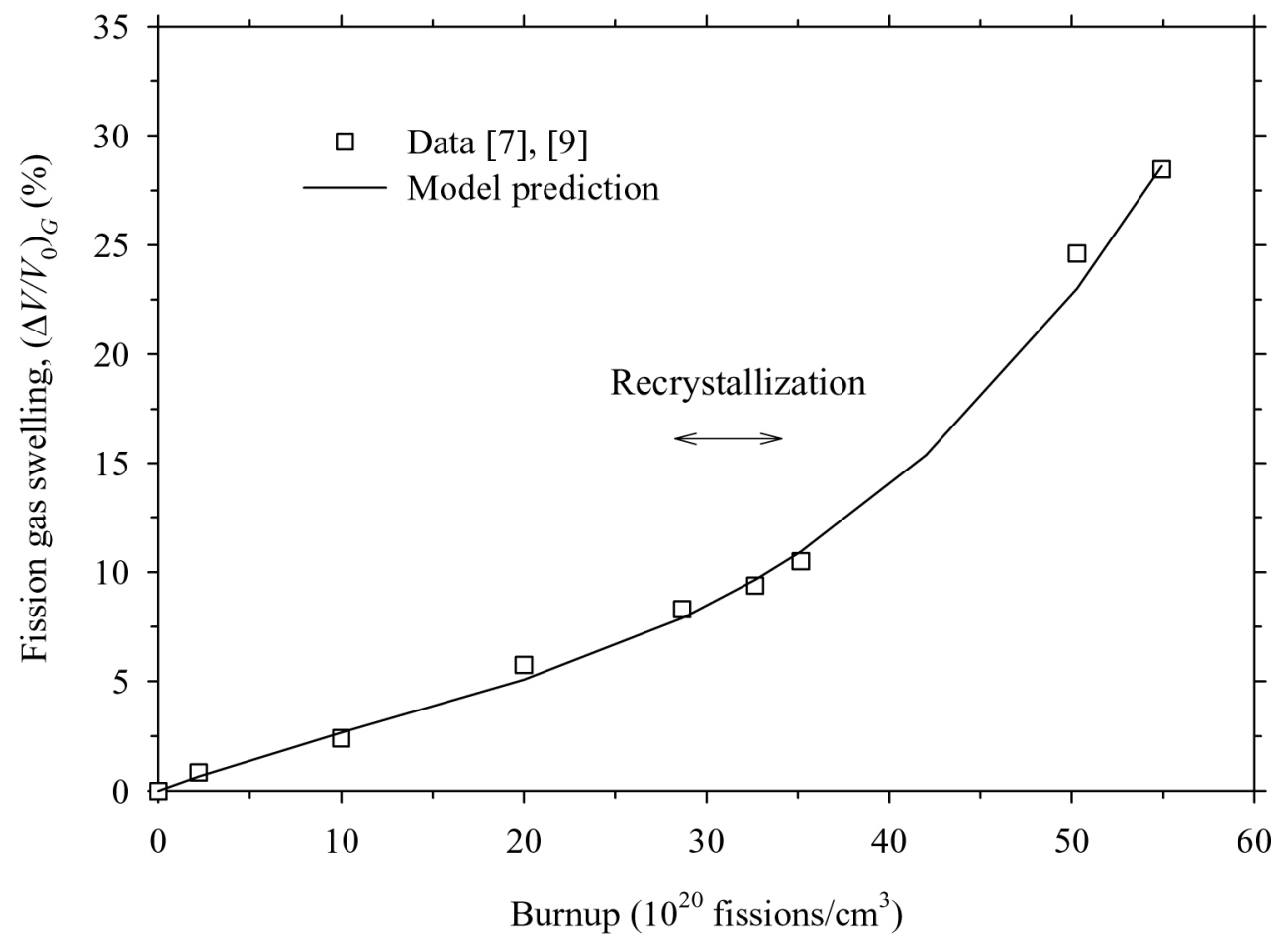

Fig. C.2. Burnup dependence of U-10Mo gaseous swelling.

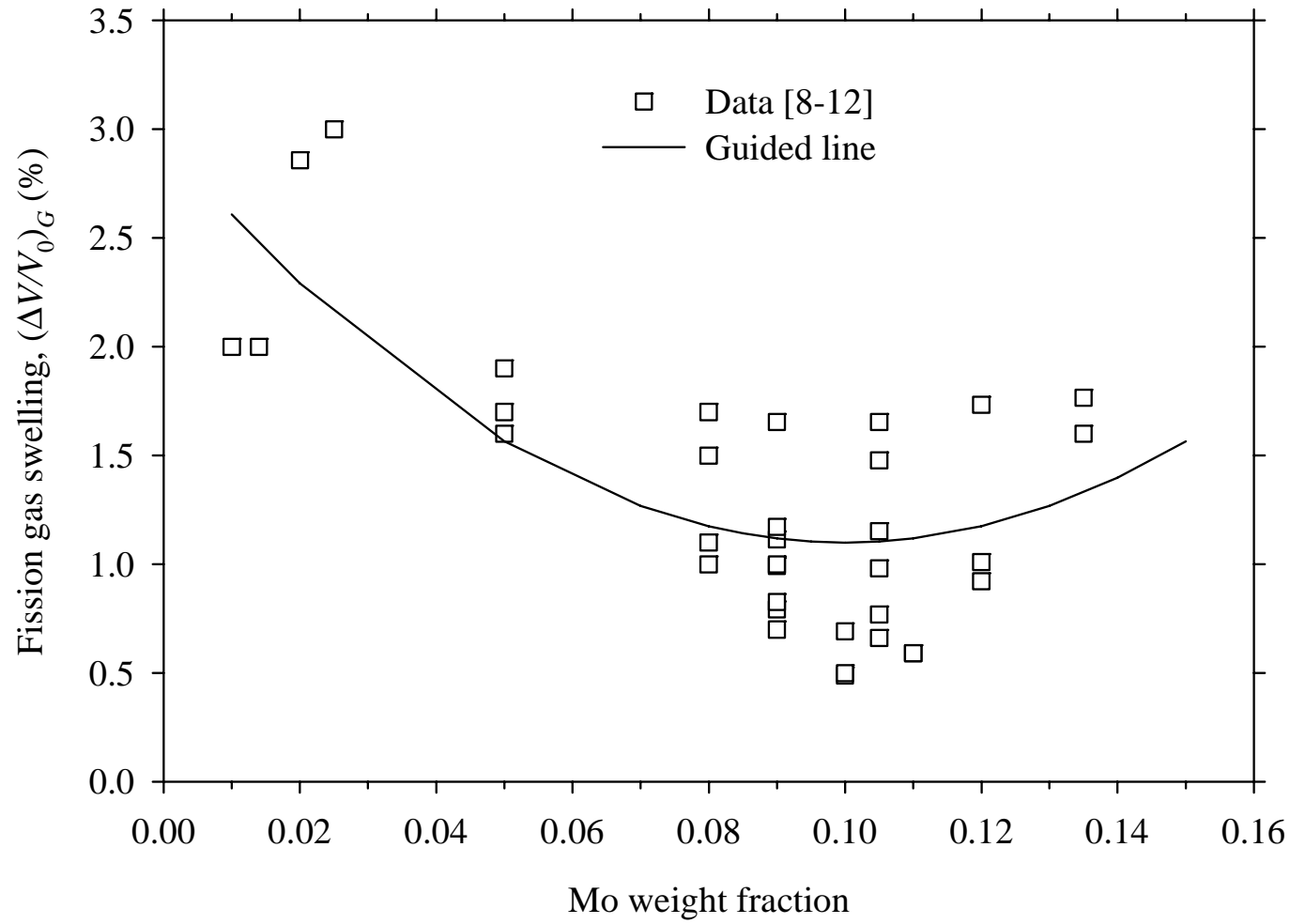

Fig. C.3. Dependence of molybdenum content on swelling at the temperature range of $100-400^{\circ} \mathrm{C}$ and burnup range of $0.2-8 \times 10^{20}$ fission $/ \mathrm{cm}^{3}$. 
3. At temperatures below $200^{\circ} \mathrm{C}$, the swelling is a weak linear function of temperature. The swelling is nearly (a-thermal) at this temperature regime especially for low burnup. At higher temperatures, the temperature dependence resembles a bell shape with a peak at $\sim 450^{\circ} \mathrm{C}$. The severity of peaking at $450^{\circ} \mathrm{C}$ depends on burnup and the deviation of Mo-content from U-10Mo. In other words, the higher the burnup and the more molybdenum-content deviation from $\mathrm{U}-10 \mathrm{Mo}$, the higher (will be the) swelling peak at $450^{\circ} \mathrm{C}$. For example, the data for U-10Mo alloy did not even show a peak behavior at $450^{\circ} \mathrm{C}$, whereas U-2Mo shows a pronounced peak at $450^{\circ} \mathrm{C}$ as shown in Fig. C.4 (Ref. 9). This drastic change in swelling behavior at low molybdenum content is due to decomposition of the (meta-stable) $\gamma$ phase.

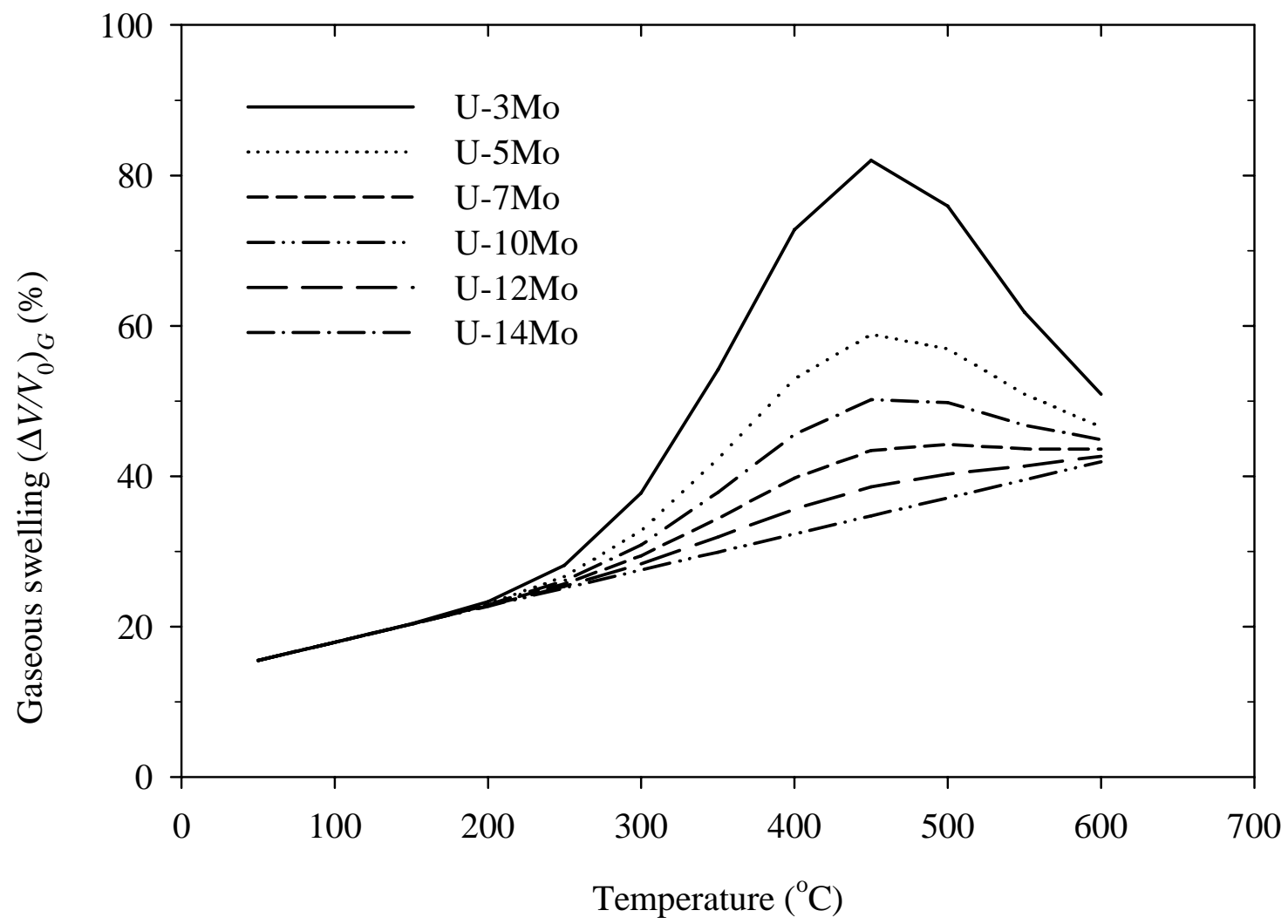

Fig. C.4. Model predictions at $50 \times 10^{20}$ fissions $/ \mathrm{cm}^{3}$.

The above characteristics were applied in fitting the data. Consequently, the model correlation takes the form

$$
\begin{aligned}
\left(\frac{\Delta V}{V_{0}}\right)_{G} & =\left[4.97 \times 10^{-6} T+\left(x_{M o}-0.1\right)^{2} \exp \left\{-0.5\left(\frac{T-720}{84}\right)^{2}\right\}\right] \\
& \times 419\left(0.321 B-7.15 \times 10^{-3} B^{2}+1.99 \times 10^{-4} B^{3}\right)
\end{aligned}
$$

where $\left(\Delta V / V_{0}\right)_{G}$ is the volume expansion by fission gas swelling in percent, $x_{M o}$, the molybdenum content in weight fraction, $B$ burnup in $10^{20}$ fissions $/ \mathrm{cm}^{3}$, and $T$ temperature in $\mathrm{K}$.

Figure C. 2 compares the data with model predictions as a function of burnup. In Fig. C.3, the effect of molybdenum content on swelling is found where a collection of data is provided. 
Figure C.4 shows the temperature dependence of the correlation for several molybdenum contents at $50 \times 10^{20}$ fissions $/ \mathrm{cm}^{3}$, and Fig. C.5 shows a comparison between predictions and the recent measured data from ANL and CEA. The ANL data are consistent with the prediction with the fuel temperature set at $200^{\circ} \mathrm{C}$. The CEA datum also fits well with the prediction.

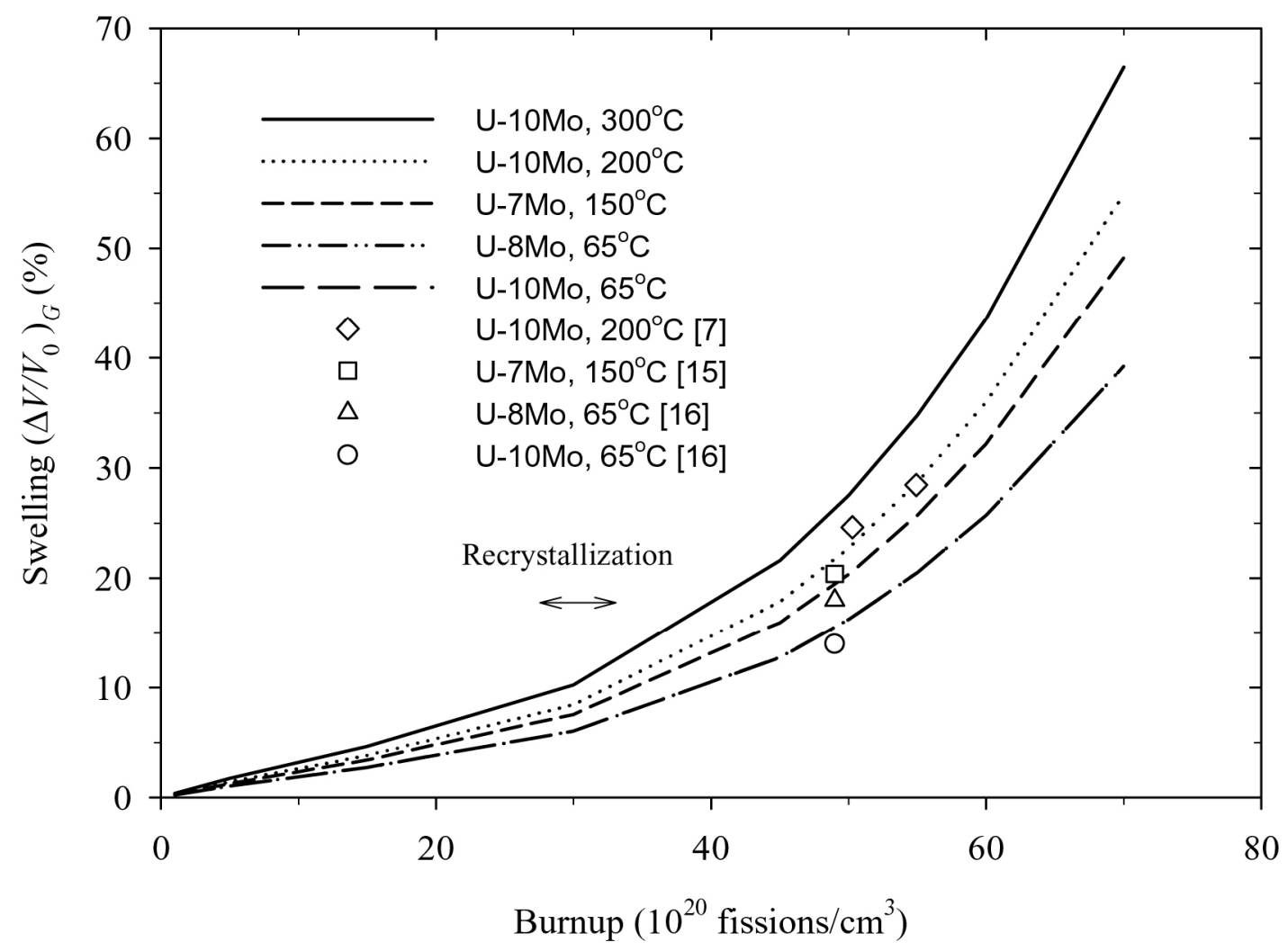

Fig. C.5. Model predictions compared with measured data.

The swelling correlation should be considered somewhat conservative in terms of magnitude and temperature dependence because it is based, primarily, on initial postirradiation examinations. More detailed characterization of fission gas bubble morphology of fuel samples from RERTR 4 test may necessitate an adjustment of Eq. (6) and therefore of Eq. (11) as well.

Notice that Eq. (6) is for the volume change based on the initial volume. The percent volume change based on the time-dependent volume to be used for thermal conductivity calculations, $(\Delta V / V)_{\mathrm{G}}$, is provided by

$$
\left(\frac{\Delta V}{V}\right)_{G}=\frac{\left(\frac{\Delta V}{V_{0}}\right)_{G}}{1+\left(\frac{\Delta V}{V_{0}}\right)_{G}} .
$$

\section{C.3.2 Thermal Conductivity Decrease by Swelling Porosity}

The thermal conductivity reduction due to swelling porosity was modeled using the Bruggeman method (Refs. 6 and 17), considering the alloy was composed of metal and distributed pores filled with fission gases. Therefore, the thermal conductivity during irradiation is expressed as follows: 


$$
k_{U-M o}=\frac{1}{4}\left[A+\left(A^{2}+8 k_{U-M o}^{0} k_{g}\right)^{\frac{1}{2}}\right] \text {, }
$$

where

$$
\begin{gathered}
A=(2-3 P) k_{U-M o}^{0}+(3 P-1) k_{g}, \\
P=\frac{1}{100}\left(\frac{\Delta V}{V}\right)_{G} .
\end{gathered}
$$

Here $k_{U-M o}$ is in $\mathrm{W} / \mathrm{m}-\mathrm{K}, k_{U-M o}^{0}$ is the unirradiated U-Mo thermal conductivity given by

Eq. (3), $k_{g}$ is the pore thermal conductivity, $P$ is porosity, and $(\Delta V / V)_{G}$ is gaseous swelling obtained in Eq. (7). The pore thermal conductivity filled with fission gases, assuming the xenon yield is nine times larger than the krypton yield, can be calculated using the data from MATPRO (Ref. 18):

$$
k_{g}=0.1\left(8.247 \times 10^{-5} T^{0.8363}\right)+0.9\left(4.351 \times 10^{-5} T^{0.8616}\right),
$$

where $k_{g}$ is in $\mathrm{W} / \mathrm{m}-\mathrm{K}$ and $T$ is in $\mathrm{K}$.

As an example, the predictions of thermal conductivity as a function of burnup for U-Mo alloys at $65-300^{\circ} \mathrm{C}$ are provided in Fig. C.6.

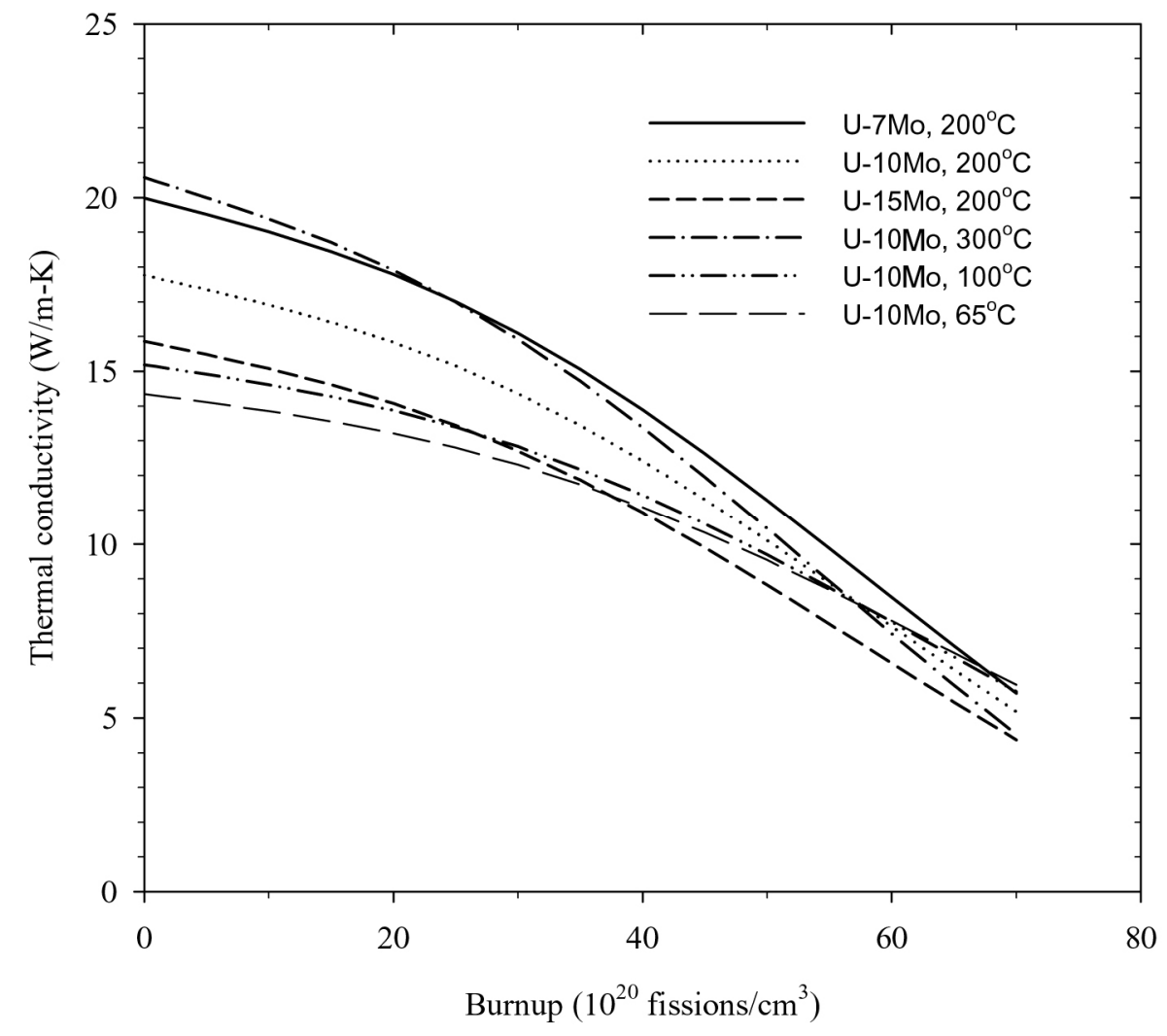

Fig. C.6. Thermal conductivity of U-Mo alloys during irradiation at temperatures $65-300^{\circ} \mathrm{C}$. 


\section{C.4 REFERENCES}

1. Y. S. Touloukian, R. W. Powell, C. Y. Ho, and P. G. Klemens, Thermophysical Properties of Matter, Vol. 1, IFI/Plenum, New York (1970).

2. Y. Takahashi, M. Yamawaki, and K. Yamamoto, J. Nucl. Mater., 154, 141 (1988).

3. T. Matsui, T. Natsume, and K. Naito, J. Nucl. Mater., 167, 152 (1989).

4. H. A. Saller, R. F. Dickerson, A. A. Bauer, and N. E. Daniel, Properties of a FissionType Alloy, Battelle Memorial Institute, Report BMI-1123 (1956).

5. E. L. Francis, Uranium Data Manual, UKAEA Report IGR-R/R-287 (1958).

6. Yeon Soo Kim and G. L. Hofman, AAA Fuels Handbook, Sect. A-6, Argonne National Laboratory, 2002.

7. G. L. Hofman and M. K. Meyer, "Process in Irradiation Performance of Experimental Uranium-molybdenum Dispersion Fuel," International Meeting on Reduced Enrichment for Research and Test Reactors, 2002.

8. M. L. Bleiberg, J. D. Eichenberg, R. H. Fillnow, and L. J. Jones, Development and Properties of Uranium-Base Alloys Corrosion Resistant in High Temperature Water, WAPD-127, Part IV, Westinghouse Electric Co., 1957.

9. D. O. Leeser, F. A. Rough, and A. A. Bauer, in International Conf. on the Peaceful Uses of Atomic Energy, p. 587, 1958.

10. R. S. Barnes, R. G. Bellamy, Butcher, and P. G. Mardon, in International Conf. on the Peaceful Uses of Atomic Energy, p. 218, 1964.

11. M. L. Bleiberg, L. J. Jones, and B. Lustman, J. Appl. Phys., 27, 1270 (1956).

12. G. W. Greenwood, J. Nucl. Mater., 6, 26, 1962.

13. R. W. Willard and A. R. Schmitt, Irradiation Swelling, Phase Reversion, and Intergranular Cracking of U-10 wt \% Mo Fuel Alloy, NAA-SR-8956, Atomics International, 1965.

14. B. Kryger, Contribution to the Study of Fission Gas Release in Metallic Nuclear Fuels, CEA-R-3888, 1969.

15. IRIS 1 Post Irradiation Examinations, CEA, personal communication.

16. M. K. Meyer, G. L. Hofman, J. L. Snelgrove, et al., in Proc. of 1999 Int. Meeting on RERTR, Budapest, Hungary, October 3-8, 1999.

17. D. A. G. Bruggeman, Annal. Physik., 24, 636 (1935).

18. SCDAP/RELAP5/Mod 3.2 Code Manual, MATPRO-A Library of Materials Properties for Light-Water-Reactor Accident Analysis, NUREG/CR-6150, Vol. 4, Rev. 1, INEL-96/0422, Idaho National Engineering and Environmental Laboratory, July 1998. 


\section{INTERNAL DISTRIBUTION}

1. S. T. Baker (bakerst@ornl.gov)

2. K. J. Beierschmitt (beierschmitt@ornl.gov)

3. J. L. Binder (binderj1@ornl.gov)

4. E. E. Bloom (bloomee@ ornl.gov)

5. C.A. Blue (blueca@ornl.gov)

6. S. E. Burnette (burnettese@ ornl.gov)

7. C. W. Coates (coatescw@ornl.gov)

8. B. S. Cowell (cowellbs@ ornl.gov)

9. R. J. Ellis (ellisrj@ ornl.gov)

10. E. C. Fox (foxec@ornl.gov)

11. J. C. Gehin (gehinjc@ ornl.gov)

12. T. J. Huxford (huxfordtj@ornl.gov)

13. G. M. Ludtka (ludtkagm1 @ ornl.gov)

14. S. B. Ludwig (ludwigsb@ornl.gov)

15. C. R. Luttrell (luttrellcr@ornl.gov)

16. D. L. Moses (mosesdl@ornl.gov)

17. S. D. Moses (mosessd@ ornl.gov)

18. D. J. Newland (newlanddj@ornl.gov)

19. L. Ott (ottlj@ornl.gov)
20. C. V. Parks (parkscv@ ornl.gov)

21. M. A. Pershing (pershingma@ornl.gov)

22. L. P. Phillips (phillipslpjr@ornl.gov)

23-25. R. T. Primm III (primmrtiii@ornl.gov)

26. L. D. Proctor (proctorld @ornl.gov)

27. R. R. Rawl (rawlrr@ornl.gov)

28. A. W. Riedy (riedyaw@ ornl.gov)

29. J. E. Rushton (rushtonje@ ornl.gov)

30. L. J. Satkowiak (satkowiaklj@ornl.gov)

31. J. D. Sease (seasejd@ornl.gov)

32. K. A. Smith (smithka@ ornl.gov)

33. R. L. Snipes (snipesrl@ ornl.gov)

34. C. C. Southmayd (southmaydcc@ornl.gov)

35. M. R. Uzzle (uzzlemr@ornl.gov)

36. J. M. Vitek (vitekjm@ornl.gov)

37. M. M. Whitaker (whitakerjm@ornl.gov)

38. N. Xoubi (xoubin@email.uc.edu)

39. S. J. Zinkle (zinklesj@ ornl.gov)

40. ORNL Laboratory Records (hamrindr@ornl.gov)

\section{EXTERNAL DISTRIBUTION}

41. T. Andes, BWXT/Y-12, Y-12 National Security Complex, P.O. Box 2009, Oak Ridge, TN 37831-8245 (andestc@y12.doe.gov)

42. R. A. Butler, Director, Research Reactor Center, 1513 Research Park Drive, Columbia, MO 65211 (ButlerRa@missouri.edu)

43. G. S. Chang, Idaho National Laboratory, P.O. Box 1625, Idaho Falls, ID 83415-3885 (gray.chang@inl.gov)

44. D. Chong, NA-212, United States Department of Energy, Washington, D.C. (Daniel.Chong@nnse.doe.gov)

45. H. E. Clark, United States Department of Energy Oak Ridge Office, P.O. Box 2001, Oak Ridge, TN 37831 (hkc@ornl.gov)

46. G. Copeland, c/o David Moses, P.O. Box 2008, Oak Ridge, TN 37831-6050 (copelandgl@ornl.gov)

47. H. D. Gougar, Manager, Fission \& Fusion Systems, INEEL, P.O. Box 1625, MS 3860, Idaho Falls, ID 83415-3860 (goughd@inl.gov) 
48. M. Hassler, BWXT/Y-12, Y-12 National Security Complex, P.O. Box 2009, Oak Ridge, TN 37831-8245 (hasslerme@y12.doe.gov)

49. M. Hutmaker, U.S. Department of Energy, 1000 Independence Ave., SW, Washington, DC 20585 (matthew.hutmaker@nuclear.energy.gov)

50. D. Kutikkad, Assistant Reactor Manager-Physics, University of MO Research Reactor Facility, Columbia, MO 65211 (kutikkadk@missouri.edu)

51. J. Matos, Argonne National Laboratory, 9700 S. Cass Avenue, Argonne, IL 60439 (jim.matos@anl.gov)

52. C. McKibben, University of Missouri Research Reactor Facility, Columbia, MO 65211 (mckibben@missouri.edu)

53. D. M. Meyer, Idaho National Laboratory, P.O. Box 1625, Idaho Falls, ID 83415-3750 (Dana.Meyer@inl.gov)

54. M. K. Meyer, Idaho National Laboratory, P.O. Box 1625, Idaho Falls, ID 83415-6188 (Mitchell.Meyer@inl.gov)

55. T. Newton, MIT Nuclear Reactor Lab, 138 Albany St., Cambridge, MA 02139 (tnewton@mit.edu)

56. B. Nielson, Idaho National Laboratory, P.O. Box 1625, Idaho Falls, ID 83415-3890 (Bruce.Nielson@inl.gov)

57. W. Richards, NIST Center for Neutron Research, 100 Bureau Drive, Stop 8561, Gaithersburg, MD 20899-8561 (wade.richards@ nist.gov)

58. J. Roglans, Argonne National Laboratory, 9700 S. Cass Avenue, Argonne, IL 60439 (roglans@anl.gov)

59. J. Snelgrove, Argonne National Laboratory, 9700 S. Cass Avenue, Argonne, IL 60439 (jimsnelgrove@anl.gov)

60. P. Staples, NA-212, United States Department of Energy, Washington, D.C. (Parrish.Staples@nnsa.doe.gov)

61. R. E. Williams, NIST Center for Neutron Research, 100 Bureau Drive, Stop 8560, Gaithersburg, MD 20899-8560 (robert.williams@nist.gov) 